\title{
EFFECT OF PREOVULATORY FOLLICLE SIZE ON CUMULUS CELL AND FOLLICULAR WALL TRANSCRIPT ABUNDANCE IN BEEF COWS
}

\author{
A Thesis Presented to
}

the Faculty of the Graduate School

at the University of Missouri

In Partial Fulfillment

Of the Requirements for the Degree

Master of Science

by

JENNA MARIE MONNIG

Dr. Michael F. Smith, Thesis Advisor

JULY 2017 
The undersigned, appointed by the Dean of the Graduate School, have examined the thesis entitled

\section{EFFECT OF PREOVULATORY FOLLICLE SIZE ON CUMULUS CELLS AND FOLLICULAR WALL TRANSCRIPT ABUNDANCE IN BEEF COWS}

presented by Jenna Marie Monnig,

a candidate for the degree of Master of Science,

and hereby certify that, in their opinion, it is worthy of acceptance.

Dr. Michael F. Smith

Dr. Jonathan A. Green

Dr. Thomas W. Geary

Dr. Scott E. Poock 


\section{DEDICATION}

This thesis is dedicated to all the family members and friends who have supported me throughout my academic journey.

To my parents, Kent and Joyce Monnig: There are not enough words to describe everything you have done for me. Thank you for being my first teachers, for putting the first books in my hand, and for only taking them away to make me go to bed. Thank you for letting me swab your computer for bacteria samples, for trying to understand why RNA is important, and for encouraging me to always follow my scientific dreams, even if you couldn't understand them yourselves. Above all, thank you for always taking the time to be there supporting me and helping me be the best I can be.

To my brothers, Grant and Joel: I know I spend most of my time complaining about you, but I wouldn't be the person I am today without you there to challenge me. Thanks for keeping me honest and making me tough, and for learning to deal with me talking about sperm and rectal palpation at the dinner table.

To all of my friends who helped along the way, especially my cousins, Heather and Elizabeth, and my former roommates, Jamie and Anna: Thank you for making me laugh and always encouraging me to boldly go after my dreams. You kept me sane when the going got rough and I treasure all the crazy times we've had together. 


\section{ACKNOWLEDGEMENTS}

Many people contributed hours of time and effort to the completion of this thesis and I will be forever thankful for all the help I received, not only with my research, but in helping me to grow as a person.

I would first like to thank my advisor, Dr. Mike Smith, for his guidance throughout my time here at Mizzou. Looking back, I am amazed at how far I have come as a scientist and as a person since I began my graduate career and I could not have asked for a better mentor to help me along the way. He has always encouraged me to seek out new educational opportunities and take every opportunity to learn something new. I especially appreciate his patience and encouragement as I struggled to learn how to write my thesis and I'm thankful he didn't give me a "bull" stamp, even though I probably deserved one.

I am also thankful for my committee members, Dr. Jon Green, Dr. Tom Geary, and Dr. Scott Poock. They have all been a tremendous help in answering all my questions and addressing any concerns I had along the way. Dr. Green has been very helpful as I entered the world of molecular biology and big data. He has always reminded me to stay curious and look into the true results beyond what the statistics showed. Dr. Tom Geary has been a great scientist to work with and learn from and I have enjoyed all the time I've spent at Fort Keogh LARRL in Miles City, MT. A special thanks to everyone at Fort Keogh, especially Abby Zezeski, Shiann Burns, and the cowboy crew. This project would not have been possible without all of their help.

Thank you to the entire Animal Science faculty, staff and graduate students at Mizzou that have provided help along the way. Specifically a big thanks to Tina Egan 
and Amanda Schmezle for teaching me lab work and how to extract RNA. Thank you to Dr. Susanta Behura for performing my sequence alignment and edgeR analysis. Without his help, I would have taken much longer to complete this project and definitely not arrived at the same results. Thanks to Dr. Bob Schnabel and Greg Burns for teaching me the basics of RNA seq and answering all my questions whenever I showed up at your door. Finally thank you to Sarah Dickinson, Lauren Ciernia, and Megan McLean for being both great friends and labmates and for putting up with all of my chute-side sarcasm. You guys made it easy to have fun while working hard and I will always appreciate the time we've spent together. 


\section{TABLE OF CONTENTS}

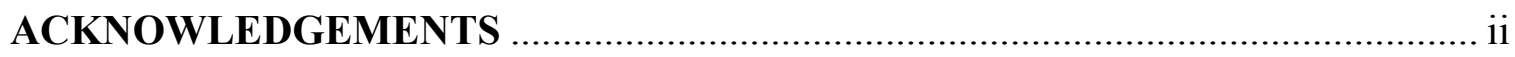

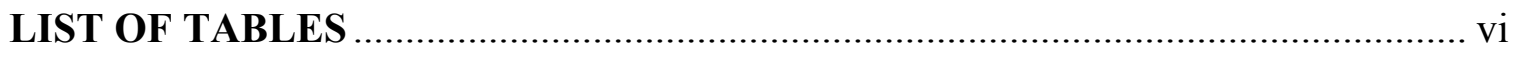

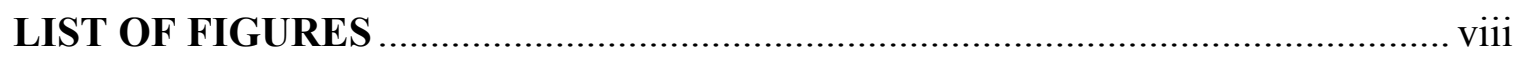

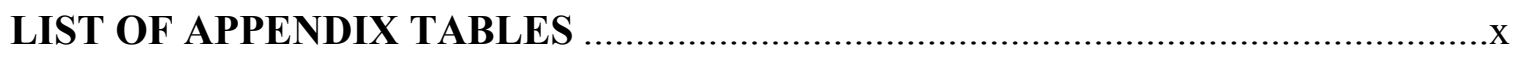

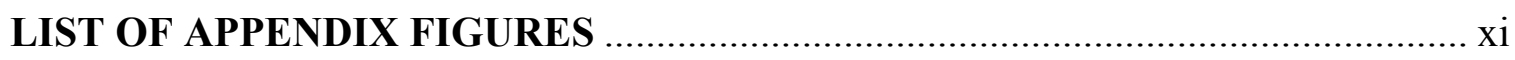

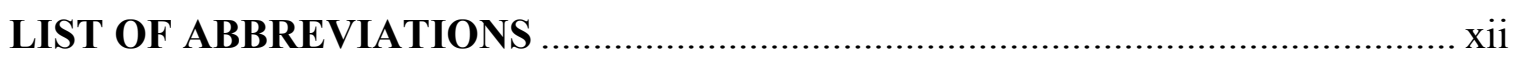

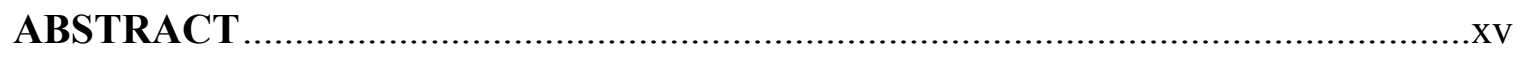

\section{CHAPTERS:}

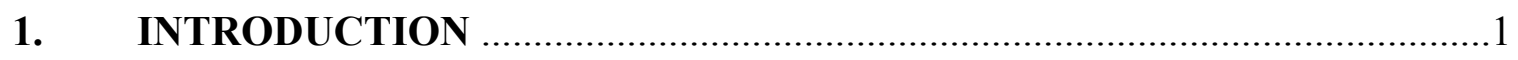

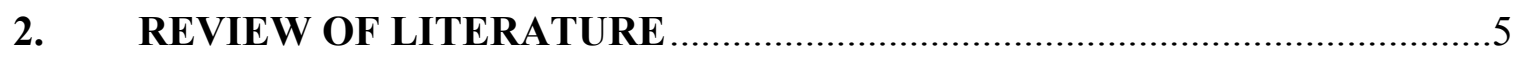

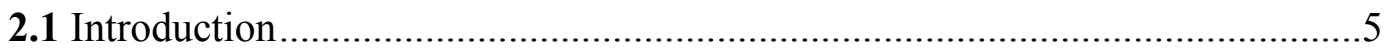

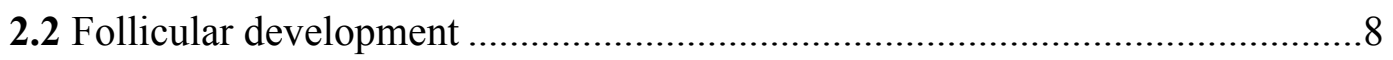

2.2.1 Primordial follicle development ...................................................

2.2.2 Primary, secondary, and tertiary follicles ..........................................10

2.2.3 Progression of follicular recruitment ...............................................11

2.3 Overview of acquisition of oocyte competence …….....................................12

2.4 Oocyte control of the follicular microenvironment .........................................14

2.5 Role of the cumulus cells in acquisition of oocyte competence ......................16

2.5.1 Formation and role of transzonal projections .................................. 16

2.5.2 Cumulus cell control of meiotic resumption.......................................17

2.5.3 Role of glucose metabolism in oocyte competence...........................17

2.6 Follicular influence on oocyte competence …………..................................... 
2.7 Follicular influence on the maternal environment

2.7.1 Role of preovulatory estradiol .....................................................20

2.7.2 Role of postovulatory progesterone .........................................22

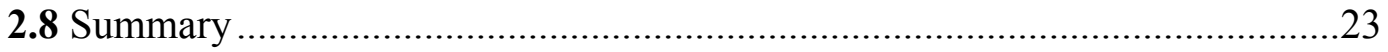

3. EFFECTS OF PREOVULATORY FOLLICLE SIZE ON CUMULUS CELL TRANSCRIPT ABUNDANCE IN BEEF CATTLE .................................25

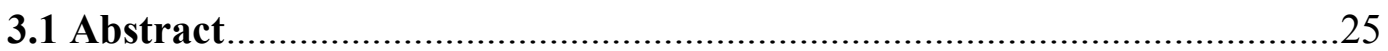

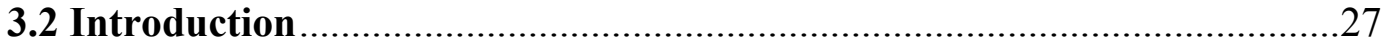

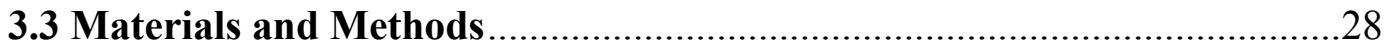

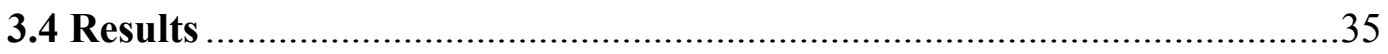

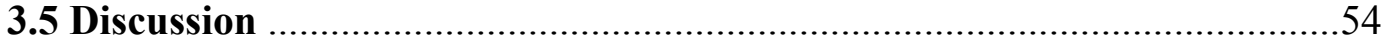

4. EFFECTS OF PREOVULATORY FOLLICLE SIZE AND CIRCULATING ESTRADIOL ON FOLLICLE WALL TRANSCRIPT ABUNDANCE IN

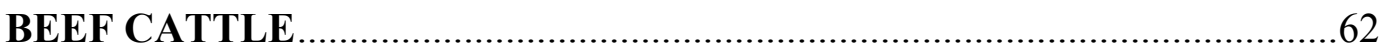

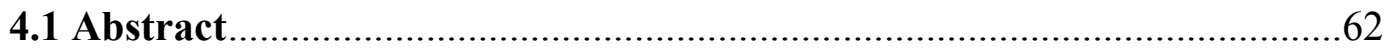

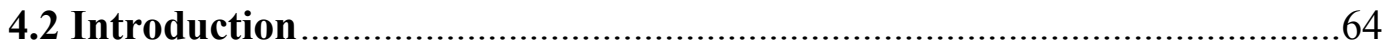

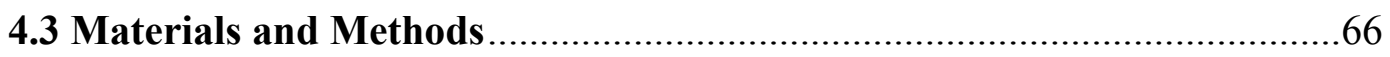

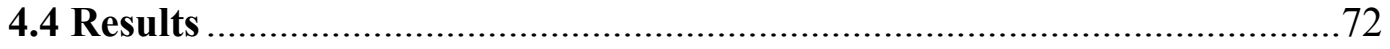

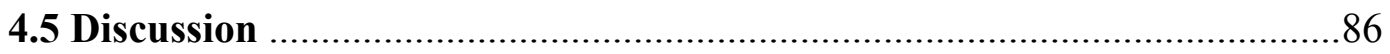

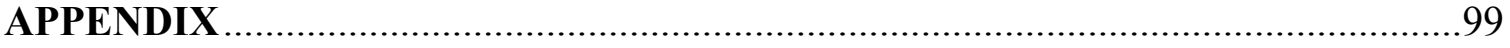

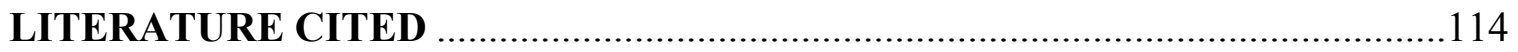

VITA 


\section{LIST OF TABLES}

Table

Page

3.1 Parameters describing the cumulus cell pools for small, large, or spontaneous follicle classifications

3.2 Previously published cumulus cell markers of oocyte competence found to be differentially abundant 38

3.3 Top fifteen transcripts (by FDR) more abundant in small follicle cumulus cell pools compared to large follicle cumulus cell pools

3.4 Top fifteen transcripts (by FDR) more abundant in large follicle cumulus cell pools compared to small follicle cumulus cell pools................................................ 42

3.5 Significant KEGG pathways enriched in large or small cumulus cell pools

3.6 Top fifteen transcripts (by FDR) more abundant in small cumulus cell pools compared to spontaneous cumulus cell pools

3.7 Top fifteen transcripts (by FDR) more abundant in spontaneous cumulus cell pools compared to small cumulus cell pools

3.8 Significant KEGG pathways enriched in small or spontaneous cumulus cell pools ....

3.9 Top fifteen transcripts (by FDR) more abundant in large follicle cumulus cell pools compared to spontaneous follicle cumulus cell pools.....

3.10 Top fifteen transcripts (by FDR) more abundant in spontaneous follicle cumulus cell pools compared to large follicle cumulus cell pools

3.11 Significant KEGG pathways enriched in large or spontaneous cumulus cell pools

4.1 Parameters of cows and treatment groups for follicles walls from follicles classified as small or large .74

4.2 Differentially abundant transcripts from follicle walls of small dominant follicles.....

4.3 Parameters of cows and treatment groups for follicle walls classified by low or high concentrations of serum estradiol 
4.4 Top fifteen transcripts (by FDR) more abundant in low serum estradiol follicles compared to high serum estradiol follicles ........................................................... 88

4.5 Top fifteen transcripts (by FDR) more abundant in high serum estradiol follicles

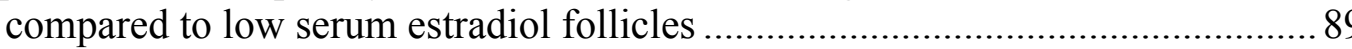




\section{LIST OF FIGURES}

$\begin{array}{lll}\text { Figure } & \text { Page }\end{array}$

3.1 Animal handling procedures and the protocol for synchronization of ovulation .....30

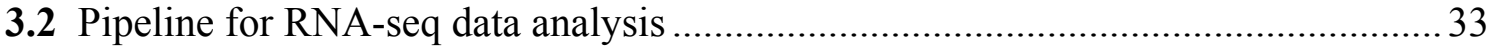

3.3 Volcano plot (small versus large cumulus cell pools) ...................................... 40

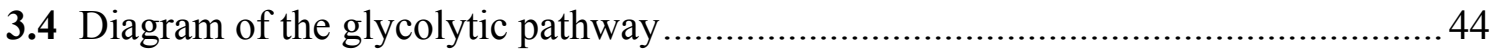

3.5 Volcano plot (small versus spontaneous cumulus cell pools) ..............................46

3.6 Diagram of the steroid biosynthesis pathway ............................................... 49

3.7 Volcano plot (large versus spontaneous cumulus cell pools) ...............................51

4.1 Animal handling procedures and protocol for synchronization of dominant follicle

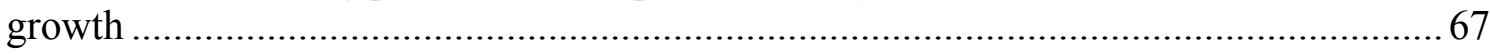

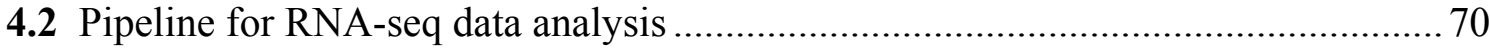

4.3 Intrafollicular concentrations of estradiol (small versus large follicle walls)..........75

4.4 Intrafollicular concentrations of progesterone (small versus large follicle walls).... 76

4.5 Preovulatory serum concentrations of estradiol (small versus large follicle walls) .....

4.6 Volcano plot (small versus large follicle walls) .............................................. 79

4.7 Preovulatory serum concentrations of estradiol (low versus high follicle walls) .....81

4.8 Mean follicle diameter (low versus high follicle walls) .................................. 82

4.9 Intrafollicular concentrations of estradiol (low versus high follicle walls) .............83

4.10 Intrafollicular concentrations of progesterone (low versus high follicle walls) .....84

4.11 Volcano plot (low verus high follicle walls) ............................................... 87

4.12 GO terms associated with low estradiol follicle walls ....................................90

4.13 GO terms associated high estradiol follicle walls ......................................... 91 
4.14 Enriched GO terms in low estradiol follicles compared to the Bos taurus genome..

4.15 Enriched GO terms in high estradiol follicles compared to the Bos taurus genome 


\section{LIST OF APPENDIX TABLES}

A.1 Summary of cumulus cell reads generated by deep sequencing ...............................99

A.2 Most abundant transcripts in preovulatory cumulus cell pools................................100

A.3 Summary of pre-gonadotropin surge follicle wall reads generated by deep sequencing

A.5 Most abundant transcripts in the pre-gonadotropin surge follicle wall 108

A.6 Known granulosa cell markers of oocyte competence...........................................109 


\section{LIST OF APPENDIX FIGURES}

A.1 Biological coefficient of variation (small versus large follicle cumulus cell pools)

A.2 Biological coefficient of variation (small versus spontaneous follicle cumulus cell pools)

A.3 Biological coefficient of variation (large versus spontaneous follicle cumulus cell pools)

A.4 Smear plot (small versus large follicle cumulus cell pools)

A.5 Smear plot (small versus spontaneous cumulus cell pools)

A.6 Smear plot (large versus spontaneous cumulus cell pools)

A.7 Biological coefficient of variation (small versus large follicle walls) 110

A.8 Smear plot (small versus large follicle walls)

A.9 Biological coefficient of variation (low versus high serum estradiol follicle walls) ......

A.10 Smear plot (low versus high serum estradiol follicle walls) 


\section{LIST OF ABBREVIATIONS}

$\begin{array}{ll}\mu \mathrm{g} & \text { micrograms } \\ \mu 1 & \text { microliters } \\ \text { AI } & \text { artificial insemination } \\ \text { AMH } & \text { anti-Müllerian hormone } \\ \text { ATP } & \text { adenosine triphosphate } \\ \text { BCS } & \text { body condition score } \\ \text { BCV } & \text { biological coefficient of variance } \\ \text { BMP15 } & \text { bone morphogenetic protein 15 } \\ \text { bp } & \text { base pairs } \\ \text { C } & \text { Celsius } \\ \text { cAMP } & \text { cyclic adenosine monophosphate } \\ \text { cDNA } & \text { complementary DNA } \\ \text { cGMP } & \text { cyclic granosine monophosphate } \\ \text { CIDR } & \text { controlled internal drug release } \\ \text { FD } & \text { fibroblast growth factor } 8 \\ \text { FGF } & \text { corpus luteum, corpora lutea } \\ \text { d } & \text { cumulus oocyte complex } \\ \text { DAVID } & \text { day } \\ \text { DNA } & \text { fold change } \\ \text { FC } & \end{array}$




\begin{tabular}{|c|c|}
\hline FSH & follicle stimulating hormone \\
\hline FTAI & fixed-time artificial insemination \\
\hline $\mathrm{g}$ & grams \\
\hline GDF9 & growth differentiation factor 9 \\
\hline GnRH & gonadotropin releasing hormone \\
\hline GO & gene ontology \\
\hline GVB & germinal vesicle breakdown \\
\hline HAS2 & hyaluronic acid synthase 2 \\
\hline HBP & hexosamine biosynthesis pathway \\
\hline $\mathrm{hr}$ & hours \\
\hline IGF-1 & insulin-like growth factor 1 \\
\hline $\mathrm{kDa}$ & kilodalton \\
\hline KEGG & Kyoto Encyclopedia of Genes and Genomes \\
\hline $\mathrm{kg}$ & kilogram \\
\hline $\mathrm{LH}$ & luteinizing hormone \\
\hline MII & metaphase II \\
\hline $\mathrm{mg}$ & milligrams \\
\hline $\mathrm{ml}$ & milliliters \\
\hline $\mathrm{mm}$ & millimeters \\
\hline mRNA & messenger ribosnucleic acid \\
\hline ng & nanogram \\
\hline OSF & oocyte-secreted factor \\
\hline PANTHER & Protein Analysis Through Evolutionary Relationships \\
\hline
\end{tabular}




$\begin{array}{ll}\text { PFK } & \text { phosphofructokinase } \\ \text { pg } & \text { picogram } \\ \text { PG } & \text { prostaglandin } \mathrm{F}_{2 \alpha} \\ \text { PPP } & \text { pentose phosphate pathway } \\ \text { RIA } & \text { radioimmunoassay } \\ \text { RNA } & \text { ribonucleic acid } \\ \text { RQN } & \text { RNA quality number } \\ \text { SEM } & \text { standard error of the mean } \\ \text { TZP } & \text { transzonal projection } \\ \text { VEGF } & \text { vascular endothelial growth factor }\end{array}$




\begin{abstract}
Gonadotropin releasing hormone (GnRH)-induced ovulation of small dominant follicles decreased pregnancy rates and increased late embryonic/fetal mortality in postpartum beef cows, which could be caused by inadequate oocyte competence and(or) maternal environment. Previous studies revealed that dominant follicle size at GnRHinduced ovulation in beef cows may affect oocyte competence, as higher fertilization rates and higher embryo quality were achieved as dominant follicle diameter at insemination increased. In addition, higher pregnancy rates and increased concentrations of circulating preovulatory estradiol and postovulatory progesterone were observed in recipient cows induced to ovulate large compared to small dominant follicles, which may affect the establishment of pregnancy. The objectives of the current study were to determine the effects of preovulatory follicle size and physiological status on the cumulus cell transcriptome (Experiment 1) and determine the effects of preovulatory follicle size and steroidogenic capacity (i.e. concentrations of circulating estradiol) on the dominant follicle wall transcriptome collected before the preovulatory gonadotropin surge (Experiment 2).

In Experiment 1, ovulation was synchronized in suckled beef cows by administering an injection of $\mathrm{GnRH}$ on d-9, prostaglandin $\mathrm{F}_{2 \alpha}(\mathrm{PG})$ on d-2, and a second injection of GnRH on d0. The dominant follicle was trans-vaginally aspirated on $\mathrm{d} 1$ and cumulus-oocyte complexes (COC) were collected. The cumulus cells were removed from the oocytes and assigned to one of the following follicle classifications based on follicle diameter and estrus expression: small ( $\mathrm{n}=6 ;<11.7 \mathrm{~mm}$; no estrus expression), large $(\mathrm{n}=6 ;>12.5 \mathrm{~mm}$; no estrus expression), or spontaneous $(\mathrm{n}=5 ; 11.6-13.9 \mathrm{~mm}$; estrus
\end{abstract}


expression and endogenous gonadotropin surge). RNA was extracted from cumulus cells collected from pools of four oocytes and sequenced before being aligned to the Bos taurus genome (UMD3.1). When comparing the cumulus cell transcriptome of small versus large preovulatory follicles, 430 transcripts were more abundant at a false discovery rate $(\mathrm{FDR})<0.10$ in small follicles and 454 were more abundant in large follicles. The glycolytic pathway was enriched in the cumulus cells of large follicles compared to small follicles. In the small versus spontaneous preovulatory follicle comparison, 597 transcripts were more abundant in small follicles and 1012 transcripts were more abundant in spontaneous follicles. The steroid biosynthesis pathway (i.e. cholesterol synthesis) was enriched in the cumulus cells of spontaneous compared to small follicles. In the large versus spontaneous preovulatory follicle comparison, 541 transcripts were more abundant in cumulus cells from large follicles and 951 were more abundant in cumulus cells from spontaneous follicles. In summary, a greater abundance of transcripts encoding for members of the glycolytic pathway in large follicles and transcripts encoding for members of the steroid biosynthesis pathway in the cumulus cells of spontaneous compared to small follicles indicate that oocytes from small follicles may be less competent.

Preovulatory follicle development was synchronized in Experiment 2 by administering GnRH on d-9 and PG on d-2 to non-lactating beef cows. The ovaries were harvested at slaughter $48 \mathrm{hr}$ after PG (d0) and the dominant follicle collected. RNA was extracted from approximately half of the follicle wall and sequenced. Cows were divided into two classifications based on dominant follicle diameter at collection: small $(\mathrm{n}=4$; $<11.5 \mathrm{~mm})$ and large $(\mathrm{n}=7 ;>12.5 \mathrm{~mm})$. Nine transcripts were more abundant in small 
follicles, and two transcripts were more abundant in large follicles. No significant pathways were found. The same 11 follicle walls were also divided into two classifications based on concentration of serum estradiol at $48 \mathrm{hr}$ after PG: low ( $\mathrm{n}=6$; $<4.0 \mathrm{pg} / \mathrm{ml})$ and high $(\mathrm{n}=5 ; \geq 4.0 \mathrm{pg} / \mathrm{ml})$. In the low estradiol classification, 281 transcripts were more abundant in the follicle wall and 40 were more abundant in the follicle wall of the high estradiol classification. No significant pathways were found. Transcripts were analyzed with PANTHER to find significant gene ontology (GO) terms. Differentially abundant transcripts in low estradiol follicles were more highly associated with mitosis, chromosome segregation, and regulation of biological processes. In summary, a small number of transcripts were differentially abundant in the follicle wall of small versus large dominant follicles prior to the preovulatory gonadotropin surge and no specific pathways were identified that might provide insight into how the physiological maturity of a dominant follicle can affect pregnancy rate. Comparisons made between follicle walls from follicles with low or high serum estradiol found a larger number of transcripts were more highly abundant in the low estradiol follicles, possibly indicating that a higher level of transcription is taking place in the low estradiol follicles, and therefore are less mature. 


\section{CHAPTER I}

\section{INTRODUCTION}

One of the most important measures of reproductive success in a beef herd is the percentage of cows that become pregnant and subsequently give birth early in the season. Current management practices allow producers to treat the cowherd as one unit with all cows being bred within a defined time period and all calves weaned on a single date. Because of this management strategy, calves born to early calving cows are older and heavier at weaning compared to calves born later in the season. Early calving cows also have a longer time period between calving and the subsequent breeding season and are more likely to resume estrous cyclicity and become pregnant early in the following breeding season. In addition, heifers that conceive early in their first breeding season have increased longevity and more pounds of calf weaned (Cushman et al. 2013).

Estrus synchronization and fixed-time artificial insemination (FTAI) are some of the most valuable management tools available to producers to increase the percentage of early calving heifers and cows. Synchronization protocols allow manipulation of the estrous cycle to induce and synchronize ovulation. This means that the entire herd can be inseminated at a pre-determined time on the first day of the breeding season. Another advantage of using FTAI is that most protocols include the use of a progestin, which can shorten the postpartum anestrous phase. One way to administer a progestin is by use of a Controlled Internal Drug Release (CIDR), which is a vaginal implant containing a progesterone that is used to mimic the short luteal phase required to reprogram the reproductive axis and resume normal estrous cycles (Day 2004, review). A fertile estrus 
occurs after CIDR removal in a significant percentage of anestrous cows, allowing them to conceive earlier in the breeding season.

Synchronization of ovulation is accomplished through management of follicular waves and luteal lifespan. First, an injection of GnRH is administered to ovulate a dominant follicle and thereby synchronize a new follicular wave. A CIDR, which acts as an artificial corpus luteum, is also inserted at the time of GnRH injection. Besides helping to induce cyclicity in anestrous cows, as previously mentioned, a CIDR will also prevent cycling cows from expressing estrus until the CIDR is removed. An injection of PG at the time of CIDR removal will induce corpus luteum (CL) regression.

A portion of cows will spontaneously express estrus and ovulate after PG-induced luteolysis. Those that do not spontaneously ovulate will ovulate in response to a second injection of $\mathrm{GnRH}$, which induces a preovulatory gonadotropin surge at the time of FTAI. This allows all cows to be inseminated at a predetermined time. Females that express estrus spontaneously before insemination have a higher pregnancy rate compared to those that do not express estrus and are induced to ovulate (Perry et al., 2005; Richardson et al., 2016).

When ovulation is induced following GnRH injection, the size of the preovulatory follicle is associated with pregnancy rates in beef cattle (Perry et al., 2005; Lamb et al., 2001). A study by Perry et al. (2005) found that GnRH-induced ovulation of small dominant follicles in postpartum beef cows $(<11.3 \mathrm{~mm})$ is associated with lower pregnancy rates compared to cows induced to ovulate large dominant follicles $(>11.3 \mathrm{~mm})$. In addition, cows that ovulated large follicles had a lower rate of late embryonic/early fetal loss. However, when cows expressed estrus and spontaneously 
ovulated, size did not affect pregnancy rate. This led to the hypothesis that the physiological maturity and not follicular size affects pregnancy establishment and maintenance (Perry et al., 2005; Atkins et al., 2013).

Small dominant follicles have been shown to negatively affect pregnancy rate through creating an inadequate uterine environment, as animals induced to ovulate small follicles were found to have both lower serum estradiol concentrations at ovulation and lower concentrations of progesterone following ovulation. Both of these conditions have been shown to decrease pregnancy rates in cattle (Atkins et al., 2013). Jinks et al. (2013) reported that an injection of estradiol cypionate $24 \mathrm{hr}$ before AI significantly increased pregnancy rates in cattle in which a small dominant follicle was induced to ovulate with GnRH. This supports the hypothesis that reduced pregnancy rates after GnRH-induced ovulation of a small dominant follicle may be caused by a compromised maternal environment.

There is also evidence that reduced pregnancy rates of GnRH-induced small follicles could be caused by inadequate oocyte competence. Atkins et al. (2013) reported that fertilization rate and the probability of recovering a transferable embryo increased as ovulatory follicle size increased. As oocytes grow and develop, mRNA and proteins are synthesized and stored in the oocyte, leading to greater oocyte competence. RNA synthesis occurs in the oocyte until the time of germinal vesicle breakdown (Fair et al. 1995). The surrounding cumulus cells can also contribute to the oocyte transcriptome through transfer of mRNA through transzonal projections (TZPs). The TZPs span the zona pellucida and directly connect the cumulus cells with the oolemma (Macaulay et al. 2014). Intercellular communication also occurs between granulosa cells and oocytes 
through paracrine (e.g. GDF-9, BMP-15, and Kit ligand) and gap junctional (e.g. cAMP) communication and has been implicated in regulation of growth and meiotic maturation in many mammalian species (Gilchrist et al., 2004).

Considerable effort has been directed toward identifying specific granulosa and cumulus cell markers of oocyte competence in cattle (Uyar et al., 2013; review). Increased expression of the following genes in granulosa cells of humans and cattle have been found to affect oocyte competence: $3 \beta$-Hydroxysteroid dehydrogenase, Ferredoxin 1, Serine proteinase inhibitor clade E member 2, Cytochrome P450 aromatase, Cell division cycle 42, and Sprouty homolog 2 (Robert et al., 2001, Hamel et al., 2008). In cumulus cells, higher expression levels of cathepsins B, S, K, and Z have been reported in follicles with lower quality oocytes (Bettegowda et al. 2008).

We hypothesized that characterization of the transcriptome of small and large dominant follicles will assist in the identification of molecules involved in acquisition of oocyte competence and(or) preparation of the maternal environment for the establishment and maintenance of pregnancy. Therefore, the specific aims of this project were to 1) determine the effects of dominant follicle diameter and estrus expression on the transcriptome of cumulus cells originating from small $(<11.7 \mathrm{~mm}, \mathrm{GnRH}$ induced gonadotropin surge, no estrus expression), large ( $>12.5 \mathrm{~mm}, \mathrm{GnRH}$ induced gonadotropin surge, no estrus expression), and spontaneous (11.6-13.9 mm; estrus expressed) preovulatory follicles and 2) determine the effects of dominant follicle diameter and concentration of circulating estradiol on the transcriptome of follicle walls from small $(<11.5 \mathrm{~mm})$ and large $(>12.5)$ preovulatory follicles collected before the preovulatory gonadotropin surge. 


\section{CHAPTER II}

\section{REVIEW OF LITERATURE}

\subsection{Introduction}

Current estrous synchronization protocols effectively synchronize ovulation in cycling and anestrous beef cows to allow for a majority of females to conceive on the first day of the breeding season. For pregnancy to be successfully established, the following series of ovarian hormone changes are required in cattle (Binelli, 2014). First, there must be elevated concentrations of progesterone followed by complete luteolysis. Second, a rapid increase in preovulatory concentrations of estradiol must occur, and third, an increase in progesterone following ovulation. Elevated circulating concentrations of progesterone before FTAI result from the presence of a CL or insertion of a CIDR; whereas, luteolysis is induced by administration of PG. The rapid decrease in circulating concentrations of progesterone permits an increase in luteinizing hormone (LH) pulse frequency (Goodman and Karsch, 1980), which stimulates an increase in estradiol secretion from the follicle wall via the two cell-two gonadotropin concept. Preovulatory concentrations of estradiol coordinate a series of events essential to the establishment of pregnancy, including gamete transport, induction of the preovulatory gonadotropin surge, estrous behavior, induction of progesterone receptors in the endometrium, and timing of endometrial PG secretion (reviewed by Dickinson et al., 2016). Following ovulation, increased concentrations of progesterone affect histotroph production and conceptus elongation (reviewed by Brooks et al., 2014).

An effective FTAI protocol will mimic the preceding hormonal changes and therefore increase chances of pregnancy success. Most FTAI protocols include: an 
injection of GnRH to induce a preovulatory gonadotropin surge and synchronize a new follicular wave, a subsequent injection of PG to induce corpus luteum regression, followed by a second injection of GnRH at the time of insemination to synchronize ovulation. Ovulation occurs 24 to 32 hours after GnRH injection (Pursley et al., 1995) and the injection is timed such that a viable oocyte will come into contact with capacitated, viable sperm.

At the time of FTAI, there are two populations of cattle: those that have had a spontaneous gonadotropin surge and expressed estrus, and those that require GnRH to induce a gonadotropin surge and ovulation. Females that express estrus prior to insemination have a higher pregnancy rate than those that fail to express estrus and are induced to ovulate (Perry et al., 2005; 2014; Richardson et al., 2016). Increased pregnancy rates in cattle that have expressed estrus at or before FTAI may be due to the deposition of semen closer to the time of ovulation (e.g. preovulatory gonadotropin surge occurs at onset of estrus), and(or) increased follicular maturity resulting in ovulation of a more competent oocyte and(or) increased circulating concentrations of estradiol.

Preovulatory follicle size at insemination affected pregnancy rate in cows in which ovulation was induced by GnRH. Perry et al. (2005) found that cows induced to ovulate small $(<11.3 \mathrm{~mm})$ follicles had significantly decreased pregnancy rates compared to cows induced to ovulate larger follicles. There was also an increased rate of embryonic mortality for cows induced to ovulate a small follicle. However, when cows spontaneously expressed estrus, pregnancy rate was independent of follicle size. This led to the hypothesis that follicle size is an indicator of follicular maturity in females that do not express estrus and that ovulate in response to a GnRH-induced gonadotropin surge. 
The preceding decrease in pregnancy rate and increased embryonic mortality is hypothesized to be caused by a combination of decreased oocyte competence and an inadequate maternal environment for pregnancy establishment. To test this hypothesis, Atkins et al. (2013) performed a reciprocal embryo transfer study to separate the effects of the follicular microenvironment on oocyte competence from an effect on the maternal environment. Cows were synchronized and induced to ovulate a single oocyte in donor and recipient females. Animals were divided into treatment groups based on dominant follicle size at GnRH-induced ovulation and were classified as ovulating a large $(>12.5 \mathrm{~mm})$ or small $(<12.5 \mathrm{~mm})$ follicle. Cows that expressed estrus were not included in this study. Donors were inseminated and embryos or unfertilized oocytes were collected seven days later. Viable embryos from cows that ovulated small or large follicles were transferred to recipients that ovulated small or large follicles. Reduced fertilization rates and embryo quality were reported from donors with small dominant follicles, providing evidence that acquisition of oocyte competence may not be complete in these follicles. There were also reduced pregnancy rates in recipients following GnRH-induced ovulation of a small follicle compared to recipients that ovulated a large follicle, providing evidence that cows that ovulate small follicles have an inadequate uterine environment (Atkins et al., 2013).

The purpose of this literature review is to briefly discuss folliculogenesis and the role of the preovulatory follicular microenvironment on the establishment of pregnancy through effects on oocyte competence and the maternal environment. Particular emphasis will be given to the physiological role of the cumulus cells and follicular wall in cattle on the establishment of pregnancy. 


\subsection{Follicular development}

Primordial follicle development

Oogenesis occurs in most female animals during gestation so that at birth, the ovaries contain a finite number of oocytes surrounded by a single layer of somatic cells (pregranulosa cells) that later differentiate into granulosa cells. Oocytes can remain in a quiescent state for long periods of time before the initial recruitment (i.e. activation of primordial follicles) occurs.

Primordial germ cells can first be detected in bovine embryos at d18 of gestation and will migrate to the gonadal ridge and be incorporated into the embryonic body by d27 (Wrobel and Süß, 1998). After migrating to the gonadal ridge, primordial germ cells lose their mobility and are referred to as oogonia (van den Huk and Zhao, 2005). An oogonium is in contact with a single layer of squamous pregranulosa somatic cells and surrounded by a basal lamina, which acts as a barrier between the developing follicle and ovarian stroma (Juengel et al., 2002a). These oogonia-pregranulosa cell clusters form the ovigerous cords, which are open at the surface epithelium. Mesothelial cells from the ovarian surface epithelium are believed to be the primary source of pregranulosa cells because they can continue to move into the ovigerous cords after the oogonia separate from other possible somatic cell sources (Juengel et al., 2002a).

The oogonia will continue to undergo rapid proliferation within the ovigerous cords until follicle formation begins. A high level of mitosis takes place in both oogonia and pregranulosa cells until the oogonia enter meiosis, when a rapid decrease in transcriptional activity occurs, and the oogonia become primary oocytes. This occurs around d75-80 in cattle (Fair 2003). After the follicle has assembled its layer of 
pregranulosa cells, the ovigerous cords break down and allow the developing follicles to separate and form primordial follicles. Primordial follicles first appear in the bovine ovary around d90 of gestation (Yang and Fortune, 2008); however the timeline of primordial follicle formation can vary (d74-110; Fortune et al., 2013) and is partly due to the methods used to determine gestational age (e.g. crown-rump length).

Since primary oocytes lack a zona pellucida, the plasma membrane of the oocyte and the surrounding pregranulosa cells are in intimate contact. This is thought to be the origin of TZPs, which connect the cumulus cells and oocyte throughout follicular development and will be discussed later in this review. Primordial follicles are developmentally incompetent until activation.

Activation of primordial follicles to form primary follicles first occurs at d140 of gestation in cattle (Yang and Fortune, 2008). The exact mechanism for activation is not yet known, but it is hypothesized that both inhibitory and stimulatory factors play a role (Fortune et al., 2010; 2013). One possible inhibitor of follicle activation is anti-Müllerian hormone (AMH). Mice null mutant for AMH were fertile; however, their oocyte pool was depleted at a younger age than control wild-type mice. This suggests that the absence of AMH allows activation to occur at a faster rate than normal (Fortune et al., 2011). Bovine fetal ovarian cortical tissue cultured with AMH also had significantly decreased percentage of primary follicles and an increased percentage of primordial follicles, suggesting that AMH has an inhibitory effect on bovine follicle activation (Fortune et al., 2013). Possible stimulatory factors include kit ligand and insulin. Kit ligand is produced by granulosa and primordial germ cells, and its receptor (cKit) can be found on oocytes. Studies in mice by Parrott and Skinner (1999) found that kit ligand 
was necessary for follicle activation. In cattle, adding kit ligand to ovaries cultured in vitro increased the percentage of activated follicles, indicating that kit ligand may also play a role in bovine follicle activation. Similarly, cortical ovarian pieces cultured in media supplemented with insulin increased the number of primary follicles observed, although further research is needed to determine if insulin plays a similar role in activation in vivo (Fortune et al., 2013).

Primary, secondary, and tertiary follicles

After activation, the follicle becomes known as a primary follicle. At this stage of follicular development, the squamous pre-granulosa cells become cuboidal granulosa cells, which begin to undergo rapid proliferation (Fair, 2003). As the primary follicle develops, the oocyte gradually increases in size and begins to synthesize and store mRNA and other molecules, although it is still considered to be meiotically incompetent (Marteil et al., 2009).

The transition from primary to secondary follicle is marked by a second layer of granulosa cells forming around the oocyte and the formation of the zona pellucida. A significant amount of RNA can be detected for the first time in bovine oocytes at this stage of development (Fair et al., 1997). Although oocytes have the ability to spontaneously resume meiosis if removed from their follicular environment at this time, they are not considered developmentally competent. In cattle, the presence of low levels of testosterone promotes transition from the primary to secondary follicle in vitro, with strong evidence for the same effect to occur in vivo (Yang and Fortune, 2006). Similarly, treatment of bovine cortical pieces with vascular endothelial growth factor (VEGF), promoted the primary to secondary follicle transition and increased the number of 
secondary follicle observed (Fortune et al., 2013). Because VEGF plays an important role in angiogenesis, this may be an indicator of the importance of follicular vasculature in further follicle development (Fortune et al., 2013).

As follicles transition from secondary to tertiary follicles, a fluid filled antrum begins to form. The granulosa cells also continue to proliferate and differentiate into theca externa and interna, the basement membrane, mural granulosa cells, and cumulus cells (Gilchrist et al., 2004). Cumulus cells are functionally different from mural granulosa in that they have a high rate of proliferation, low steroidogenic capacity and low LH receptor expression. The oocyte controls granulosa cell proliferation and differentiation through release of paracrine substances (i.e. growth differentiation factor 9 [GDF9]). Because the cumulus cells have direct communication with the oocyte through gap junctional, transzonal, and paracrine signaling, the oocyte is able to suppress the expression of genes in cumulus cells that are required for differentiation of mural granulosa cells (reviewed by Eppig 2001[mice]; Gilchrist et al., 2004 [cattle]). When the oocyte was removed from the developing follicle, the remaining cumulus cells displayed a phenotype more similar to the mural granulosa cells, providing evidence to support the hypothesis that granulosa cells will default to the mural phenotype unless influenced by contact with the oocyte. The oocyte will continue to stimulate granulosa proliferation until the resumption of meiosis (Gilchrist et al. 2004).

\section{Progression of follicular recruitment}

The final stages of follicular development occur as a rise in follicle stimulating hormone (FSH) leads to the recruitment of a cohort of follicles, which are dependent on FSH for growth. Follicles in the cohort synthesize estradiol and inhibin, which exert 
negative feedback on FSH secretion. All but one follicle undergo atresia due to the rapid decline in available FSH and follicular divergence at selection occurs when circulating concentrations reach baseline. The selected follicle gains increased sensitivity to gonadotropins from higher intrafollicular concentrations of free insulin-like growth factor 1 (IGF1). The granulosa cells also gain LH receptors and the follicle switches its dependency from FSH to LH (Lucy, 2007). The dominant follicle will continue to grow and inhibit follicular recruitment until it undergoes atresia or ovulation. The final follicular maturation in vivo is initiated by the pre-ovulatory LH surge, which sets in motion an irreversible chain of events culminating in follicular rupture and luteinization of theca and granulosa cells (Lonergan et al., 2003).

In response to the preovulatory gonadotropin surge, cumulus cell expansion occurs and the oocyte ceases transcription of maternal mRNA and goes through germinal vesicle breakdown (GVB). The first polar body is extruded and second meiosis begins. At this point in cattle, the oocyte completes meiosis I and progresses to the second meiotic arrest at metaphase II. The oocyte will remain at meiotic arrest until fertilization occurs, after which meiosis resumes and the second polar body is extruded. The male and female pronuclei join, and the resulting zygote begins a series of cleavage divisions that lead to further stages of fetal development.

\subsection{Overview of acquisition of oocyte competence}

For an oocyte to be considered fully competent, it must successfully complete three specific events that allow the oocyte to gain the ability to be fertilized, cleave, and provide instruction for early embryonic development until the activation of the embryonic genome. These three events are: meiotic or nuclear maturation, cytoplasmic 
maturation, and molecular maturation. The three types of oocyte maturation are briefly discussed below.

Meiotic maturation: Meiotic maturation refers to the ability of the oocyte to condense its chromatin, progress from the first meiotic arrest (prophase I; dictyate stage) and extrude a polar body. Actively growing oocytes are considered meiotically incompetent, and continue to gain competence as the oocyte grows. The first steps to acquiring nuclear maturation occur as the oocyte gains the ability to condense chromatin, followed by the formation of the metaphase I plate and a functional spindle. Next, the metaphase II (MII) plate is formed followed by the expulsion of a polar body. Finally, final meiotic maturation occurs when chromatin is arrested at the MII spindle (Sirard 2001). Bovine oocytes gain the ability to resume meiosis at a diameter of $100 \mu \mathrm{m}$, and reach MII at a diameter of $110 \mu \mathrm{m}$, when the antral follicle is approximately $3 \mathrm{~mm}$ in diameter (Hyttel et al., 1997).

Cytoplasmic maturation: Cytoplasmic maturation prepares the oocyte for fertilization and subsequent fetal development by making ultrastructural changes to the oocyte. A larger number of oocytes with a diameter greater than $115 \mu \mathrm{m}$ reached the blastocyst stage than those $<115 \mu \mathrm{m}$. Since meiotic maturation is reached at $110 \mu \mathrm{m}$, it can be concluded that further cytoplasmic maturation is needed to reach oocyte competence (Arlotto et al., 1996). As the follicle grows to full size, changes occur in many of the cell organelles. The number of mitochondria present in the oocyte increases throughout oocyte maturation and the mitochondria move from the peripheral regions of the oocyte to surround the nucleolus after exposure to the preovulatory gonadotropin surge. An increased number of mitochondria is linked to increased oocyte competence, 
as more ATP is available to the nuclear compartments of the cell (Bavister and Squirrell, 2000). The endoplasmic reticulum is responsible for protein folding, lipid metabolism, membrane synthesis, and regulation of the calcium ion gradient. As the oocyte matures, the endoplasmic reticulum gains increased sensitivity to calcium signaling, and is responsible for the calcium release during fertilization that signals the release of cortical granules (Ferreira et al., 2009). Reorganization of the organelles is regulated by cytoskeletal microfilaments and microtubules located in the cytoplasm as the cell transitions from germinal vesicle to metaphase II.

Molecular maturation: The third stage of oocyte maturation is molecular maturation, which involves the transcription and storage of maternal mRNA, from which the oocyte and embryo will synthesize proteins until the maternal zygotic transition occurs. Maternal mRNAs are transcribed and stored beginning at the secondary follicle stage and continues throughout oocyte growth until GVB (Fair et al., 1995) in both the oocyte and cumulus cells (Macaulay et al. 2014). Both the quantity and integrity of the transcriptome affect oocyte competence, as the mRNA must be of high quality and in adequate supply for an embryo to successfully develop (Sirard, 2001). An inadequate transcriptome may occur due to a premature stop of transcription due to a GnRH-induced gonadotropin surge, or because of inadequate transfer of mRNA from the cumulus cells.

\subsection{Oocyte control of the follicular microenvironment}

The oocyte and surrounding cumulus and granulosa cells are intimately associated from early development. Bidirectional communication occurs between the cumulus and oocyte and is essential for follicular and oocyte development. Oocytes play an essential role in follicle development including initial follicle formation, granulosa cell 
proliferation and differentiation, cumulus expansion, and cumulus-oocyte dissociation (reviewed by Eppig, 2001), although there can be differences among species. Oocyte secreted factors (OSF) are paracrine factors which are produced by the oocyte and act upon neighboring follicular cells to control their function and proliferation. Two members of the transforming growth factor beta family, growth-differentiation factor 9 (GDF9) and bone morphogenetic protein 15 (BMP15), are known to have a role in follicle growth and ovulation rate in sheep (McNatty et al., 2005) and mice (Yan et al., 2001). Sheep immunized against either GDF9 or BMP15 had fewer follicles beyond the primary stage of development after ovarian collection. Ewes immunized against GDF9 formed corpora lutea but did not display normal circulating concentrations of progesterone, indicating a possible role in granulosa cell function, while sheep immunized against BMP15 failed to ovulate and lacked surface-visible antral follicles, indicating a possible role in earlier follicle development (Juengel et al., 2002b). In mice, BMP15 is not as essential, as BMP15 knockout mice are still fertile. GDF9 knockout mice are infertile due to a block in folliculogenesis at the primary follicle stage (Yan et al., 2001). The roles of GDF9 and BMP15 have not been as well defined in cattle. Juengel et al. (2009) immunized heifers against BMP15 and(or) GDF9 and found that heifers immunized against BMP15 had different ovulation rates compared to the control, with some heifers having increased ovulation rates; whereas other heifers did not ovulate. In addition, immunization with GDF9 and(or) BMP15 decreased the number of follicles and follicular diameter in heifers. These results were similar to those observed in other monovular species such as humans and sheep (Juengel et al., 2009). Therefore it is likely 
that GDF9 and BMP15 have similar functions in cattle. In summary, the oocyte has a regulatory role in folliculogenesis in several species.

\subsection{Role of the cumulus cells in acquisition of oocyte competence}

\section{Formation and role of transzonal projections}

The innermost layer of cumulus cells, known as the corona radiata, remains in close contact with the oocyte from the primordial to the preovulatory follicle stage. In cattle, the zona pellucida begins to form as the follicles enter the secondary follicle stage and separates the cumulus and oocyte. However, the corona radiata maintain contact with the oolemma by forming the cellular projections known as TZPs, which penetrate the zona pellucida and make direct contact with the oolemma, forming zonula-adherinslike junctions at the end of the projection (Macaulay et al., 2014).

The current model of bidrectional communication includes paracrine signaling and exchange of small molecules $(<1 \mathrm{kDa})$ through gap junctions. Recently, however, Macaulay et al. (2014) found that TZPs could be used to transport larger molecules, such as newly synthesized long ( $>200 \mathrm{bp}$ ) RNA from the cumulus to the oocyte. RNAs transported to the oocyte from the cumulus cells could add to the maternal reserve and thereby contribute to acquisition of oocyte competence, even when the oocyte is transcriptionally quiescent. In the paper by Macaulay et al. (2016), RNA was collected from TZPs and polyribosomes and sequenced to detect cumulus cell transcripts that were actively being transported into the oocyte and translated into proteins. Many of the sequenced transcripts were associated with transcription, translation, and cell cycle control. In addition, a decreased percentage of bovine oocytes denuded of their surrounding cumulus cells reached the blastocyst stage during culture compared to 
oocytes cultured with the cumulus intact. This provides evidence that the RNA transported into the oocyte from the cumulus cells via TZPs has an important role in oocyte development and maturation (Macaulay et al., 2016). RNAs continue to be transported into the oocyte until the preovulatory gonadotropin surge and initiation of germinal vesicle breakdown. Cumulus expansion begins at this point, and the TZPs are broken as the cumulus cells lose contact with the oocyte.

Cumulus cell control of meiotic resumption

Cumulus cells also play an important role in regulating oocyte maturation through control of meiosis. High concentrations of cAMP in the oocyte inhibit the resumption of meiosis. During the first meiotic arrest, cGMP passes from the cumulus cells to the oocyte through gap junctions and inhibits the breakdown (i.e. phosphodiesterase) of cAMP in the oocyte. The preovulatory gonadotropin surge breaks the gap junctional bonds and decreases the level of cGMP in the cumulus cells, allowing resumption of meiosis and extrusion of the first polar body (reviewed by Uyar et al., 2013).

\section{Role of glucose metabolism in oocyte competence}

Developing COCs require large amounts of glucose for use in energy production, cellular homoeostasis, nuclear maturation, and as substrates for signaling. The bovine oocyte has a low capacity for glucose uptake and a low glycolytic rate due to decreased activity of phosphofructokinase, one of the rate limiting enzymes of glycolysis (SuttonMcDowall et al., 2010). In contrast, cumulus cells have a high affinity for glucose uptake, and consume 23-fold more glucose than oocytes (Thompson et al., 2007). Because of this, the bovine oocyte relies heavily on cumulus cells to metabolize glucose 
and provide the oocyte with substrates it can more readily utilize, such as pyruvate and lactate.

Glucose can be metabolized by the cumulus cells through one of three pathways in the bovine oocyte: glycolysis, the pentose phosphate pathway, and the hexosamine biosynthesis pathway. The largest proportion of glucose in cumulus cells is metabolized through the glycolytic pathway and an increased glycolytic rate has been associated with increased oocyte competence in cattle (Sutton-McDowall et al., 2010). Glucose metabolism increased over $24 \mathrm{hr}$ in oocytes from both prepubertal (lower oocyte competence) and adult cows (increased oocyte competence). However, glucose metabolism was significantly lower in oocytes from prepubertal heifers from 0-12 hr of maturation and GVB was delayed in oocytes from heifers compared to oocytes from adult cows (Steeves and Gardner, 1999). Once transported to the oocyte, the pyruvate produced though glycolysis is metabolized via the tricarboxylic acid cycle, followed by oxidative phosphorylation to produce ATP. Peak oxidative metabolism was also significantly lower in oocytes from prepubertal heifers compared to adult cows, providing evidence that glycolysis plays an important role in developing oocyte competence (Steeves and Gardner, 1999).

The pentose phosphate pathway (PPP) accounts for only a small portion of glucose metabolism $(<3 \%)$ in the oocyte, and although it has never been measured in the whole bovine COC, PPP activity has been found to be essential for murine oocyte nuclear maturation (Sutton-McDowall et al., 2010). Stimulation of the PPP in mice increased the rate of GVB and resumption of meiosis. Inhibition of the PPP in porcine oocytes also reduced meiotic resumption and decreased cleavage rates and blastocyst development 
(Herrick et al., 2006). Bovine oocytes have relatively high concentrations of glucose-6phosphate dehydrogenase, the rate-limiting enzyme of the PPP, compared to the cumulus cells, suggesting that a higher level of PPP activity takes place in the oocyte and may aid in oocyte competence (Cetica et al., 2002).

The hexosamine biosynthesis pathway (HBP) is a major fuel-sensing pathway and is responsible for synthesizing substrates used in matrix production. The end product of the HBP is UDP- $N$-acetyl glucosamine, which is converted into hyaluronic acid in cumulus cells. Hyaluronic acid is the major structural backbone of the cumulus cell extracellular matrices involved in cumulus expansion and synthesized in response to the preovulatory gonadotropin surge. Cumulus expansion is commonly associated with increased oocyte competence and increased expression of hyaluronic acid synthase 2 (HAS2) has been used as a marker of oocyte competence (Assidi et al., 2008). However, the HBP pathway can also have negative effects on oocyte development. The end product of the HBP, UDP- $N$-acetyl glucosamine, can alternatively be used for $O$-linked glycosylation of proteins. Increased glucose metabolism through the HBP leads to increased $O$-linked glycosylation and changes in target protein conformation.

Downstream, these protein changes can lead to upregulation or downregulation of important protein signaling pathways that can decrease oocyte competence (SuttonMcDowall et al., 2010).

\subsection{Follicular influence on oocyte competence}

The most important factor affecting the oocyte transcriptome is the follicular environment prior to resumption of meiosis and ovulation (Sirard, 2012). Several studies have been performed to identify granulosa and cumulus cell markers of oocyte 
competence in humans and cattle. An increased expression of hyaluonan synthase 2, inhibin betaA, epidermal growth factor receptor, gremlin 1, betacellulin, CD44, prostaglandin-endoperoxide synthase 2, and glypican 4 in bovine cumulus cells were positively associated with oocytes having increased competence (Assidi et al., 2008; Kussano et al., 2015). Increased expression of thrombospondin 1, epiregulin, ubiquitin conjugating enzyme E2N, and tumor necrosis factor $\alpha$-induced protein were also observed in bovine cumulus cells of more competent oocytes after the preovulatory gonadotropin surge (Assidi et al., 2010). In addition, increased levels of cathepsins B, S, $\mathrm{K}$, and $\mathrm{Z}$ have been reported in oocytes collected from prepubertal heifers (lower oocyte competence) compared to oocytes from cows (Bettegowda et al. 2008).

Increased expression of $3 \beta$-hydroxysteroid dehydrogenase, ferredoxin 1 , serine proteinase inhibitor clade $\mathrm{E}$ member 2, cytochrome $\mathrm{P} 450$ aromatase, cell division cycle 42, LH receptor, and Sprouty homolog in granulosa cells of humans and cattle have been positively associated with increased oocyte competence (Robert et al., 2001; Robert et al., 2003; Hamel et al., 2008).

\subsection{Follicular influence on the maternal environment}

\section{Role of preovulatory estradiol}

Circulating estradiol plays many roles that aid in the establishment and maintenance of pregnancy in cattle. For example, increased preovulatory concentrations of estradiol initiate estrous behavior (Asdell et al., 1945), stimulate uterine contractions to facilitate sperm transport (Hawk, 1983), influence uterine $\mathrm{pH}$ (Perry and Perry, 2008) induce progesterone receptors in the endometrium (Xiao and Goff, 1999), and induce the preovulatory gonadotropin surge (Kesner et al., 1981). 
Increased dominant follicle size at GnRH-induced ovulation has been associated with increased concentrations of circulating preovulatory estradiol, although much variation has been observed (Atkins et al., 2013; Jinks et al., 2013). In a reciprocal embryo transfer study, donor cows with high $(>8.4 \mathrm{pg} / \mathrm{ml})$ circulating estradiol at the time of GnRH-induced ovulation were more likely to yield a transferable embryo. In addition, recipient cows with high circulating estradiol had increased pregnancy rates compared to cows with low estradiol (Jinks et al., 2013). Cows induced to ovulate small $(<12.2 \mathrm{~mm})$ dominant follicles supplemented with estradiol cypionate $24 \mathrm{hr}$ before ovulation had increased pregnancy rates compared to control cows induced to ovulate small follicles (Jinks et al., 2013). This indicates that preovulatory estradiol plays an important role in pregnancy establishment, most likely through an effect on the maternal environment. Proestrus is defined as the period from luteolysis until the onset of estrus and is characterized by an increase in LH pulsatility and increasing circulating concentrations of estradiol. Pregnancy rates were increased in FTAI protocols that lengthened proestrus (Bridges et al., 2008; 2010). Increased length of proestrus was also associated with increased concentrations of circulating preovulatory estradiol and postovulatory progesterone in the subsequent luteal phase (Bridges et al., 2008). Heifers with a shorter proestrus period had a decreased expression of estradiol receptor alpha mRNA in the uterine endometrium and decreased expression of progesterone receptor in the glandular epithelium on $\mathrm{d} 15.5$ of gestation. This may indicate that the decreased concentration of estradiol in these animals alters uterine function and may play a role in decreased pregnancy rates observed later in gestation (Bridges et al., 2012). 
Increased pregnancy rates associated with increased circulating estradiol at FTAI may also be due to a direct effect of estradiol on the COC. The bovine oocyte contains estradiol receptor beta mRNA and the surrounding cumulus cells contain both estradiol receptor alpha and beta mRNA (Beker-van Woudenberg et al., 2004). Oocytes from preovulatory bovine follicles that had increased intrafollicular concentrations of estradiol were more likely to develop into blastocysts (Mermillod et al., 1999). However, addition of estradiol to in vitro maturation media had either no effect or a negative effect on nuclear maturation of bovine oocytes (Beker-van Woudenberg et al., 2004, 2006) Role of postovulatory progesterone

The preovulatory gonadotropin surge induces ovulation and the transformation of follicular cells into the corpus luteum, which serves as the primary source of progesterone throughout gestation (reviewed by Smith et al., 1994). GnRH-induced ovulation of small dominant follicles was associated with decreased concentrations of postovulatory progesterone (Atkins et al., 2013). The early ruminant conceptus relies on the progesterone-stimulated production of growth factors and uterine secretions needed for growth. In cattle, elevation of progesterone before embryo transfer increased conceptus length on $\mathrm{d} 14$ of gestation in vivo, but had no effect on blastocyst development in vitro (Clemente et al., 2009). Although the bovine embryo contains progesterone receptor mRNA which may allow progesterone to have a direct effect on conceptus growth (Clemente et al., 2009), progesterone predominantly effects blastocyst development and conceptus growth through the maternal environment (Brooks et al., 2014). Interferon tau is produced by the elongating conceptus on approximately d14-20 in cattle and is essential for maternal recognition of pregnancy and prevention of luteolysis. A delayed 
rise in postovulatory progesterone has been associated with decreased conceptus size and decreased production of interferon tau, resulting in luteolysis and a failure to maintain pregnancy (reviewed by Brooks et al., 2014). Therefore, an adequate concentration of circulating postovulatory progesterone is necessary for pregnancy establishment and maintenance in cattle.

\subsection{Summary}

Both a developmentally competent oocyte and an adequate maternal environment are essential for the establishment and maintenance of a viable pregnancy. The bovine oocyte must undergo meiotic, cytoplasmic, and molecular maturation to reach full developmental competency. The oocyte and surrounding cumulus and granulosa cells are intimately associated from follicular formation until the preovulatory gonadotropin surge. Bidirectional paracrine, gap junctional, and transzonal communication between the oocytes and somatic cells play many important roles in follicular development and oocyte competence. Oocytes control the differentiation of follicular somatic cells into the cumulus and granulosa through the release of OSF. The cumulus cells provide newly transcribed mRNAs to the oocyte transcriptome through TZPs. The oocyte and early zygote relies on these stored RNAs to produce essential proteins until the maternal zygotic transition occurs. In addition, cumulus cells metabolize glucose at a higher rate and provide pyruvate and lactate to the oocyte to produce the energy needed for maturation. An increased concentration of preovulatory estradiol is associated with increased pregnancy success and may aid in pregnancy establishment through a direct effect on preparing the uterine environment or indirectly through gamete transport. An adequate concentration of postovulatory progesterone is also necessary for pregnancy 
maintenance and conceptus growth. Therefore, both acquisition of oocyte competence and an adequate maternal environment are necessary for the establishment of pregnancy. 


\section{CHAPTER III}

\section{EFFECT OF PREOVULATORY FOLLICLE SIZE ON CUMULUS CELL TRANSCRIPT ABUNDANCE IN BEEF CATTLE}

\subsection{Abstract}

Inadequate oocyte competence is a potential explanation for reduced pregnancy rates and(or) late embryonic/early fetal mortality when small dominant follicles are induced to ovulate with GnRH in postpartum beef cows. Bidirectional communication between the oocyte and surrounding follicular cells has a role in promoting oocyte competence, and bovine cumulus cells can contribute to the mRNA reserve in bovine oocytes via transzonal projections (Macaulay et al., 2016). The objective of this experiment was to determine if the transcriptome of cumulus cells collected from cumulus-oocyte complexes (approximately $20 \mathrm{hr}$ after an induced or endogenous gonadotropin surge) differs among the following classifications: small follicles (<11.7mm; no estrus expression), large follicles (>12.5 mm; no estrus expression), or spontaneous follicles (11.6-13.9 mm; estrus expression). To synchronize ovulation in suckled beef cows $(n=250)$, GnRH1 was administered on day -9, PG on day -2, GnRH2 (to initiate the ovulatory process) on day 0 , and dominant follicles $(n=68)$ were transvaginally aspirated 17 to $31 \mathrm{hr}$ after GnRH2 and before follicular rupture. Cows assigned to the spontaneous follicle group were detected in estrus and did not receive GnRH2. On day 0 , cows were assigned to one of the preceding groups. Cumulus cells were collected from individual cumulus-oocyte complexes after trans-vaginal aspiration. RNA was later extracted from cumulus cell pools collected from 4 COCs per pool $(n=6$ cumulus cell pools from both small and large follicles; $n=5$ cumulus cell pools from spontaneous 
follicles) and sequenced on an Illumina HiSeq 2000 (single reads, 100 bases). The sequences were trimmed using fqtrim and mapped to the Bos taurus genome (UMD3.1) using Hisat2 (Kim et al., 2015). FeatureCounts (Liao et al., 2014) was used to quantify transcript abundance using gene annotation obtained from Ensembl. Differentially abundant genes were determined using edgeR Robust with a false discovery rate of 0.10. When the cumulus cell transcriptome from small and large follicle classifications was compared, 430 transcripts had a higher abundance in small follicles and 454 had higher abundance in large follicles. Differentially abundant transcripts were analyzed for significant pathways using DAVID and the glycolytic pathway was found to be enriched in the cumulus cells of large follicles compared to small follicles. Oocytes have a poor capacity for metabolizing glucose and rely on the cumulus cells to supply pyruvate for energy production necessary for maturation. When cumulus cell pools from small and spontaneous follicles were compared, 597 transcripts were more abundant in small follicles and 1012 transcripts were more abundant in spontaneous follicles. Analysis with DAVID revealed that the steroid biosynthesis pathway (i.e. cholesterol synthesis) was enriched in the cumulus cells collected from spontaneous compared to small follicles. Comparison between large and spontaneous cumulus cell pools revealed that 541 transcripts were more abundant in large follicles and 951 were more abundant in cumulus cells from spontaneous follicles. The lysosome pathway was enriched in the cumulus cells of spontaneous compared to large follicles. Members of this pathway that were of interest include the cathepsins, which have been shown to be less abundant in oocytes that were more competent after the preovulatory gonadotropin surge. In summary, a greater abundance of members of the glycolytic pathway in large cumulus cells of 
follicles and members of the steroid biosynthesis pathway in cumulus cells from spontaneous compared to small follicles indicate that oocytes from small follicles may be less competent.

\subsection{Introduction}

The physiological maturity of the preovulatory bovine follicle may affect pregnancy establishment and embryonic mortality in beef cattle (Perry et al., 2005). Pregnancy rates were decreased after GnRH-induced ovulation of small dominant follicles compared to large dominant follicles. However, when cows expressed estrus by the time of FTAI, follicle size was not a significant factor (Perry et al., 2005). Decreased pregnancy rates in small follicles could be caused by decreased oocyte competence or an inadequate maternal environment. In a reciprocal embryo transfer study, Atkins et al. (2013) found that donor cows induced to ovulate small dominant follicles had decreased fertilization rates and reduced embryo quality compared to donors induced to ovulate large follicles, providing evidence that decreased oocyte competence is a contributing factor. However, the effect of the maternal environment of the donor from the time of fertilization until embryo collection is a possible confounding influence .

In cattle, RNA is synthesized and stored in the oocyte from the preantral stage until the maternal zygotic transition occurs (Fair et al. 1995). Although most transcription ceases after completion of oocyte growth, transcription continues at a low level in the oocyte until GVB. Bidirectional communication between the oocyte and surrounding cumulus cells also occurs at this time and is necessary for the acquisition of oocyte competence. Cumulus cell projections known as transzonal projections (TZPs) span the zona pellucida and allow a direct connection between the cumulus cells and 
oolemma. Long RNAs can be transported to the oocyte through the TZPs and contribute to the oocyte transcriptome (Macaulay et al. 2014; Macaulay et al., 2016). The TZPs remain intact until cumulus expansion in response to the preovulatory gonadotropin surge and the projections are disrupted. GnRH-induced ovulation of physiologically immature (small) follicles may induce premature ovulation of a transcriptionally active oocyte and(or) disrupt transfer of RNA from the cumulus cells to the oocyte through the TZPs and thereby reduce oocyte competence.

The effect of follicular diameter and estrus expression on the oocyte transcriptome was examined in a previous study and oocytes from large follicles had an increased abundance of members of the ubiquitin proteosome pathway and mitochondrial transcripts compared to oocytes from small follicles (Dickinson 2016). Since cumulus cells also contribute to the bovine oocyte transcriptome (Macaulay et al., 2016), the objective of the current study was to compare the cumulus cell transcriptome of COCs originating from small $(<11.7 \mathrm{~mm}, \mathrm{GnRH}$ induced gonadotropin surge, no estrus expression), large (>12.5mm, GnRH induced gonadotropin surge, no estrus expression), and spontaneous (11.6-13.9 mm; estrus expression) dominant follicles. Although previous studies have identified granulosa and cumulus cell markers of oocyte competence (Assidi et al., 2008; 2010; Bettegowda et al., 2008; Kussano et al., 2015), we hypothesized that characterizing the cumulus cell transcriptome will aid in the identification of additional molecules involved in acquisition of oocyte competence.

\subsection{Materials and Methods}

All protocols and procedures were approved by the Fort Keogh Livestock and 
Range Research Laboratory Animal Care and Use Committee (IACUC approval number 022014-2).

\section{Animal handling}

A timeline for synchronization of ovulation, blood collection, and ovarian mapping is depicted in Figure 3.1. Suckled crossbred postpartum beef cows $(n=250)$ were pre-synchronized using a 5-day CIDR protocol. An injection of $100 \mu \mathrm{g} \mathrm{GnRH}$ (i.m.; Factrel®; Zoetis Inc., Kalamazoo, MI) was administered and a CIDR (intravaginal insert; 1.38g progesterone; Eazi-Breed ${ }^{\circledR}$ CIDR; Zoetis Inc., Kalamazoo, MI) was inserted on d-15. The CIDR was removed and an injection of PG (i.m.; 25 mg; Lutalyse ${ }^{\circledR}$ Zoetis Inc., Kalamazoo, MI) was administered on d-10. Cows were also divided into five replicates $(n=50)$ for transvaginal aspiration on d10. Each replicate was synchronized between 10 to 14 days following CIDR removal by injecting GnRH (GnRH1; i.m.; Factrel®; Zoetis Inc., Kalamazoo, MI) on d0, followed by an injection of PG (i.m.; 25 mg; Lutalyse ${ }^{\circledR}$ Zoetis Inc., Kalamazoo, MI) on d7. Cows received an estrous detection patch (Estrotect; Rockway Inc.; Spring Valley, WI) on d0. The patch was monitored on $\mathrm{d} 7$ and replaced if scratched. The combination of estrous detection patches and visual assessment of estrous expression was performed three times daily beginning on $\mathrm{d} 7$ until follicle aspiration on d10. Estrus was defined as when cows stood to be mounted or had a fully activated patch. Cows that had not expressed estrus by $\mathrm{d} 9$ received a second injection of GnRH (GnRH2; i.m.; Factrel®; Zoetis Inc., Kalamazoo, MI) to induce a preovulatory gonadotropin surge.

Approximately 23 hours after GnRH2 injection $(\mathrm{d} 10$; mean $=23 \mathrm{hr}$; range $=17$ $31 \mathrm{hr}$ ), follicular fluid and the cumulus-oocyte complex of the largest follicle were 


\begin{tabular}{|c|c|c|c|c|c|}
\hline \multicolumn{6}{|c|}{$\begin{array}{l}\text { Presynchronization: } \\
5 \text { Day CIDR }\end{array}$} \\
\hline $\begin{array}{c}\text { Day -15 } \\
\text { GnRH } \\
\text { Bleed }\end{array}$ & $\begin{array}{c}\text { Day -10 } \\
\text { PGF } \\
\text { Bleed }\end{array}$ & $\begin{array}{c}\text { Day 0 } \\
\text { GnRH } \\
\text { (GNRH1) } \\
\text { Bleed }\end{array}$ & $\begin{array}{c}\text { Day } 7 \\
\text { PG } \\
\text { Ovarian Mapping, } \\
\text { Bleed }\end{array}$ & $\begin{array}{l}\text { Day } 9 \\
\text { Ovarian Mapping, } \\
\text { GnRH (GnRH2) } \\
\text { to Lg/Sm, Bleed } \\
\text { Estrous Detection }\end{array}$ & $\begin{array}{c}\text { Day } 10 \\
\text { Ovarian Mapping, } \\
\text { Follicle Aspiration, } \\
\text { Bleed } \\
\end{array}$ \\
\hline
\end{tabular}

Figure 3.1. Animal handling procedures and the protocol for synchronization of ovulation. Follicle classification groups were assigned based on ovulatory follicle size at GnRH2 (day 9), administration of GnRH2 injection, and expression of estrus and were defined as follows: Small ( $<11.7 \mathrm{~mm}$; received GnRH2; no estrus expression), Large $(>12.5 \mathrm{~mm}$; received GnRH2; no estrus expression), and Spontaneous (11.6-13.9 mm; did not receive GnRH2; estrus expression). CIDR= Controlled Internal Drug Release, $\mathrm{GnRH}=$ Gonadotropin Releasing Hormone, $\mathrm{PG}=$ Prostaglandin $\mathrm{F}_{2 \alpha}$, Bleed= blood collection for quantification of serum progesterone or estradiol, Ovarian Mapping=ultrasound examination or ovarian structures and measurement of follicles, Estrous Detection=visual detection of estrus 3 times daily 
collected through transvaginal aspiration by one of two technicians as described below. Ovaries of all cows were examined by an experienced technician using trans-rectal ultrasonography (Aloka 3500 with $7.5 \mathrm{MHz}$ probe) on days 7, 9, and 10. All follicles greater than $7 \mathrm{~mm}$ and any CL present were recorded. Follicle size was defined as the average of the greatest follicle diameter and the diameter perpendicular to it. Cows were assigned to one of the following three classifications based on largest follicle size, estrous expression, and GnRH2 treatment: small $(<11.7 \mathrm{~mm}$ follicle, no estrous expression, received GnRH2 injection), large (>12.5 mm follicle, no estrous expression, received GnRH2), or spontaneous (11.6-13.9mm follicle, estrus expression, no GnRH2 injection).

\section{Transvaginal aspiration}

All animals received a spinal block injection of approximately $5 \mathrm{ml}$ of $2 \%$ lidocaine into the first intercoccygeal space of the tailhead. The perineal region was cleaned of contaminants and an ultrasound guided aspiration gun containing an 18-gauge needle and a series of tubing to allow for follicular flushing was positioned in the anterior vagina. Both ovaries were examined by ultrasonography and the ovary containing the largest follicle was secured near the aspiration needle. The needle was pushed through the vaginal wall and guided through the ovarian cortex into the antrum of the selected follicle. Follicular fluid was aspirated into a $12 \mathrm{ml}$ syringe, examined for the presence of a COC, and saved for hormone analysis. The collapsed follicle was flushed 3-4 times using a new syringe with PBS-TL HEPES (Dickinson, 2016) and all flushed media was collected. The needle was withdrawn into the probe and removed from the cow. The probe was washed with a dilute chlorohexidine solution and sprayed with $70 \%$ ethanol between cows. 
Cumulus-oocyte complex recovery and processing

Syringes containing the follicular fluid and subsequent flushes were divided into 4-well Petri plates and searched to find the COC. Once located, the COC was pipetted in $500 \mu \mathrm{l}$ of surrounding of media and placed in a $2 \mathrm{ml}$ RNAse free Eppendorf tube. After vortexing for 40 seconds, the contents were placed into a smaller search plate filled with PVA-TL HEPES (Dickinson 2016). The majority of the cumulus cells were cut away from the oocyte with a clean pair of needles. The remaining cumulus cells were removed from the oocyte by rapid pipetting. All cumulus cells were placed in an RNAse free collection tube and centrifuged at $1500 \mathrm{~g}$ for 3 minutes. The media was removed, leaving a small amount to avoid disrupting the cell pellet and $90 \mu \mathrm{l}$ of lysis buffer (RNAqueous ${ }^{\circledR}$ MicroKit; Ambion ${ }^{\circledR}$; Foster City, CA) was added. Cumulus cells were snap frozen in liquid nitrogen and then stored at $-80^{\circ} \mathrm{C}$ until RNA extraction.

\section{$R N A$ extraction and amplification}

The pipeline for RNA sequencing and analysis is shown in Figure 3.2. A preliminary experiment was conducted to determine the minimum number of oocytes that could be pooled to obtain adequate amounts of RNA for amplification and sequencing (Dickinson, 2016). Oocytes were pooled in groups of four oocytes and the analysis of the oocyte transcriptome was previously reported by Dickinson (2016). The cumulus cells corresponding to each of the oocyte pools were also pooled and the transcriptome sequenced for the current experiment. Pools were designed to be as uniform as possible and were established based on the following criteria: 1) treatment groups, 2) cow age, and 3) time from follicle aspiration to freezing. 


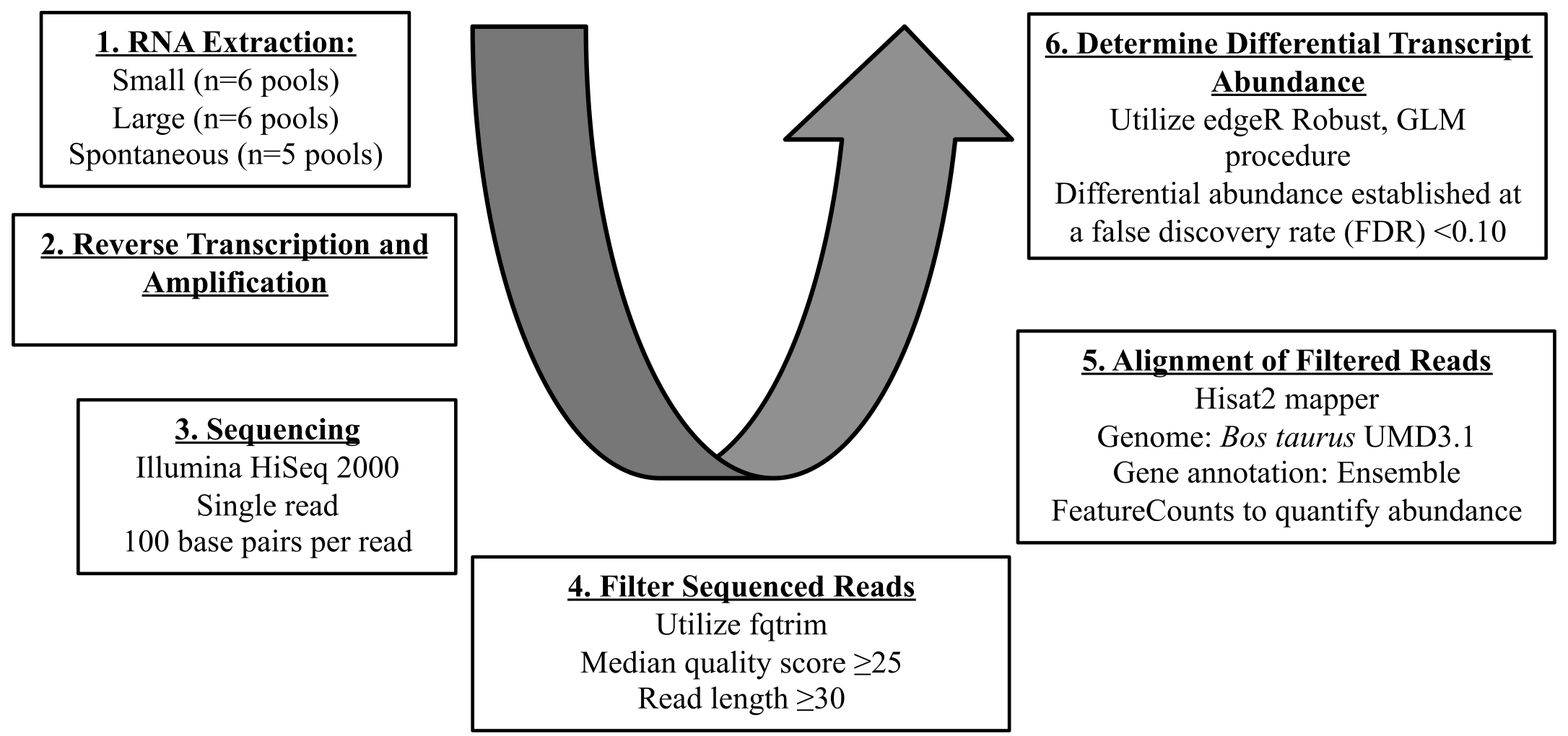

Figure 3.2. The chronological steps employed to generate and analyze the data for this project include the following: 1) Extract RNA from cumulus cell pools from four oocytes from each follicle classification: small follicle (Small; <11.7mm; received GnRH2; no estrus expression), large follicle (Large; $>12.5 \mathrm{~mm}$; received GnRH2; no estrus expression) or spontaneous follicle (Spontaneous; follicle diameter = 11.6-13.9 mm; no GnRH2; estrus expression), 2) Generate and amplify cDNA for each pool, 3) Generate nucleotide sequence data, 4) Filter the data based on established criteria (e.g. Quality score), 5) Align the reads to the genome, and 6) Analyze the data for differential transcript abundance. A FDR of $<0.10$ was chosen for the purposes of this study. 
Total RNA was extracted from pools using the AllPrep ${ }^{\circledR}$ DNA/RNA Micro Kit (Qiagen, Germantown, MD) following manufacturer's instructions. Following extraction, RNA was subjected to reverse transcription and amplified using the Ovation ${ }^{\circledR}$ RNA-Seq System V2 (NuGen Technologies, Inc., San Carlos, CA) by following manufacturer's instructions. The amplified sample was further refined using the MinElute ${ }^{\circledR}$ Reaction Cleanup Kit (Qiagen, Germantown, MD).

\section{Illumina Sequencing}

Amplified cDNA from each pool was diluted with RNAse free water to a concentration of $80 \mathrm{ng} / \mu 1$, and $25 \mu 1$ of each dilution was sent to the University of Missouri DNA Core for deep sequencing. Complementary DNA libraries were prepared for sequencing using the TruSeq DNA PCR-Free Library Preparation Kit (Illumina, Inc., San Diego, CA). Each sample was then subjected to high-throughput sequencing with a HighSeq 2000 (Illumina, Inc, San Diego, CA), using single reads with 100 bases per read. All pools were sequenced in a single lane. Since greater sequencing depth was later desired, all sample pools were sequenced a second time.

\section{Sequence Trimming and Alignment}

Sequence adaptors were removed and remaining sequences were filtered for quality using fqtrim (https://ccb.jhu.edu/software/fqtrim/). Sequences were retained if they met a median quality score of 25 , and had a minimum read length of 30 base pairs. Filtered sequences were aligned to the Bos taurus reference genome UMD3.1 using Hisat2mapper (Kim et al., 2015). FeatureCounts (Liao et al., 2014) was used to quantify transcript abundance in each sample using Bos taurus gene notation from Ensembl (http://www.ensembl.org/Bos_taurus/). 


\section{Statistical analysis of cumulus cell pools}

Analysis of Variance (ANOVA) was utilized to determine any significant differences between follicle classifications in cow age, weight, BCS, days post-partum, interval from $\mathrm{PG}$ to $\mathrm{GnRH} 2$, interval from $\mathrm{GnRH} 2$ to follicle aspiration, and interval from follicle aspiration to cumulus cell freezing, as well as to confirm a difference in follicular diameter between treatments.

\section{Determination of differentially abundant genes}

After alignment, a spreadsheet of read counts was generated for each cumulus cell pool and the data were submitted to edgeR (Zhou et al., 2014) and an edgeR Robust test was used to determine differentially abundant genes. Because the goal of this study was to identify a list of differentially abundant transcripts that can be further examined, a FDR $<0.10$ was used so as to generate a larger list. Comparisons were made between the following classifications: small follicle cumulus pools compared to large follicle cumulus pools, small follicle cumulus pools compared to spontaneous follicle cumulus pools, and large follicle cumulus pools compared to spontaneous follicle cumulus pools.

Differentially abundant transcripts were uploaded into DAVID Bioinformatics Software (Huang et al., 2009a; 2009b) to detect significant biological pathways or functional clusters.

\subsection{Results}

Mean follicle diameter \pm SEM (range) at GnRH2 injection differed among the small, large, and spontaneous follicle classifications: $\left(10.4 \pm 0.1 \mathrm{~mm}^{\mathrm{x}}[8.5-11.7 \mathrm{~mm}]\right.$; $13.6 \pm 0.1 \mathrm{~mm}^{\mathrm{y}}[12.7-15.3 \mathrm{~mm}]$, and $12.2 \pm 0.2 \mathrm{~mm}^{\mathrm{z}}[11.7-14.0 \mathrm{~mm}]$, respectively; Table 3.1; $\left.{ }^{\mathrm{xyz}} \mathrm{P}<0.0001\right)$. However, there was no difference in cow age $(\mathrm{P}>0.69)$, weight 
( $\mathrm{P}>0.54)$, body condition score (BCS; $\mathrm{P}>0.83$ ), days postpartum $(\mathrm{P}>0.70)$, or time from PG to GnRH2 injection $(\mathrm{P}>0.89)$ in all follicle classifications. Time from GnRH2 injection to follicle aspiration was similar for the small versus large follicle comparison ( $P>0.14$; see Table 3.1 for means and ranges of all parameters).

Analysis of reads generated from RNA-seq

Cumulus cells from four cumulus cell oocyte complexes (COCs) were pooled as described in the methods section. RNA was extracted from seventeen pools as follows: small follicle classification ( $\mathrm{n}=6$ pools); large follicle classification $(\mathrm{n}=6)$; and spontaneous follicle classification $(\mathrm{n}=5)$. Initially, deep sequencing of cumulus cell pools yielded an average of 10,463,377 raw reads per pool. Pools were sequenced a second time to achieve greater sequencing depth and yielded an average of 18,577,166 additional raw reads per pool. A mean of $77 \%$ of all reads mapped to the Bos taurus genome. A summary of read counts is depicted in table A.1.

\section{Differential transcript abundance}

Previously published cumulus cell markers of oocyte competence

Several studies have identified cumulus cell markers of oocyte competence (i.e. EREG, ATP6V1C1, $A K A P 7$, and THBS1), which were upregulated in cumulus cells associated with more competent bovine oocytes (Assidi et al., 2008; 2010; Kussano et al., 2016). In another study, increased expression in the cumulus cells of cathepsins B, S, K, and $\mathrm{Z}$ have been associated with less competent oocytes (Bettegowda et al., 2008). Some previously published cumulus cell markers were differentially abundant in the current study and are listed in Table 3.2. 
Table 3.1. Parameters describing the cumulus cell pools for small, large, or spontaneous follicle classifications.

\begin{tabular}{|l|c|c|c|}
\hline \multicolumn{1}{|c|}{ Parameter } & $\begin{array}{c}\text { Small Follicle } \\
\text { Classification }\end{array}$ & $\begin{array}{c}\text { Large Follicle } \\
\text { Classification }\end{array}$ & $\begin{array}{c}\text { Spontaneous Follicle } \\
\text { Classification }\end{array}$ \\
\hline Follicle Size at & $10.4^{\mathrm{x}} \pm 0.1 \mathrm{~mm}$ & $13.6^{\mathrm{y}} \pm 0.1 \mathrm{~mm}$ & $12.2^{\mathrm{z}} \pm 0.2 \mathrm{~mm}$ \\
GnRH2 $^{\mathrm{a}}$ & $(8.5-11.7 \mathrm{~mm})$ & $(12.7-15.3 \mathrm{~mm})$ & $(11.7-14.0 \mathrm{~mm})$ \\
\hline Cow Age $^{\mathrm{b}}$ & $6.5 \pm 0.4 \mathrm{yr}$ & $6.3 \pm 0.4 \mathrm{yr}$ & $6.9 \pm 0.5 \mathrm{yr}$ \\
& $(4-12 \mathrm{yr})$ & $(4-9 \mathrm{yr})$ & $(4-13 \mathrm{yr})$ \\
\hline Cow Weight $^{\mathrm{c}}$ & $548 \pm 11 \mathrm{~kg}$ & $564 \pm 11 \mathrm{~kg}$ & $548 \pm 14 \mathrm{~kg}$ \\
& $(454-674 \mathrm{~kg})$ & $(452-668 \mathrm{~kg})$ & $(468-646 \mathrm{~kg})$ \\
\hline Cow BCS $^{\mathrm{d}}$ & $4.8 \pm 0.1$ & $4.8 \pm 0.1$ & $4.7 \pm 0.1$ \\
& $(4-5)$ & $(4-6)$ & $(4-5)$ \\
\hline Cow Days & $88 \pm 1.7 \mathrm{days}$ & $86 \pm 1.7 \mathrm{days}$ & $86 \pm 2.0$ days \\
Postpartum & $(65-96 \mathrm{days})$ & $(58-98 \mathrm{days})$ & $(76-95$ days $)$ \\
\hline Time from PG to & $51 \pm 1.5 \mathrm{hr}$ & $51 \pm 1.5 \mathrm{hr}$ & NA \\
GnRH2 $^{\mathrm{f}}$ & $(43-56 \mathrm{hr})$ & $(43-56 \mathrm{hr})$ & \\
\hline Time from GnRH2 to & $24 \pm 0.8 \mathrm{hr}$ & $22 \pm 0.8 \mathrm{hr}$ & NA \\
Follicle Aspiration & \\
\hline
\end{tabular}

${ }^{a}$ Size of the pre-ovulatory follicle on day 9 at GnRH2 injection; Mean \pm SEM (range)

${ }^{\mathrm{b}}$ Cow age; Mean \pm SEM (range)

${ }^{\mathrm{c}}$ Body weight ; Mean \pm SEM (range)

${ }^{\mathrm{d}}$ Body condition score (BCS) ; Mean \pm SEM (range)

${ }^{\mathrm{e}}$ Days postpartum ; Mean \pm SEM (range)

${ }^{\mathrm{f}}$ Time from injection of PG to injection of $\mathrm{GnRH} 2$ in cows within the small or large follicle size classifications; Mean \pm SEM (range); NA=not applicable

${ }^{\mathrm{g}}$ Time from injection of GnRH2 to follicle aspiration in cows within the small or large follicle size classifications; Mean \pm SEM (range); NA=not applicable

${ }^{x y z} \mathrm{P}$ - means having different superscripts $\operatorname{differ}(\mathrm{P}<0.0001)$ 
Table 3.2. Previously published cumulus cell markers of oocyte competence found to be differentially abundant.

\begin{tabular}{|l|l|l|l|l|l|}
\hline Gene & Abundance & Reference & Comparison & Abundance & FDR \\
\hline $\begin{array}{l}\text { Thrombospondin } \\
1\end{array}$ & Increased & $\begin{array}{l}\text { Assidi et al., } \\
2010\end{array}$ & $\begin{array}{l}\text { Spontaneous } \\
\text { vs Small } \\
\text { Spontaneous } \\
\text { vs Large }\end{array}$ & $\begin{array}{l}\text { Increased } \\
\text { Spontaneous }\end{array}$ & 0.0009 \\
\hline $\begin{array}{l}\text { ATPase H+ } \\
\text { Transporting V1 } \\
\text { Subunit C1 }\end{array}$ & Increased & $\begin{array}{l}\text { Assidi et al., } \\
2010\end{array}$ & $\begin{array}{l}\text { Spontaneous } \\
\text { vs Small } \\
\text { Spontaneous } \\
\text { vs Large }\end{array}$ & $\begin{array}{l}\text { Increased } \\
\text { Spontaneous }\end{array}$ & 0.0008 \\
\hline Epigregulin & Increased & $\begin{array}{l}\text { Assidi et al., } \\
2010\end{array}$ & $\begin{array}{l}\text { Spontaneous } \\
\text { vs Small } \\
\text { Spontaneous } \\
\text { vs Large }\end{array}$ & $\begin{array}{l}\text { Increased } \\
\text { Spontaneous }\end{array}$ & 0.005 \\
\hline Cathepsin Z & Decreased & $\begin{array}{l}\text { Bettegowda } \\
\text { et al., 2008 }\end{array}$ & $\begin{array}{l}\text { Spontaneous } \\
\text { vs Large }\end{array}$ & $\begin{array}{l}\text { Increased } \\
\text { Spontaneous }\end{array}$ & 0.028 \\
\hline $\begin{array}{l}\text { A-Kinase } \\
\text { Anchoring Protein } \\
7\end{array}$ & Increased & $\begin{array}{l}\text { Assidi et al., } \\
2010\end{array}$ & $\begin{array}{l}\text { Spontaneous } \\
\text { vs Small } \\
\text { Spontaneous } \\
\text { vs Large }\end{array}$ & $\begin{array}{l}\text { Increased } \\
\text { Spontaneous }\end{array}$ & 0.031 \\
\hline $\begin{array}{l}\text { Hyaluronan } \\
\text { Synthase 2 }\end{array}$ & Increased & $\begin{array}{l}\text { Assidi et al., } \\
2010\end{array}$ & $\begin{array}{l}\text { Spontaneous } \\
\text { vs Small }\end{array}$ & $\begin{array}{l}\text { Increased } \\
\text { Spontaneous }\end{array}$ & 0.048 \\
\hline Cathepsin K & Decreased & $\begin{array}{l}\text { Bettegowda } \\
\text { et al., 2008 }\end{array}$ & $\begin{array}{l}\text { Spontaneous } \\
\text { vs Small } \\
\text { Spontaneous } \\
\text { vs Large }\end{array}$ & $\begin{array}{l}\text { Increased } \\
\text { Spontaneous }\end{array}$ & 0.062 \\
\hline Cathepsin B & Decreased & $\begin{array}{l}\text { Bettegowda } \\
\text { et al., 2008 }\end{array}$ & $\begin{array}{l}\text { Spontaneous } \\
\text { vs Large }\end{array}$ & $\begin{array}{l}\text { Increased } \\
\text { Spontaneous }\end{array}$ & 0.064 \\
\hline Glypican 4 & Increased & $\begin{array}{l}\text { Kussano et } \\
\text { al., 2016 }\end{array}$ & $\begin{array}{l}\text { Spontaneous } \\
\text { vs Large }\end{array}$ & $\begin{array}{l}\text { Increased } \\
\text { Spontaneous }\end{array}$ & 0.076 \\
\hline $\begin{array}{l}\text { Inhibin Beta A } \\
\text { Subunit }\end{array}$ & Increased & $\begin{array}{l}\text { Assidi et al., } \\
2010\end{array}$ & $\begin{array}{l}\text { Spontaneous } \\
\text { vs Small }\end{array}$ & $\begin{array}{l}\text { Increased } \\
\text { Spontaneous }\end{array}$ & 0.083 \\
\hline
\end{tabular}

${ }^{\mathrm{a}}$ Level of relative abundance found in cumulus cells associated with more competent oocytes. 
Cumulus cell pools from small versus large preovulatory follicles

After alignment to the Bos taurus genome, there were 884 differentially abundant transcripts $(\mathrm{FDR}<0.10)$ when comparing cumulus cells from large and small follicles. Of these, 430 transcripts were more abundant in cumulus cells from small follicles and 454 transcripts were more highly abundant in cumulus cells from large follicles. In the small follicle classification, 393 transcripts were annotated; whereas, 414 transcripts were annotated in the large follicle classification. All other differentially abundant transcripts were unannotated. Figure 3.3 is a volcano plot that depicts the differentially abundant transcripts in cumulus cells from the small versus large follicle classifications and depicts the fold change between follicle classifications. The fifteen most differentially abundant annotated cumulus cell transcripts (ranked by FDR) for small and large follicle classifications are listed in Tables 3.3 and 3.4, respectively.

Analysis with DAVID found that many members of the glycolytic KEGG pathway were more abundant in cumulus cells from large compared to small follicles. Other KEGG pathways were found to be significant by DAVID (Table 3.5) in both large and small follicle cumulus cells; however we chose to focus on glycolysis as the other pathways did not seem biologically relevant (e.g. Parkinson's disease) or did not have enough members of the pathway identified to constitute a meaningful pathway (e.g. Galactose metabolism). A simplified diagram of glycolysis is shown in Figure 3.4 and transcripts of enzymes that were more abundant in cumulus cells of large versus small follicles in our analysis are highlighted. 


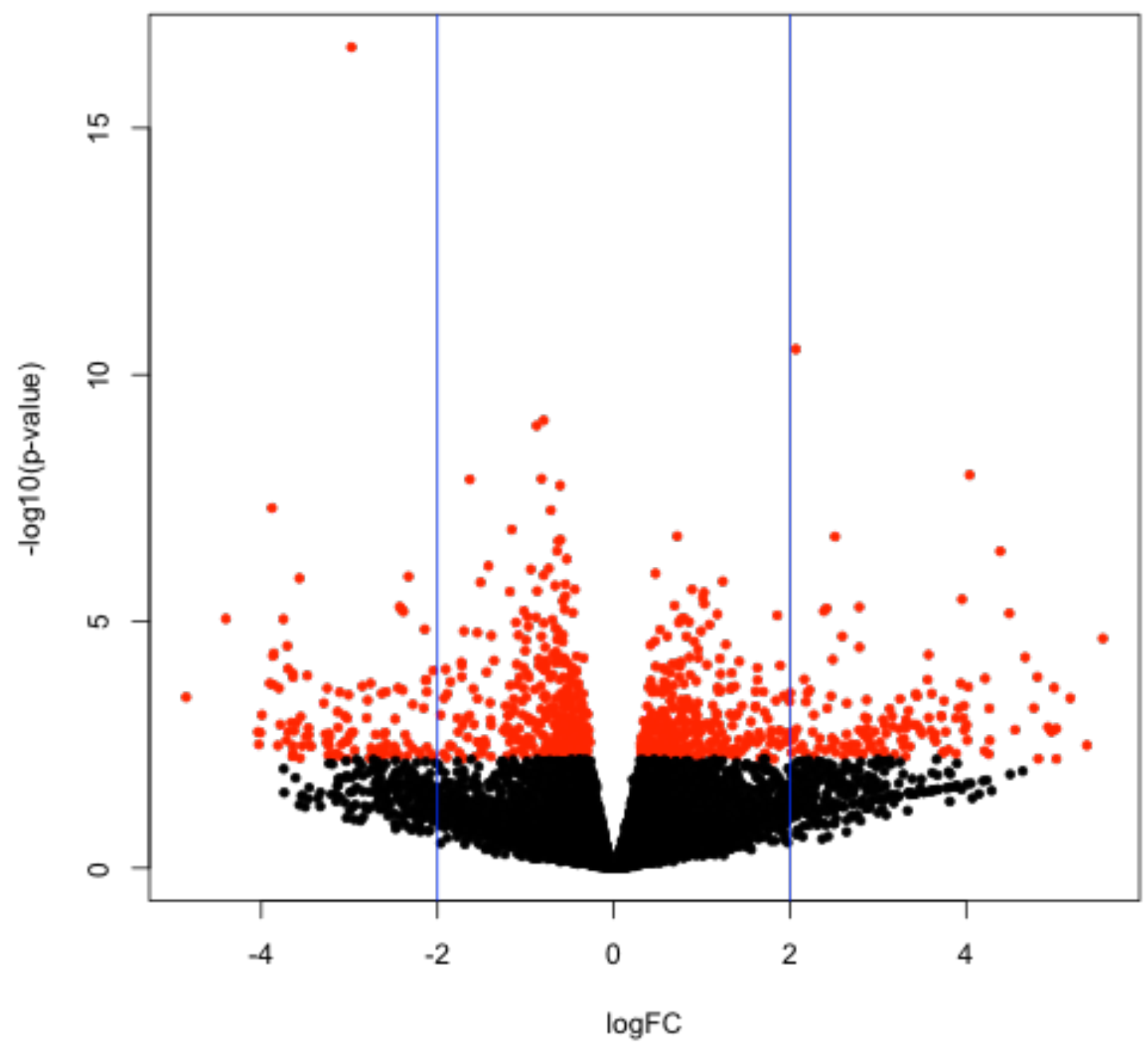

Figure 3.3. Volcano plot depicting differences in transcript abundance between small follicle cumulus cell pools and large follicle cumulus cell pools when mapped to the Bos taurus genome. $\mathrm{X}$-axis denotes the $\log 2$ of the ratio between the normalized edgeR Robust read count values for small and large follicle cumulus cell pools $(-5=32$ fold lower in small follicle cumulus cell pools; $0=$ equal transcript abundance between follicle classifications; $5=32$ fold higher in small follicle cumulus pools). Y-axis denotes $\log 10$ (FDR P-Value) where 1.3 equals FDR $=0.05$ and 1 equals FDR $=0.10$. Each dot represents one transcript. Red dots denote transcripts significantly different between small and large follicle cumulus cell pools at a FDR of $<0.10$. Vertical blue lines mark $\operatorname{logFC}$ greater than 2 . 
Table 3.3. Top fifteen transcripts (by FDR) more abundant in small follicle cumulus cell pools compared to large follicle cumulus cell pools ${ }^{\mathrm{a}}$

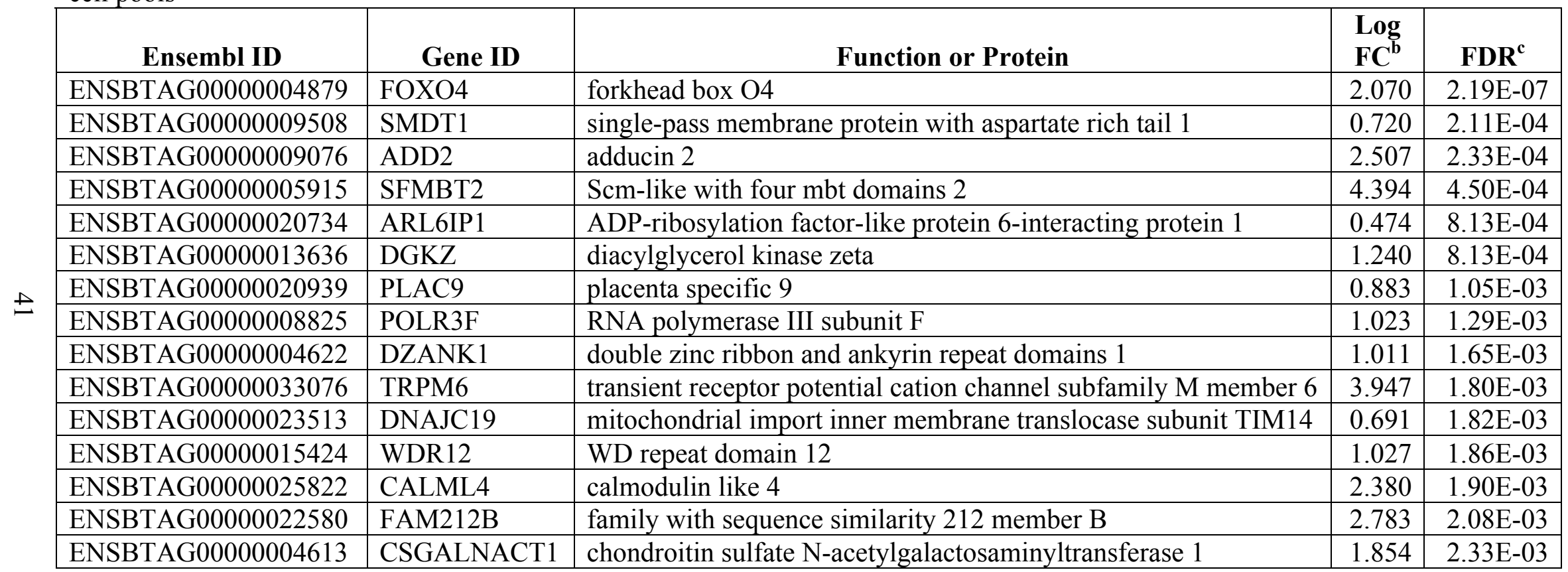

${ }^{\text {a }}$ Data represent top 15 transcripts aligned to the Bos taurus genome (UMD3.1) and found to be differentially abundant by the edgeR Robust GLM test (FDR <0.10). Transcripts are ranked by FDR. Only protein coding transcripts from annotated regions of the genome are included.

${ }^{\mathrm{b}} \log 2$ of the ratio between the normalized edgeR read count values for small or large follicle cumulus cell pools $(-5=32$ fold higher in small follicle cumulus cell pools; $0=$ equal transcript abundance between follicle classifications; $5=32$ fold higher in large follicle cumulus cell pools.)

${ }^{\mathrm{c}}$ FDR P-Value (adjusted for multiple comparisons) for the difference in transcript abundance between cumulus cell pools derived from small and large follicle classifications. 
Table 3.4. Top fifteen transcripts (by FDR) more abundant in large follicle cumulus cell pools compared to small follicle cumulus cell pools $^{\mathrm{a}}$

\begin{tabular}{|c|c|c|c|c|}
\hline Ensembl ID & Gene ID & Function or Protein & $\begin{array}{l}\text { Log } \\
\text { FC }^{b} \\
\end{array}$ & FDR $^{\mathbf{c}}$ \\
\hline ENSBTAG00000019839 & LTBP1 & latent-transforming growth factor beta-binding protein 1 precursor & -0.797 & $1.25 \mathrm{E}-06$ \\
\hline ENSBTAG00000009617 & SLC2A1 & solute carrier family 2 member 1 & -0.871 & $6.86 \mathrm{E}-06$ \\
\hline ENSBTAG00000007476 & BTRC & beta-transducin repeat containing E3 ubiquitin protein ligase & -0.817 & $2.72 \mathrm{E}-05$ \\
\hline ENSBTAG00000032680 & TMEM63B & transmembrane protein $63 \mathrm{~B}$ & -0.605 & $2.72 \mathrm{E}-05$ \\
\hline ENSBTAG00000017133 & GINS4 & GINS complex subunit 4 & -1.634 & $3.23 \mathrm{E}-05$ \\
\hline ENSBTAG00000014906 & VCAN & versican & -0.632 & $3.37 \mathrm{E}-05$ \\
\hline ENSBTAG00000017626 & GFPT1 & glutamine--fructose-6-phosphate transaminase 1 & -0.721 & 4.61E-05 \\
\hline ENSBTAG00000017461 & SLC16A3 & solute carrier family 16 member 3 & -1.152 & $1.91 \mathrm{E}-04$ \\
\hline ENSBTAG00000045728 & & acyl-CoA desaturase & -0.601 & $2.75 \mathrm{E}-04$ \\
\hline ENSBTAG00000013108 & HK2 & hexokinase 2 & -0.640 & 4.00E-04 \\
\hline ENSBTAG00000011966 & LAMC1 & laminin subunit gamma 1 & -0.535 & $4.59 \mathrm{E}-04$ \\
\hline ENSBTAG00000031503 & NDUFA4L2 & NDUFA4, mitochondrial complex associated like 2 & -0.945 & $5.65 \mathrm{E}-04$ \\
\hline ENSBTAG00000008683 & LDHA & lactate dehydrogenase $\mathrm{A}$ & -0.796 & $5.65 \mathrm{E}-04$ \\
\hline ENSBTAG00000000210 & ARHGAP31 & rho GTPase-activating protein 31 & -0.741 & $5.65 \mathrm{E}-04$ \\
\hline
\end{tabular}

${ }^{a}$ Data represent top 15 transcripts aligned to the Bos taurus genome (UMD3.1) and found to be differentially abundant by the edgeR

Robust GLM test $($ FDR $<0.10)$. Transcripts are ranked by FDR. Only protein coding transcripts from annotated regions of the genome are included.

${ }^{b} \log 2$ of the ratio between the normalized edgeR read count values for small or large follicle cumulus cell pools $(-5=32$ fold higher in small follicle cumulus cell pools; $0=$ equal transcript abundance between follicle classifications; $5=32$ fold higher in large follicle cumulus cell pools.)

${ }^{c}$ FDR P-Value (adjusted for multiple comparisons) for the difference in transcript abundance between cumulus cell pools derived from small and large follicle classifications. 
Table 3.5. Significant KEGG pathways enriched in large or small cumulus cell pools

\begin{tabular}{|l|c|c|}
\hline \multicolumn{1}{|c|}{ KEGG Pathway } & $\begin{array}{c}\text { Number of Genes } \\
\text { Present in Pathway }\end{array}$ & P-Value \\
\hline \multicolumn{1}{|c|}{ Pathways enriched in small compared to large follicle cumulus cell pools } \\
\hline Spliceosome & 9 & $2.5 \mathrm{E}-3$ \\
\hline Oxidative phosphorylation & 9 & $4.1 \mathrm{E}-3$ \\
\hline Non-alcoholic fatty liver disease & 9 & $9.0 \mathrm{E}-3$ \\
\hline Parkinson's disease & 8 & $2.1 \mathrm{E}-2$ \\
\hline Huntington's disease & 9 & $3.0 \mathrm{E}-2$ \\
\hline Alzheimer's disease & 9 & $4.5 \mathrm{E}-2$ \\
\hline \multicolumn{1}{|c|}{ Pathways enriched in large compared to small follicle cumulus cell pools } \\
\hline Glycolysis/Gluconeogenesis & 12 & $1.1 \mathrm{E}-7$ \\
\hline Biosynthesis of antibiotics & 19 & $6.4 \mathrm{E}-7$ \\
\hline Carbon metabolism & 12 & $2.8 \mathrm{E}-5$ \\
\hline Biosynthesis of amino acids & 10 & $3.5 \mathrm{E}-5$ \\
\hline Central carbon metabolism in cancer & 9 & $6.3 \mathrm{E}-5$ \\
\hline Fructose and mannose metabolism & 6 & $5.5 \mathrm{E}-4$ \\
\hline Metabolic pathways & 45 & $9.0 \mathrm{E}-4$ \\
\hline Pentose phosphate pathway & 5 & $2.8 \mathrm{E}-3$ \\
\hline ECM-receptor interaction & 8 & $3.2 \mathrm{E}-3$ \\
\hline Protein processing in endoplasmic reticulum & 10 & $1.3 \mathrm{E}-2$ \\
\hline Focal adhesion & 11 & $1.8 \mathrm{E}-2$ \\
\hline PI3K-Akt signaling pathway & 15 & $2.3 \mathrm{E}-2$ \\
\hline Galactose metabolism & 4 & $3.1 \mathrm{E}-2$ \\
\hline Thyroid hormone signaling pathway & 7 & $4.0 \mathrm{E}-2$ \\
\hline
\end{tabular}




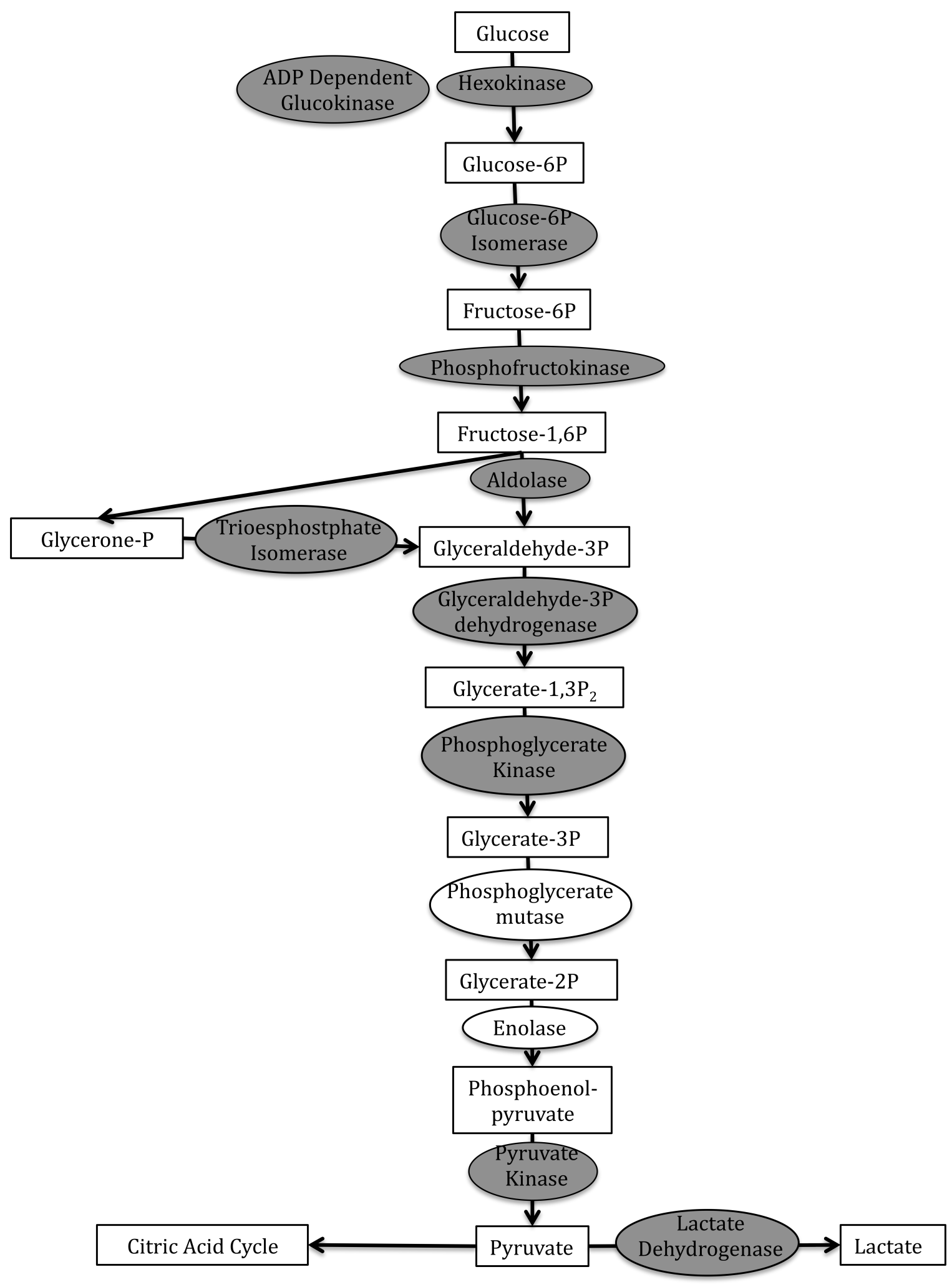

Figure 3.4. Diagram of the glycolytic pathway. Substrates are shown in boxes and enzymes are depicted in ovals. Shaded shapes indicate that transcripts were more abundant in large follicle cumulus cells. 
Cumulus cell pools from small versus spontaneous preovulatory follicles

When comparing small and spontaneous follicle cumulus cell pools, 1609 transcripts were differentially abundant, with 597 transcripts (553 annotated) more abundant in small follicles and 1012 transcripts (901 annotated) more abundant in spontaneous follicles. The volcano plot in Figure 3.5 shows fold change between follicle classifications and indicates differentially abundant transcripts. The fifteen most differentially abundant transcripts ranked by FDR for cumulus cells obtained from small and spontaneous follicle classifications are shown in Tables 3.6 and 3.7, respectively. When analyzed with DAVID, the steroid biosynthesis KEGG pathway (i.e. cholesterol synthesis; Figure 3.6) was found to be significant in cumulus cells of the spontaneous follicle classification. Other significant KEGG pathways are listed in Table 3.8, but were not biologically relevant or did not have enough members of the pathway present to justify further investigation.

Cumulus cell pools from large versus spontaneous preovulatory follicles

Cumulus cells pools collected from follicles classified as large or spontaneous follicles were compared and 540 transcripts were found to be more abundant in the cumulus cells of large follicles, while 951 transcripts were more abundant in the cumulus cells of spontaneous follicles. Of these transcripts, 486 transcripts in the large follicle classification and 860 transcripts in spontaneous follicle classification were annotated. All other differentially abundant transcripts were unannotated. A volcano plot (Figure 3.7) depicts differentially abundant transcripts in cumulus cells and shows fold change between follicle classifications. The top fifteen transcripts ranked by FDR are listed for each follicle classification in Tables 3.9 (large) and 3.10 (spontaneous). Differentially 


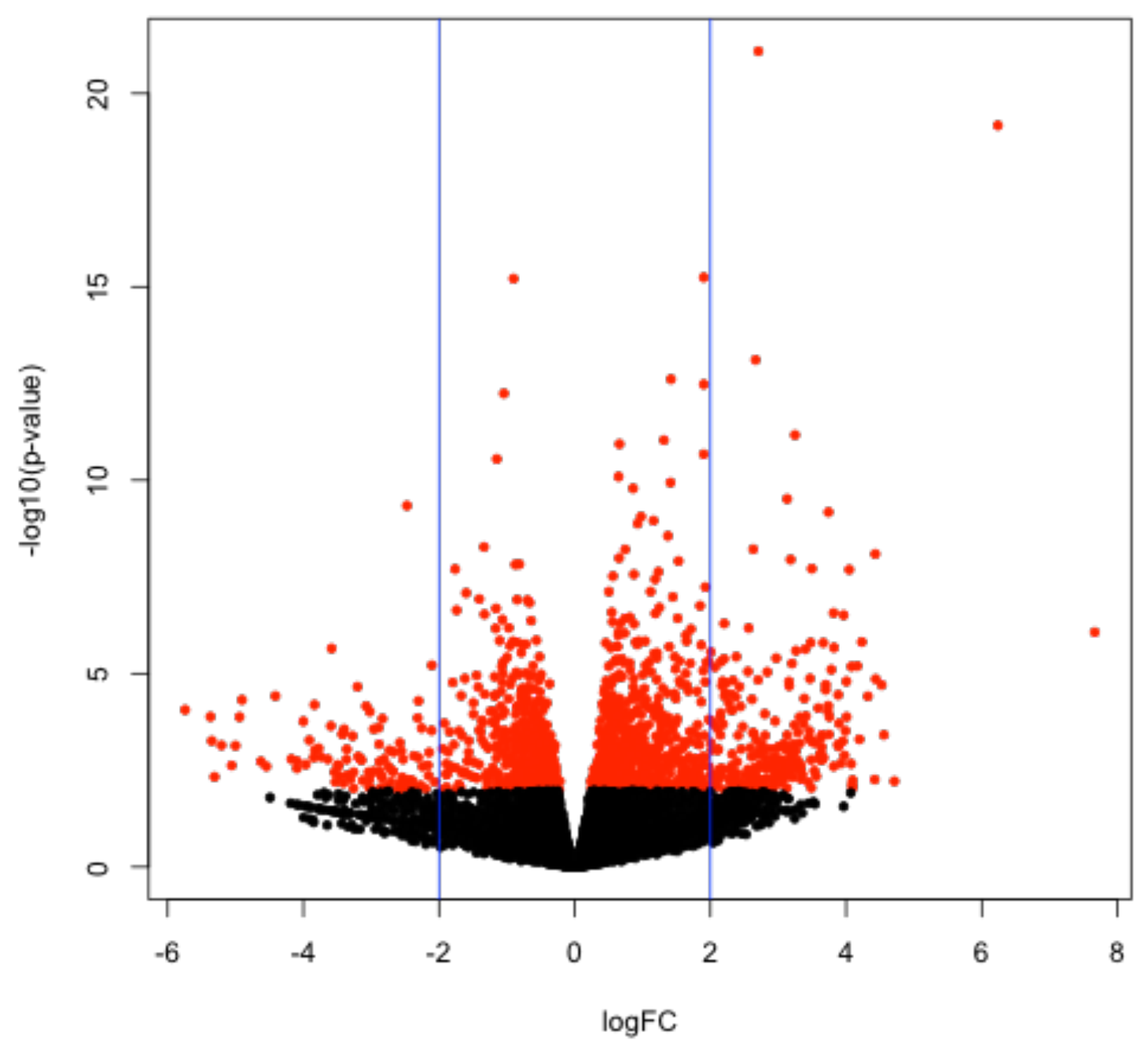

Figure 3.5. Volcano plot depicting differences in transcript abundance between small follicle cumulus cell pools and spontaneous follicle cumulus cell pools when mapped to the genome. $\mathrm{X}$-axis denotes the $\log 2$ of the ratio between the normalized edgeR Robust read count values for small and spontaneous follicle cumulus cell pools $(-5=32$ fold higher in small follicle oocyte pools; $0=$ equal transcript abundance between follicle classifications; $5=32$ fold lower in small follicle cumulus cell pools). Y-axis denotes log-10(FDR P-Value) where 1.3 equals FDR=0.05 and 1 equals FDR=0.10. Each dot represents one transcript. Red dots denote transcripts significantly different between small and spontaneous follicle cumulus cell pools at a FDR of $<0.10$. Vertical blue lines mark a $\log$ FC greater than 2 . 
Table 3.6. Top fifteen transcripts (by FDR) more abundant in small follicle cumulus cell pools compared to spontaneous follicle cumulus cell pools $^{\mathrm{a}}$

\begin{tabular}{|l|l|l|r|r|}
\hline \multicolumn{1}{|c|}{ Ensembl ID } & \multicolumn{1}{c|}{ Function or Protein } & \multicolumn{1}{c|}{$\begin{array}{l}\text { Log } \\
\text { FC }^{\mathbf{b}}\end{array}$} & \multicolumn{1}{c|}{ FDR $^{\mathbf{c}}$} \\
\hline ENSBTAG00000021048 & ADM & adrenomedullin & -0.895 & $2.48 \mathrm{E}-12$ \\
\hline ENSBTAG00000005408 & CLK1 & CDC like kinase 1 & -1.042 & $1.77 \mathrm{E}-09$ \\
\hline ENSBTAG00000044022 & KIAA1671 & KIAA1671 & -1.144 & $2.55 \mathrm{E}-08$ \\
\hline ENSBTAG00000012215 & CPNE7 & copine 7 & -2.468 & $3.29 \mathrm{E}-07$ \\
\hline ENSBTAG00000016319 & CYB5D2 & cytochrome b5 domain containing 2 & -1.332 & $5.23 \mathrm{E}-06$ \\
\hline ENSBTAG00000015124 & ARGLU1 & arginine and glutamate rich 1 & -0.812 & $5.23 \mathrm{E}-06$ \\
\hline ENSBTAG00000009305 & ANKRD27 & ankyrin repeat domain 27 & -0.871 & $6.82 \mathrm{E}-06$ \\
\hline ENSBTAG00000018799 & GPSM1 & G-protein signaling modulator 1 & -1.758 & $7.74 \mathrm{E}-06$ \\
\hline ENSBTAG00000021071 & TRIM8 & tripartite motif containing 8 & -1.596 & $2.69 \mathrm{E}-05$ \\
\hline ENSBTAG00000009844 & CYR61 & cysteine rich angiogenic inducer 61 & -0.691 & $4.61 \mathrm{E}-05$ \\
\hline ENSBTAG00000009427 & PPM1D & protein phosphatase, Mg2+/Mn2+ dependent 1D & -1.407 & $4.74 \mathrm{E}-05$ \\
\hline ENSBTAG00000015222 & RSRP1 & arginine and serine rich protein 1 & -0.839 & $5.63 \mathrm{E}-05$ \\
\hline ENSBTAG00000047766 & G0S2 & G0/G1 switch 2 & -0.656 & $5.83 \mathrm{E}-05$ \\
\hline ENSBTAG00000013260 & & Spindlin-2 & -1.733 & $5.96 \mathrm{E}-05$ \\
\hline ENSBTAG00000016128 & GGA3 & ADP-ribosylation factor-binding protein GGA3 & -1.155 & $7.10 \mathrm{E}-05$ \\
\hline
\end{tabular}

${ }^{a}$ Data represent transcripts aligned to the Bos taurus genome (UMD3.1) and found to be differentially abundant by the edgeR Robust GLM test (FDR <0.10). Transcripts are ranked by FDR. Only protein coding transcripts from annotated regions of the genome are included.

${ }^{\mathrm{b}} \log 2$ of the ratio between the normalized edgeR read count values for small or spontaneous follicle cumulus cell pools $(-5=32$ fold higher in spontaneous follicle cumulus cell pools; $0=$ equal transcript abundance between follicle classifications; $5=32$ fold higher in small follicle cumulus cell pools.)

${ }^{c}$ FDR P-Value (adjusted for multiple comparisons) for the difference in transcript abundance between cumulus cell pools derived from small and spontaneous follicle classifications. 
Table 3.7. Top fifteen transcripts (by FDR) more abundant in spontaneous follicle cumulus cell pools compared to small follicle cumulus cell pools ${ }^{\mathrm{a}}$

\begin{tabular}{|c|c|c|c|c|}
\hline Ensembl ID & Gene ID & Function or Protein & $\begin{array}{l}\text { Log } \\
\text { FC }^{b}\end{array}$ & $\mathbf{F D R}^{\mathrm{c}}$ \\
\hline ENSBTAG00000014402 & GIMAP8 & GTPase, IMAP family member 8 & 2.711 & $1.63 \mathrm{E}-17$ \\
\hline ENSBTAG00000046332 & ACTA1 & actin, alpha 1 , skeletal muscle & 6.240 & $2.65 \mathrm{E}-16$ \\
\hline ENSBTAG00000014912 & FMOD & fibromodulin & 1.904 & $2.53 \mathrm{E}-12$ \\
\hline ENSBTAG00000006031 & ADGRV1 & adhesion $\mathrm{G}$ protein-coupled receptor V1 & 1.429 & $3.86 \mathrm{E}-10$ \\
\hline ENSBTAG00000017863 & SRGN & serglycin precursor & 1.912 & $3.86 \mathrm{E}-10$ \\
\hline ENSBTAG00000010591 & ZNF365 & zinc finger protein 365 & 3.252 & 7.71E-09 \\
\hline ENSBTAG00000014370 & NETO2 & neuropilin and tolloid like 2 & 1.323 & $1.84 \mathrm{E}-08$ \\
\hline ENSBTAG00000001246 & ATP1A1 & sodium/potassium-transporting ATPase subunit alpha-1 & 0.666 & $2.25 \mathrm{E}-08$ \\
\hline ENSBTAG00000015441 & ACTG2 & actin, gamma 2 , smooth muscle, enteric & 1.908 & $2.69 \mathrm{E}-08$ \\
\hline ENSBTAG00000010529 & FZD6 & frizzled class receptor 6 & 1.423 & $8.13 \mathrm{E}-08$ \\
\hline ENSBTAG00000018207 & M6PR & mannose-6-phosphate receptor, cation dependent & 0.652 & $1.99 \mathrm{E}-07$ \\
\hline ENSBTAG00000003045 & BAMBI & BMP and activin membrane bound inhibitor & 3.137 & $3.03 \mathrm{E}-07$ \\
\hline ENSBTAG00000027991 & ANAPC1 & anaphase promoting complex subunit 1 & 0.869 & $3.30 \mathrm{E}-07$ \\
\hline ENSBTAG00000011116 & PAQR9 & progestin and adipoQ receptor family member 9 & 3.746 & $3.80 \mathrm{E}-07$ \\
\hline ENSBTAG00000010564 & ELOVL6 & ELOVL fatty acid elongase 6 & 1.168 & $5.60 \mathrm{E}-07$ \\
\hline
\end{tabular}

${ }^{a}$ Data represent transcripts aligned to the Bos taurus genome (UMD3.1) found to be differentially abundant by the edgeR Robust GLM test (FDR <0.10). Transcripts are ranked by FDR. Only protein coding transcripts from annotated regions of the genome are included.

${ }^{b} \log 2$ of the ratio between the normalized edgeR read count values for small or spontaneous follicle cumulus cell pools $(-5=32$ fold higher in spontaneous follicle cumulus cell pools; $0=$ equal transcript abundance between follicle classifications; $5=32$ fold higher in small follicle cumulus cell pools.)

${ }^{c}$ FDR P-Value (adjusted for multiple comparisons) for the difference in transcript abundance between cumulus cell pools derived from small and spontaneous follicle classifications. 


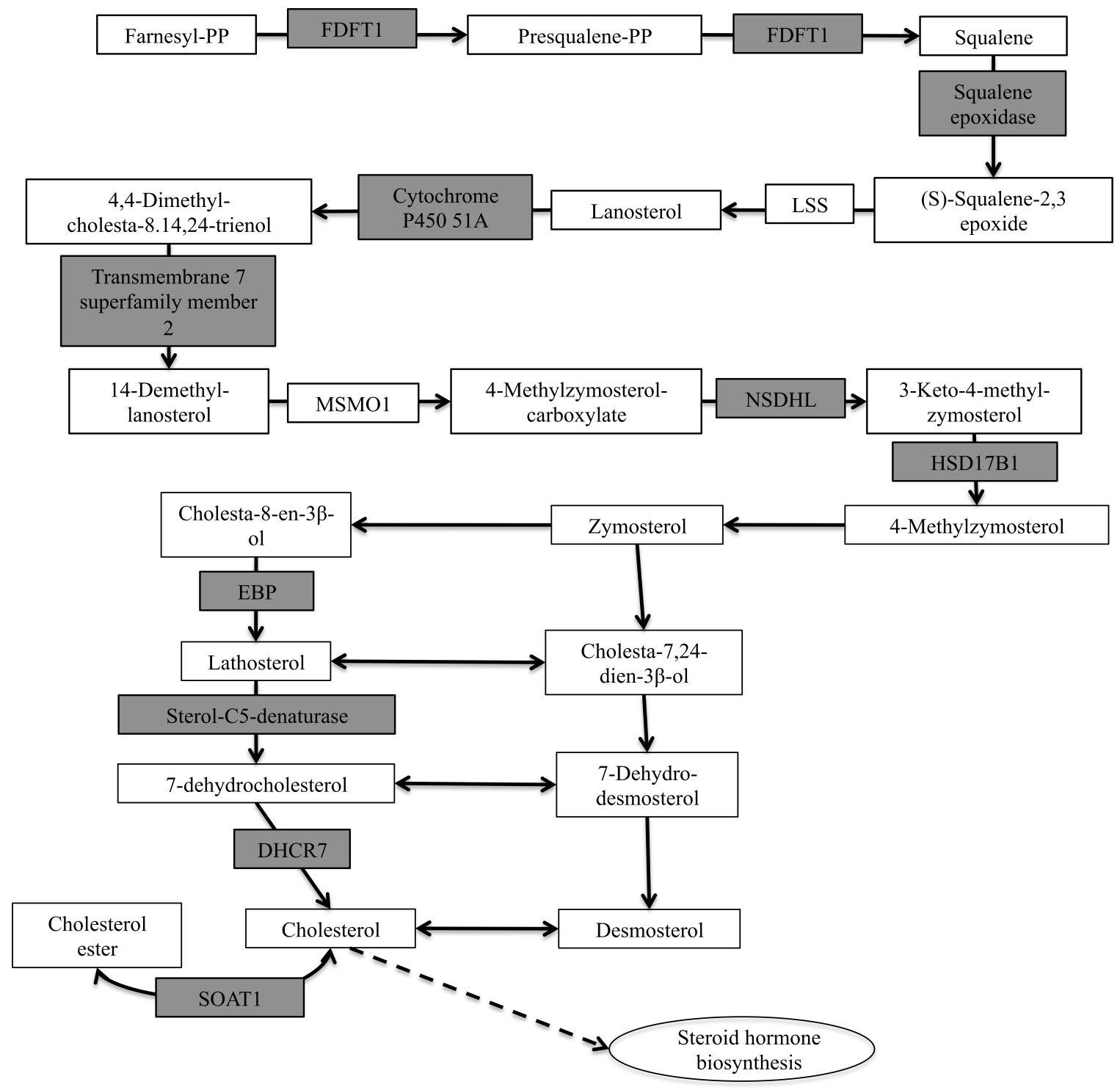

Figure 3.6 Diagram of the steroid biosynthesis pathway. Members of the pathway with transcripts present in spontaneous cumulus cell pools are shaded grey. FDFT1=farnesyldiphosphate farnesyltransferase 1; LSS=lanosterol synthase (2,3-oxidosqualenelanosterol cyclase); MSMO1=methylsterol monooxygenase $1 ; \mathrm{NSDHL}=\mathrm{NAD}(\mathrm{P})$ dependent steroid dehydrogenase-like; HSD17B1=hydroxysteroid 17-beta dehydrogenase; $\mathrm{EBP}=$ emopamil binding protein (sterol isomerase); DHCR7=7dehydrocholesterol reductase; SOAT1=sterol O-acyltransferase 1. 
Table 3.8. Significant KEGG pathways enriched in small or spontaneous cumulus cell pools

\begin{tabular}{|l|r|r|}
\hline \multicolumn{1}{|c|}{ KEGG Pathway } & $\begin{array}{c}\text { Number of Genes } \\
\text { Present in Pathway }\end{array}$ & P-Value \\
\hline \multicolumn{2}{|c|}{ Pathways encriched in small compared to spontaneous follicle cumulus cell pools } \\
\hline Oxidative phosphorylation & 13 & $2.6 \mathrm{E}-4$ \\
\hline Parkinson's disease & 13 & $5.4 \mathrm{E}-4$ \\
\hline Mineral absorption & 6 & $7.6 \mathrm{E}-3$ \\
\hline \multicolumn{1}{|c|}{ Pathways enriched in spontaneous compared to small follicle cumulus cell pools } \\
\hline Biosynthesis of antibiotics & 34 & $6.4 \mathrm{E}-9$ \\
\hline Steroid biosynthesis & 10 & $2.8 \mathrm{E}-7$ \\
\hline Metabolic pathways & 96 & $5.7 \mathrm{E}-5$ \\
\hline Phagosome & 20 & $7.3 \mathrm{E}-4$ \\
\hline PI3K-Akt signaling pathway & 32 & $2.4 \mathrm{E}-3$ \\
\hline Arrhythmogenic right ventricular cardiomyopathy & 11 & $3.0 \mathrm{E}-3$ \\
\hline Glycolysis/Gluconeogenesis & 10 & $5.3 \mathrm{E}-3$ \\
\hline Protein processing in endoplasmic reticulum & 18 & $7.3 \mathrm{E}-3$ \\
\hline Hypertrophic cardiomyopathy & 11 & $8.7 \mathrm{E}-3$ \\
\hline Carbon metabolism & 13 & $1.2 \mathrm{E}-2$ \\
\hline Fatty acid metabolism & 8 & $1.2 \mathrm{E}-2$ \\
\hline Focal adhesion & 20 & $1.3 \mathrm{E}-2$ \\
\hline Dilated cardiomyopathy & 11 & $1.4 \mathrm{E}-2$ \\
\hline Central carbon metabolism in cancer & 9 & $1.5 \mathrm{E}-2$ \\
\hline ECM-receptor interaction & 11 & $1.5 \mathrm{E}-2$ \\
\hline cAMP signaling pathway & 19 & $1.6 \mathrm{E}-2$ \\
\hline Fructose and mannose metabolism & 6 & $2.1 \mathrm{E}-2$ \\
\hline Bile secretion & 9 & $2.5 \mathrm{E}-2$ \\
\hline Pathways in cancer & 31 & $3.0 \mathrm{E}-2$ \\
\hline Insulin resistance & 12 & $3.1 \mathrm{E}-2$ \\
\hline Lysosome & 13 & $3.2 \mathrm{E}-2$ \\
\hline Biosynthesis of unsaturated fatty acids & 5 & $3.5 \mathrm{E}-2$ \\
\hline Glyoxylate and dicarboxylate metabolism & 5 & $4.5 \mathrm{E}-2$ \\
\hline Ovarian steroidogenesis & 7 & $4.5 \mathrm{E}-2$ \\
\hline Osteoclast differentiation & 13 & $4.8 \mathrm{E}-2$ \\
\hline
\end{tabular}




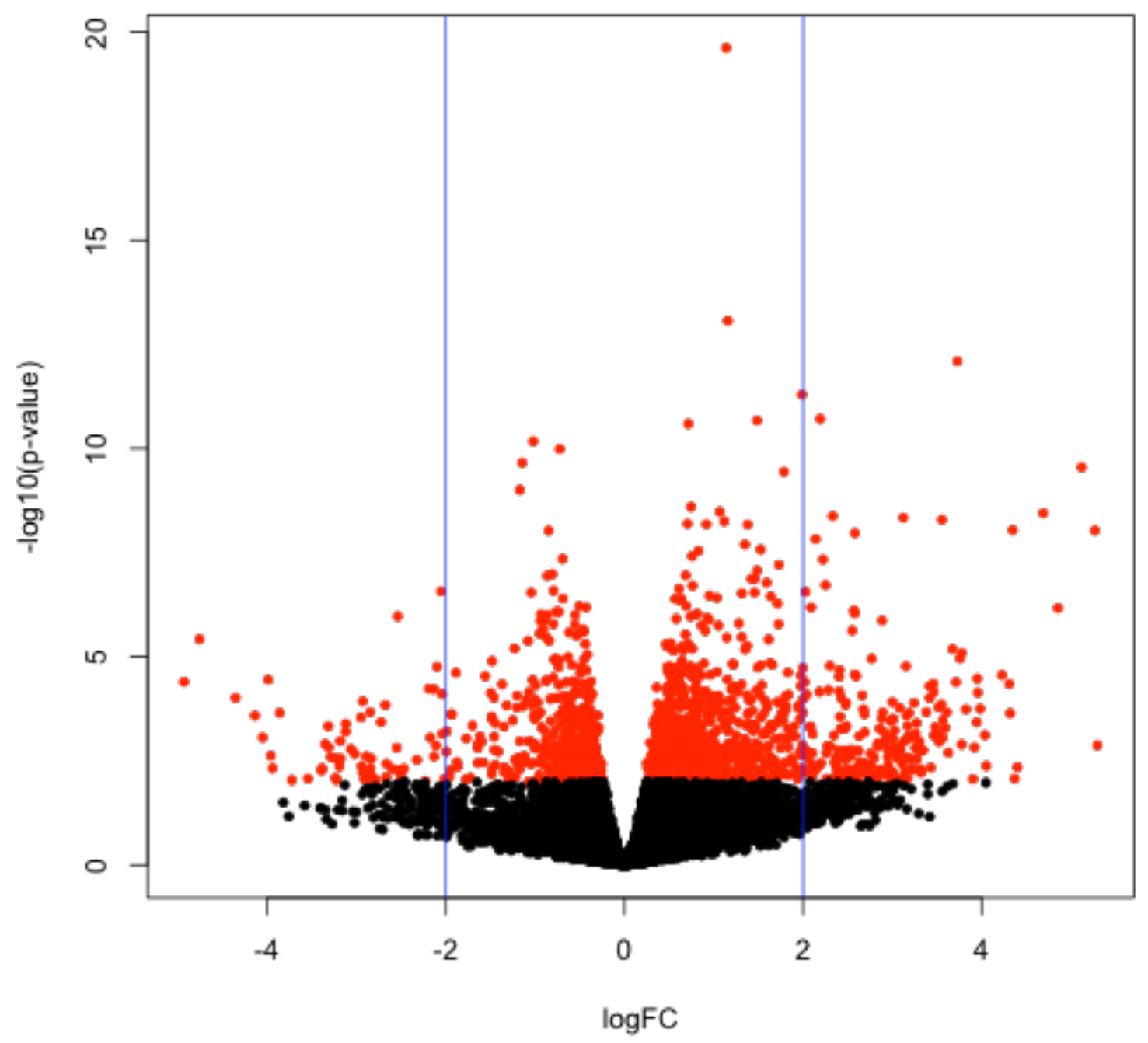

Figure 3.7. Volcano plot depicting differences in transcript abundance between large follicle cumulus cell pools and spontaneous follicle cumulus cell pools when mapped to the Bos taurus genome (UMD3.1). X-axis denotes the $\log 2$ of the ratio between the normalized edgeR Robust read count values for large and spontaneous follicle cumulus cell pools $(-5=32$ fold higher in large follicle oocyte pools; $0=$ equal transcript abundance between follicle classifications; $5=32$ fold lower in large follicle cumulus cell pools). Yaxis denotes $-\log 10$ (FDR P-Value) where 1.3 equals $\mathrm{FDR}=0.05$ and 1 equals $\mathrm{FDR}=0.10$. Each dot represents one transcript. Red dots denote transcripts significantly different between large and spontaneous follicle cumulus cell pools at FDR $<0.10$. Vertical blue lines mark a $\log \mathrm{FC}$ greater than 2 . 
Table 3.9. Top fifteen transcripts (by FDR) more abundant in large follicle cumulus cell pools compared to spontaneous follicle cumulus cell pools ${ }^{\mathrm{a}}$

\begin{tabular}{|l|l|l|c|c|}
\hline \multicolumn{1}{|c|}{ Ensembl ID } & \multicolumn{1}{|c|}{ Function or Protein } & \multicolumn{1}{c|}{$\begin{array}{c}\text { Log } \\
\text { FC }^{\mathbf{b}}\end{array}$} & \multicolumn{1}{c|}{ FDR $^{\mathbf{c}}$} \\
\hline ENSBTAG00000017626 & GFPT1 & glutamine--fructose-6-phosphate transaminase 1 & -0.724 & $1.18 \mathrm{E}-07$ \\
\hline ENSBTAG00000021048 & ADM & adrenomedullin & -1.012 & $1.33 \mathrm{E}-07$ \\
\hline ENSBTAG00000008026 & OXT & oxytocin/neurophysin I prepropeptide & -1.139 & $2.71 \mathrm{E}-07$ \\
\hline ENSBTAG00000005950 & GPR50 & G protein-coupled receptor & -1.165 & $1.86 \mathrm{E}-06$ \\
\hline ENSBTAG00000015086 & HSD11B1 & hydroxysteroid 11-beta dehydrogenase 1 & -0.843 & $7.76 \mathrm{E}-06$ \\
\hline ENSBTAG00000021469 & CTTNBP2 & cortactin binding protein 2 & -0.856 & $4.39 \mathrm{E}-05$ \\
\hline ENSBTAG00000022886 & RYR2 & ryanodine receptor 2 & -0.689 & $4.39 \mathrm{E}-05$ \\
\hline ENSBTAG00000007375 & MIF & Macrophage migration inhibitory factor & -0.799 & $4.99 \mathrm{E}-05$ \\
\hline ENSBTAG00000038333 & RBM23 & RNA binding motif protein 23 & -0.789 & $7.12 \mathrm{E}-05$ \\
\hline ENSBTAG00000015974 & FLVCR1 & feline leukemia virus subgroup C cellular receptor 1 & -1.043 & $8.68 \mathrm{E}-05$ \\
\hline ENSBTAG00000004258 & EEF2 & eukaryotic translation elongation factor 2 & -0.424 & $8.82 \mathrm{E}-05$ \\
\hline ENSBTAG00000000873 & SLC13A3 & solute carrier family 13 member 3 & -2.048 & $9.30 \mathrm{E}-05$ \\
\hline ENSBTAG00000025450 & SYNE2 & nesprin-2 & -0.736 & $9.68 \mathrm{E}-05$ \\
\hline ENSBTAG00000046841 & IRF2BP2 & interferon regulatory factor 2 binding protein 2 & -0.683 & $1.43 \mathrm{E}-04$ \\
\hline ENSBTAG00000001652 & SLCO3A1 & solute carrier organic anion transporter family member 3A1 & -0.929 & $2.30 \mathrm{E}-04$ \\
\hline
\end{tabular}

${ }^{a}$ Data represent transcripts aligned to the Bos taurus genome (UMD3.1)and found to be differentially abundant by the edgeR Robust GLM test (FDR <0.10). Transcripts are ranked by FDR. Only protein coding transcripts from annotated regions of the genome are included.

${ }^{b} \log 2$ of the ratio between the normalized edgeR read count values for small or spontaneous follicle cumulus cell pools $(-5=32$ fold higher in small follicle cumulus cell pools; $0=$ equal transcript abundance between follicle classifications; $5=32$ fold higher in spontaneous follicle cumulus cell pools.)

${ }^{\mathrm{c}}$ FDR P-Value (adjusted for multiple comparisons) for the difference in transcript abundance between cumulus cell pools derived from small and spontaneous follicle classifications. 
Table 3.10. Top fifteen transcripts (by FDR) more abundant in spontaneous follicle cumulus cell pools compared to large follicle cumulus cell pools ${ }^{\mathrm{a}}$

\begin{tabular}{|l|l|l|r|r|}
\multicolumn{1}{|c|}{ Ensembl ID } & \multicolumn{1}{|c|}{ Gene ID } & \multicolumn{1}{c|}{ Function or Protein } & Log FC $^{\mathbf{b}}$ & \multicolumn{1}{c|}{ FDR $^{\mathbf{c}}$} \\
\hline ENSBTAG00000002317 & PTN & pleiotrophin & 1.142 & $1.64 \mathrm{E}-15$ \\
\hline ENSBTAG00000016026 & PCOLCE2 & procollagen C-endopeptidase enhancer 2 & 1.164 & $8.36 \mathrm{E}-10$ \\
\hline ENSBTAG00000046332 & ACTA1 & actin, alpha 1, skeletal muscle & 3.731 & $2.31 \mathrm{E}-09$ \\
\hline ENSBTAG00000007651 & TARSL2 & threonyl-tRNA synthetase like 2 & 1.994 & $1.76 \mathrm{E}-08$ \\
\hline ENSBTAG00000031998 & CXCL16 & C-X-C motif chemokine ligand 16 & 2.201 & $5.02 \mathrm{E}-08$ \\
\hline ENSBTAG00000020202 & CRHBP & corticotropin releasing hormone binding protein & 1.491 & $8.77 \mathrm{E}-08$ \\
\hline ENSBTAG00000004059 & SOAT1 & sterol O-acyltransferase 1 & 0.718 & $2.71 \mathrm{E}-07$ \\
\hline ENSBTAG00000010273 & EREG & epiregulin & 5.124 & $4.30 \mathrm{E}-07$ \\
\hline ENSBTAG00000000736 & LRP8 & LDL receptor related protein 8 & 1.788 & $4.30 \mathrm{E}-07$ \\
\hline ENSBTAG00000021103 & SLC35F5 & solute carrier family 35 member F5 & 0.751 & $1.57 \mathrm{E}-06$ \\
\hline ENSBTAG00000034827 & PDGFD & platelet derived growth factor D & 2.338 & $2.43 \mathrm{E}-06$ \\
\hline ENSBTAG00000011116 & PAQR9 & progestin and adipoQ receptor family member 9 & 3.128 & $2.89 \mathrm{E}-06$ \\
\hline ENSBTAG00000019368 & IGFBP7 & insulin like growth factor binding protein 7 & 1.076 & $2.89 \mathrm{E}-06$ \\
\hline ENSBTAG00000006797 & MARCH3-201 & membrane associated ring-CH-type finger 3 & 3.567 & $2.89 \mathrm{E}-06$ \\
\hline ENSBTAG00000005915 & SFMBT2 & Scm-like with four mbt domains 2 & 4.696 & $3.31 \mathrm{E}-06$ \\
\hline
\end{tabular}

${ }^{a}$ Data represent transcripts aligned the Bos taurus genome (UMD3.1) and found to be differentially abundant by the edgeR Robust GLM test (FDR <0.10). Transcripts are ranked by FDR. Only protein coding transcripts from annotated regions of the genome are included.

${ }^{b} \log 2$ of the ratio between the normalized edgeR read count values for small or spontaneous follicle cumulus cell pools $(-5=32$ fold higher in small follicle cumulus cell pools; $0=$ equal transcript abundance between follicle classifications; $5=32$ fold higher in spontaneous follicle cumulus cell pools.)

${ }^{\mathrm{c}}$ FDR P-Value (adjusted for multiple comparisons) for the difference in transcript abundance between cumulus cell pools derived from small and spontaneous follicle classifications. 
abundant transcripts were analyzed using DAVID and significant KEGG pathways are listed in Table 3.11. Transcripts more abundant in cumulus cells from spontaneous follicles include many members of the lysosome KEGG pathway, including cathepsins A, $\mathrm{B}, \mathrm{F}, \mathrm{K}$, and $\mathrm{Z}$.

\subsection{Discussion}

Decreased pregnancy rates and increased late embryonic/fetal mortality were observed after GnRH-induced ovulation of small dominant follicles in postpartum beef cows (Perry et al., 2005). Further investigation determined that lowered pregnancy rates were caused by both an inadequate maternal environment and decreased oocyte competence (Atkins et al., 2013). Cows induced to ovulate small $(<12.5 \mathrm{~mm})$ dominant follicles had decreased fertilization rates and lower embryo quality compared to cows induced to ovulate large $(>12.5 \mathrm{~mm})$ dominant follicles, supporting the hypothesis that decreased oocyte competence is at least a partial cause of decreased pregnancy rates following GnRH-induced ovulation of small dominant follicles (Atkins et al., 2013). However, the potential role of the maternal environment could not be eliminated since embryo collection occurred on d 7 after induced ovulation.

Bidirectional communication between the oocyte and the surrounding cumulus cells is essential for the acquisition of oocyte competence (Eppig, 2001). Rapid accumulation and storage of mRNA occurs in the oocyte during the preantral stage and low levels of transcription continue until GVB (Fair et al., 1995). The surrounding cumulus cells also contribute to the maternal reserve through transportation of RNAs to the oocyte through the TZPs (Macaulay et al., 2014; Macaulay et al., 2016). The early 
Table 3.11. Significant KEGG Pathways enriched in large or spontaneous cumulus cell pools

\begin{tabular}{|l|l|l|}
\hline \multicolumn{1}{|c|}{ KEGG Pathway } & \multicolumn{1}{c|}{$\begin{array}{c}\text { Pumber of Genes } \\
\text { Present in Pathway }\end{array}$} & P-Value \\
\hline \multicolumn{2}{|c|}{ Pathways enriched in large compared to spontaneous follicle cumulus cell pools } \\
\hline Oxidative phosphorylation & 11 & $2.4 \mathrm{E}-3$ \\
\hline Small cell lung cancer & 8 & $6.0 \mathrm{E}-3$ \\
\hline Parkinson's disease & 10 & $1.3 \mathrm{E}-2$ \\
\hline Focal adhesion & 12 & $1.4 \mathrm{E}-2$ \\
\hline Adherens junction & 6 & $2.6 \mathrm{E}-2$ \\
\hline AMPK signaling pathway & 8 & $2.9 \mathrm{E}-2$ \\
\hline p53 signaling pathway & 6 & $3.1 \mathrm{E}-2$ \\
\hline Pathways in cancer & 17 & $3.9 \mathrm{E}-2$ \\
\hline \multicolumn{1}{|c|}{ Pathways enriched in spontaneous compared to large follicle cumulus cell pools } \\
\hline Lysosome & 21 & $4.0 \mathrm{E}-6$ \\
\hline Fatty acid metabolism & 11 & $1.1 \mathrm{E}-4$ \\
\hline Biosynthesis of unsaturated fatty acids & 7 & $9.6 \mathrm{E}-4$ \\
\hline Biosynthesis of antibiotics & 22 & $1.5 \mathrm{E}-3$ \\
\hline Small cell lung cancer & 12 & $4.4 \mathrm{E}-3$ \\
\hline Metabolic pathways & 83 & $4.7 \mathrm{E}-3$ \\
\hline Mineral absorption & 8 & $9.5 \mathrm{E}-3$ \\
\hline Phagosome & 16 & $1.5 \mathrm{E}-2$ \\
\hline NF-kappa B signaling pathway & 11 & $1.5 \mathrm{E}-2$ \\
\hline Glutathione metabolism & 8 & $1.8 \mathrm{E}-2$ \\
\hline Carbon metabolism & 12 & $2.1 \mathrm{E}-2$ \\
\hline PPAR signaling pathway & 9 & $2.3 \mathrm{E}-2$ \\
\hline Peroxisome & 10 & $2.4 \mathrm{E}-2$ \\
\hline p53 signaling pathway & 9 & $2.5 \mathrm{E}-2$ \\
\hline Biosynthesis of amino acids & 9 & $3.1 \mathrm{E}-2$ \\
\hline Primary immunodeficiency & 6 & $3.3 \mathrm{E}-2$ \\
\hline Toll-like receptor signaling pathway & 11 & $3.8 \mathrm{E}-2$ \\
\hline Fatty acid elongatin & 5 & $3.9 \mathrm{E}-2$ \\
\hline Toxoplasmosis & 12 & $4.0 \mathrm{E}-2$ \\
\hline Hematopoietic cell lineage & 10 & $4.1 \mathrm{E}-2$ \\
\hline Glycosphingolipid biosynthesis-ganglio series & 4 & $4.3 \mathrm{E}-2$ \\
\hline NOD-like receptor signaling pathway & 7 & $4.5 \mathrm{E}-2$ \\
\hline Colorectal cancer & 8 & $4.7 \mathrm{E}-2$ \\
\hline
\end{tabular}


embryo must rely on maternally stored mRNA until the maternal zygotic transition occurs (Sirard et al., 2006). Consequently, GnRH-induced ovulation of oocytes containing an inadequate transcriptome may compromise oocyte competence and subsequent establishment of pregnancy.

Several studies have identified cumulus cell markers of oocyte competence (i.e. EREG, ATP6V1C1, AKAP7, and THBS1), which were upregulated in cumulus cells associated with more competent bovine oocytes (Bettegowda et al., 2008; Assidi et al., 2010; Kussano et al., 2016). Cumulus cell markers are listed in Table A.2 in the appendix. In the current study EREG, ATP6V1C1, AKAP7, and THBS1 (Assidi et al., 2010) were more abundant in the cumulus cells of spontaneous follicles compared to both small and large follicles. In addition, GPC4 (Kussano et al., 2015) was more abundant in cumulus cells of spontaneous compared to large follicles and HAS2 and INHBA (Assidi et al., 2010) were more abundant in spontaneous compared to small follicles. No previously published markers of oocyte competence were more abundant in the small versus large follicle comparison. This supports the hypothesis that oocytes from the spontaneous follicle classification had greater competence.

Previous studies also found that oocytes associated with cumulus cells that had increased expression of cathepsins B, S, K, and Z had decreased oocyte competence (Bettegowda et al., 2008; Pohler, 2011). However, in our study, there was increased abundance of cathepsins $\mathrm{B}, \mathrm{K}$, and $\mathrm{Z}$ in spontaneous compared to large follicles and increased abundance of cathepsin $\mathrm{K}$ in spontaneous compared to small follicles. Reasons for increased cathepsin abundance in follicles with more competent oocytes (spontaneous follicles) are currently unknown. 
Instead of examining specific bovine cumulus cell markers in the present study, we took a more comprehensive approach (RNAseq) to identify additional potential pathways that might affect the acquisition of oocyte competence in dominant bovine follicles. The current study compared the transcriptomes of cumulus cells harvested from small $(<11.7 \mathrm{~mm})$ and large $(>12.5 \mathrm{~mm})$ dominant follicles in cows that did not express estrus and received an injection of GnRH. Follicles from cows that expressed estrus and did not receive an injection of GnRH were classified as spontaneous and served as a control group, as there is no negative effect of a small dominant follicle size on pregnancy establishment when a cow spontaneously expresses estrus and ovulates (Perry et al., 2005). The preovulatory gonadotropin surge occurs within 90 minutes after GnRH injection (Atkins et al., 2008) and before or at the onset of estrus in cows that spontaneously express estrus (Swanson and Hafs, 1971). Because of this, it should be noted that the exact time of the preovulatory gonadotropin surge is not known in the spontaneous classification and the interval from the gonadotropin surge to oocyte aspiration in this classification may be different from the interval from the small and large follicle classifications. This could be a factor when comparing the transcriptome of cumulus cells in the spontaneous follicle group to the other treatment groups.

\section{Glycolytic pathway}

Cumulus cells and oocytes have differing metabolic requirements (Thompson et al., 2007). Cumulus cells have a high capacity to metabolize glucose, characterized by a high activity of glycolytic enzymes such as the rate-limiting enzyme phosphofructokinase (PFK) and express an additional glucose transporter compared to oocytes (Downs et al., 1996). Conversely, oocytes are deficient in their ability to carry out glycolysis, and so 
rely on the surrounding cumulus cells to convert glucose to pyruvate, which is then metabolized through the TCA cycle followed by oxidative phosphorylation to produce ATP within the oocyte (reviewed by Thompson et al, 2007; Sutton-McDowell et al. 2010).

In the current study, the glycolytic pathway was enriched in the cumulus cells of large compared to small follicles. In addition, several members of the glycolytic pathway were more abundant in the cumulus cells of spontaneous compared to small follicles. This may indicate that a higher level of glycolysis is occurring in these follicles, thereby producing more ATP and a more developmentally competent oocyte.

As oocytes mature, the ATP content increases and is reported to be a marker of oocyte competence in cattle (Bavister and Squirrell 2000). In vitro maturation of bovine oocytes in media supplemented with pyruvate had higher blastocyst development rates. When physiological levels of glucose and pyruvate were used, oocytes with increased levels of glycolytic activity had greater blastocyst development rates, reflecting that oocytes with increased glycolysis have increased competence (Krishner and Bavister, 1999).

In addition to energy production and nuclear maturation, pyruvate, provided by the cumulus cells, is essential for oocyte cytoplasmic maturation. Cumulus denuded oocytes supplemented with glucose and lactate had low levels of nuclear maturation, but could not complete cytoplasmic maturation without the presence of pyruvate (Xie et al., 2016). Because pyruvate is so essential for oocyte maturation, oocytes can control and promote the rate of glycolysis in cumulus cells through the secretion of BMP15 and fibroblast growth factor 8 (FGF8). BMP15 knockout mice had reduced levels of 
glycolysis and decreased expression of PFK in the cumulus cells. Treatment with BMP15 and FGF8 in these knockout mice raised glycolysis levels to that of wildtype mice (Sugiura et al., 2007). Both BMP15 and FGF8 were present but not differentially abundant in the current study.

Transcriptome analysis of the oocytes corresponding to the cumulus cells used in this study were previously reported by Dickinson (2016). Two transcripts associated with mitochondrial function and oxidative phosphorylation were found to be more abundant in oocytes from large follicles compared to small follicles and two additional transcripts associated with mitochondrial function had higher abundance in oocytes from spontaneous compared to large and small follicles. These results may indicate a higher level of mitochondrial function in oocytes from cows with larger follicles or cows that had an endogenous gonadotropin surge. An increased number of mitochondria has been associated with oocyte competence, as a greater amount of ATP is synthesized and available to the developing oocyte. Therefore, these results might indicate that oocytes from large or spontaneous follicles are more competent because they have more ATP. However, the previous study used a different data pipeline and different software to map reads to the genome, so results may not be directly comparable to the current study.

\section{Steroid Biosynthesis Pathway}

The steroid biosynthesis pathway (i.e. synthesis of cholesterol from acetate) was enriched in cumulus cells of spontaneous compared to small follicles. Similar to the dependence of oocytes on cumulus cells to provide pyruvate for energy metabolism, oocytes also depend on cumulus cells to provide cholesterol for lipid metabolism and oocyte development (Prates et al., 2014). The oocyte can increase the activity of 
enzymes necessary for cholesterol biosynthesis in this pathway via the oocyte secreted paracrine factors BMP15 and GDF9. In both BMP15 and GDF9 knockout mice, transcripts encoding enzymes in the steroid biosynthesis pathway were downregulated in the cumulus cells resulting in a reduction in cholesterol synthesis from acetate, and providing evidence that oocytes stimulate production to make up for their cholesterol deficiency (Su et al., 2008).

Cholesterol may have a direct and(or) indirect role in acquisition of oocyte competence. In regards to a direct role, cholesterol synthesis by cumulus cells could play a role in the oocyte cell membrane function. Enrichment of phospholipids and cholesterol is crucial for formation of membranes during rapid cell division after fertilization in both pigs and cattle (Prates et al., 2014.) The preceding lipids may increase oocyte maturation through formation of lipid rafts, which are made of cholesterol and other lipids and contain signaling proteins important for gamete fusion and subcellular localization (Prates et al., 2014). In mice, removal of cholesterol from the oocyte caused disruption of lipid rafts, which resulted in a delay in the extrusion of the second polar body and decreased fertilization and similar effects are expected in other mammals (Buschiazzo et al., 2013).

Alternatively, cholesterol can enter the steroid hormone biosynthesis pathway to synthesize progestins, androgens, and estrogens. LH and (or) FSH can cause an increase in progesterone production by the cumulus cells (Armstrong et al., 1996) and the cumulus cells analyzed in this project were collected from follicles that had undergone either an endogenous or GnRH-induced preovulatory gonadotropin surge. At the present time, it is not known whether there was an effect of treatment on progesterone secretion by the 
cumulus cells. Interestingly, progesterone, secreted by human cumulus cells of the COC, has been identified as a chemoattractant for human spermatozoa (Oren-Benaroya et al., 2008). However, whether or not this is the case in cattle is not clear. Progesterone also helps stimulate resumption of meiosis through binding to its receptor in the cumulus cells and possibly mediating the close of gap junctional communication (Sirotkin, 1992; Shimada and Terada, 2002).

In summary, analysis of the cumulus cell transcriptome from follicles that differ in size or physiological status revealed a list of differentially abundant transcripts associated with the glycolytic and steroid biosynthesis pathways and these pathways may have important roles in the acquisition of oocyte competence. 


\section{CHAPTER IV}

\section{EFFECT OF FOLLICLE SIZE AND PREOVULATORY ESTRADIOL ON FOLLICLE WALL TRANSCRIPT ABUNDANCE IN BEEF}

\section{CATTLE}

\subsection{Abstract}

GnRH-induced ovulation of small dominant follicles decreased pregnancy rates and increased late embryonic/fetal mortality in beef cows. Inadequate oocyte competence and(or) maternal environment, as affected by the physiological status of the dominant follicle, is a potential explanation for the reduction in pregnancy rates and late embryonic/fetal survival. Decreased ovulatory follicle diameter has been associated with decreased circulating concentrations of preovulatory estradiol and postovulatory progesterone secretion, which could decrease pregnancy rates. The objective of this experiment was to determine the effect of ovulatory follicular diameter on steroidogenic capacity and the follicular wall transcriptome collected $48 \mathrm{hr}$ after PG-induced luteolysis in beef cows (Experiment 2a). A second objective was to determine the effect of high or low circulating concentrations of estradiol on the follicular wall transcriptome $48 \mathrm{hr}$ after PG-induced luteolysis (Experiment 2b)

Non-lactating postpartum beef cows $(n=40)$ were synchronized by injecting GnRH on d -9 , followed by administration of PG on $d-2$. Animals were observed for signs of behavioral estrus three times daily from PG until harvest and animals that displayed estrus, had a detectable LH surge, or had a follicular fluid estradiol to progesterone ratio $<1$ were not included in the study. In Experiment 2a, cows were divided into two classifications based on dominant follicle diameter at collection: small 
$(\mathrm{n}=4$; mean $\pm \mathrm{SEM}=10.4 \pm 0.4 \mathrm{~mm})$ and large $(\mathrm{n}=7 ;$ mean $\pm \mathrm{SEM}=13.2 \pm 0.2 \mathrm{~mm})$. Mean follicular diameter and concentration of estradiol in follicular fluid were different $(\mathrm{P}<0.02)$; however, circulating concentrations of estradiol from PG to ovary collection were similar $(\mathrm{P}=0.16)$. RNA collected from each follicle wall was sequenced using an Illumina NextSeq 500 (paired end reads, 75 bases). The sequences were trimmed and filtered using fqtrim before being tiled against the Bos taurus genome using Hisat2 mapper. Differentially abundant transcripts were identified at FDR $<0.10$ using edgeR Robust. Nine transcripts were more abundant in small follicles, and 2 transcripts were more abundant in large follicles. Of the preceding differentially abundant transcripts, four in the small follicles (ITGA2,CSMD2, DNER, and TNNII) and zero in the large follicles have been annotated; all other transcripts are uncharacterized. For Experiment $2 b$, the same 11 follicle walls were divided into two classifications based on concentration of serum estradiol at $48 \mathrm{hr}$ after PG: low ( $\mathrm{n}=6$; mean $\pm \mathrm{SEM}=2.3 \pm 0.5$ $\mathrm{pg} / \mathrm{ml})$ and high $(\mathrm{n}=5 ; \mathrm{mean} \pm \mathrm{SEM}=5.8 \pm 0.6 \mathrm{pg} / \mathrm{ml} ; \mathrm{P}<0.01)$. Differentially abundant transcripts were identified using edgeR Robust at FDR $<0.10$ and analyzed for functional clusters with PANTHER as in Experiment 2a. In the low estradiol classification, 281 transcripts were more abundant, and 40 were more abundant in the high estradiol classification. Of these, 230 transcripts more abundant in the low and 33 in the high classification were annotated. Differentially abundant transcripts in both classifications were associated with mitosis, chromosome segregation, and regulation of biological processes. In summary, a small number of transcripts were differentially abundant in the follicle wall of small versus large dominant follicles prior to the preovulatory gonadotropin surge and no specific pathways were identified that might provide insight 
into how the physiological maturity of a dominant follicle can affect pregnancy rate post breeding. However, when comparisons were made between follicle walls from follicles with low or high serum estradiol, a greater number of transcripts were differentially expressed. A larger number of transcripts were more highly abundant in the follicle wall of low estradiol follicles, possibly indicating that they are less physiologically mature due to a higher level of transcription.

\subsection{Introduction}

In beef and dairy cattle, protocols for FTAI have been developed to synchronize ovulation and allow for insemination at a specified time. Perry et al (2005) reported that the GnRH-induced ovulation of physiologically immature dominant follicles resulted in decreased pregnancy rates and increased late embryonic/fetal mortality in postpartum beef cows. However, if the cows expressed estrus at GnRH-induced ovulation, there was no effect of dominant follicle size on pregnancy rate. This provides evidence that physiological maturity and not dominant follicle diameter is the cause for decreased pregnancy rates. The physiological mechanisms underlying the preceding decreased fertility has been a focus of several laboratories and may include an effect of the follicular microenvironment on both oocyte competence and the maternal environment.

The microenvironment of a preovulatory follicle is unique relative to the surrounding nonovulatory follicles and may affect acquisition of oocyte competence, preovulatory secretion of estradiol, and preparation of the maternal environment for pregnancy (Pohler et al., 2012; Dickinson, 2016). A reciprocal embryo transfer study was performed to differentiate between an effect of microenvironment of the dominant follicle at GnRH-induced ovulation on acquisition of oocyte competence and the 
maternal environment (Atkins et al 2013). Fertilization rate and embryo quality were both decreased in donor cows following GnRH-induced ovulation of small dominant follicles, providing support for decreased oocyte competence being a contributing factor to the decreased pregnancy rates (Atkins et al. 2013).

Bidirectional intercellular communication occurs between follicular cells and oocytes through paracrine and gap junctional communication to regulate proliferation and differentiation of follicular cells and growth, survival, and regulation of meiotic arrest in oocytes (Kidder and Vanderhyden, 2010). Consequently, cumulus and granulosa cells have been studied to find non-invasive markers of oocyte competence. Increased expression of the following genes in granulosa cells have been reported to positively affect oocyte competence: $3 \beta$-hydroxysteroid dehydrogenase, ferredoxin 1 , serine proteinase inhibitor clade E member 2, cytochrome P450 aromatase, cell division cycle 42, and sprouty homolog 2 (Robert et al., 2001, Hamel et al., 2008). Increased expression of versican and estrogen receptor 1 in bovine thecal cells has also been positively associated with increased oocyte competence (Matoba et al., 2013).

The follicular microenvironment can affect pregnancy rate via preovulatory secretion of estradiol. Estradiol plays many important roles in pregnancy establishment including estrous expression (Asdell et al., 1945), gamete transport (Hawk and Cooper, 1975), preparation of follicular cells for luteinization (McNatty and Sawers, 1975), and regulation of estradiol and progesterone receptors in the endometrium (Ing and Tornesi, 1997). The preceding reciprocal embryo transfer experiment also found that recipient cows with large dominant follicles had higher pregnancy rates than those with small dominant follicles (Atkins et al., 2013). Increased follicular diameter was correlated with 
an increase in the concentration of preovulatory estradiol. Higher concentrations of circulating preovulatory estradiol was correlated with increased concentrations of postovulatory progesterone on day 7 and increased pregnancy rate at day 28 following embryo transfer (Atkins et al., 2013, Jinks et al., 2013). Pregnancy rates were also increased when estradiol was supplemented $24 \mathrm{hr}$ before GnRH-induced ovulation and FTAI in cows induced to ovulate small compared to large dominant follicles (Jinks et al., 2013).

We hypothesized that characterization of the transcriptome of small and large dominant follicles will assist in the identification of molecules involved in acquisition of oocyte competence and(or) preparation of the maternal environment for the establishment and maintenance of pregnancy. The objective of this experiment was to determine the effect of ovulatory follicular diameter on steroidogenic capacity and the follicular wall transcriptome collected $48 \mathrm{hr}$ after prostaglandin $\mathrm{F}_{2} \alpha(\mathrm{PG})$ induced-luteolysis in beef cows (Experiment 1). A second objective was to determine the effect of high or low circulating concentrations of estradiol on the follicular wall transcriptome $48 \mathrm{hr}$ after PGinduced luteolysis (Experiment 2b).

\subsection{Materials and Methods}

All protocols and procedures were approved by Fort Keogh Livestock and Range Research Laboratory Animal Care and Use Committee.

A timeline for synchronization of ovulation, blood collection, and ovarian mapping is depicted in Figure 4.1. Follicular waves were synchronized in approximately 40 non-lactating beef cows using the Select Synch protocol. GnRH (i.m.; $100 \mu \mathrm{g}$; Cystorelin, Merial) was administered on d -9, followed by an injection of PG (i.m.; 25 


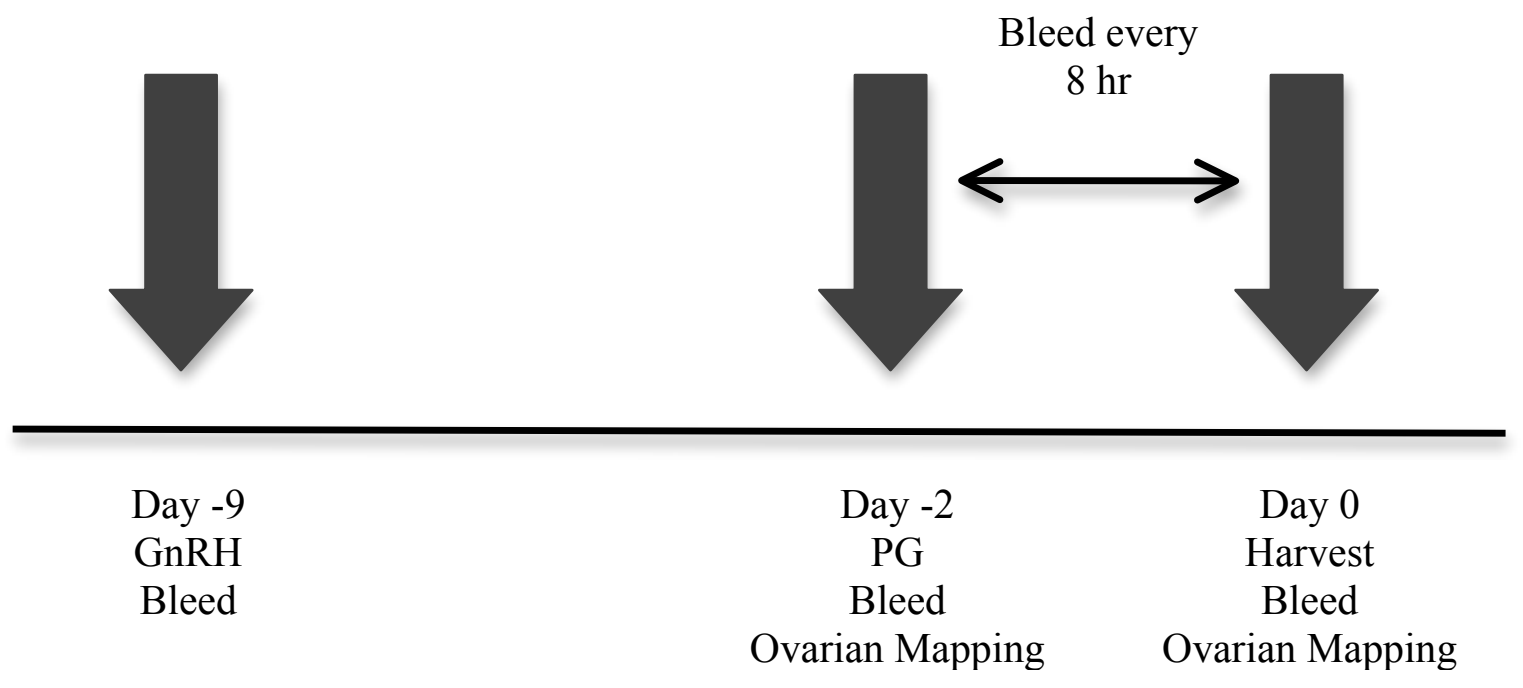

Figure 4.1. Protocol for animal handling and synchronization of dominant follicle growth. Follicle classifications groups were assigned based on follicle diameter at harvest (day 0). $\mathrm{GnRH}=$ Gonadotropin Releasing Hormone, $\mathrm{PG}=$ Prostaglandin $\mathrm{F}_{2 \alpha}$, Bleed= blood collection for quantification of circulating estradiol, progesterone, and luteinizing hormone. Ovarian Mapping=ultrasound examination of ovarian structures and measurement of dominant follicles. 
mg; Lutalayse ${ }^{\circledR}$, Pfizer Animal Health, Kalamazoo, MI) seven days later on d -2.

Ovaries of all animals were examined on $\mathrm{d}-2$ and 0 by transrectal ultrasonography using an Aloka 3500V ultrasound with a $7.5 \mathrm{MHz}$ probe to record follicular development.

Follicles with a diameter greater than $8 \mathrm{~mm}$ were recorded, with follicle diameter determined as the average of the diameter at the widest point and point perpendicular to the widest point.

The ovary containing the dominant follicle was collected at the abattoir $(n=20) 48$ hr after PG (d 0) for another study (Pohler 2011). Cattle were observed for signs of behavioral estrus three times daily from PG until harvest, and animals that displayed estrus, had a LH surge detectable by radioimmunoassay (RIA), or an intrafollicular estradiol to progesterone ratio < 1 (Sunderland et al., 1994) by $48 \mathrm{hr}$ after PG were not included in the experiment.

\section{Blood collection}

Blood samples were collected via tail venipuncture into $10 \mathrm{~mL}$ Vacutainer tubes on d $-9, \mathrm{~d}-2$, and every $8 \mathrm{hr}$ from PG until follicle collection. Samples were allowed to clot at room temperature for 1 hour and stored at $4^{\circ} \mathrm{C}$ for $24 \mathrm{hr}$. Blood samples were centrifuged at $3000 \mathrm{xg}$ for $20 \mathrm{~min}$ and serum was decanted and stored at $-20^{\circ} \mathrm{C}$ until concentrations of estradiol and LH were determined by RIA (see below). Collection of follicular wall and follicular fluid

The ovary containing the dominant follicle was immediately placed in hamster embryo collection media at $37^{\circ} \mathrm{C}$ and transported to the laboratory. The dominant follicle was manually dissected free from the stroma and the diameter was measured with calipers. The follicle was opened and follicular fluid was collected. The cumulus oocyte 
complexes were identified within the follicular fluid, collected, and frozen at $-80 \mathrm{C}$ for a different study (Pohler 2011). Follicular fluid was collected into an Eppendorf tube and centrifuged to pellet cellular debris, before being decanted into a clean tube and frozen at $-80^{\circ} \mathrm{C}$ until concentrations of estradiol and progesterone were determined by RIA (see below). The oocytes and their associated cumulus cells were previously reported on by Pohler (2011). The follicle wall was split into two pieces and each piece was placed into a separate Eppendorf tube and snap frozen. Follicle walls were stored at $-80^{\circ} \mathrm{C}$ until RNA extraction.

RNA Extraction and Seqencing

Figure 4.2 depicts the chronological steps for RNA analysis. Total RNA was extracted from each follicle wall using the TRIzol-chloroform extraction method (Chromczynski and Sacchi 1987). RNA was diluted to $100 \mathrm{ng} / \mu 1$ in RNAse-free water and an aliquot of $15 \mu$ l of each sample was sent to the University of Missouri DNA Core to measure quality. Samples with a RNA quality number (RQN) greater than 6 were submitted for sequencing (mean=7.7; range 6.1 to 8.9 ). Samples were sequenced utilizing the NextSeq 500 (Illumina, Inc, San Diego, CA) using paired end reads with 75 base pairs per read. All samples were sequenced in a single lane.

\section{Sequence trimming and alignment}

Sequence adaptors were removed and remaining sequences were filtered for quality using fqtrim (https://ccb.jhu.edu/software/fqtrim/). Sequences were retained if they met a median quality score of at least 25 , and had a minimum read length of 30 base pairs. Filtered sequences were aligned to the Bos taurus reference genome UMD3.1 


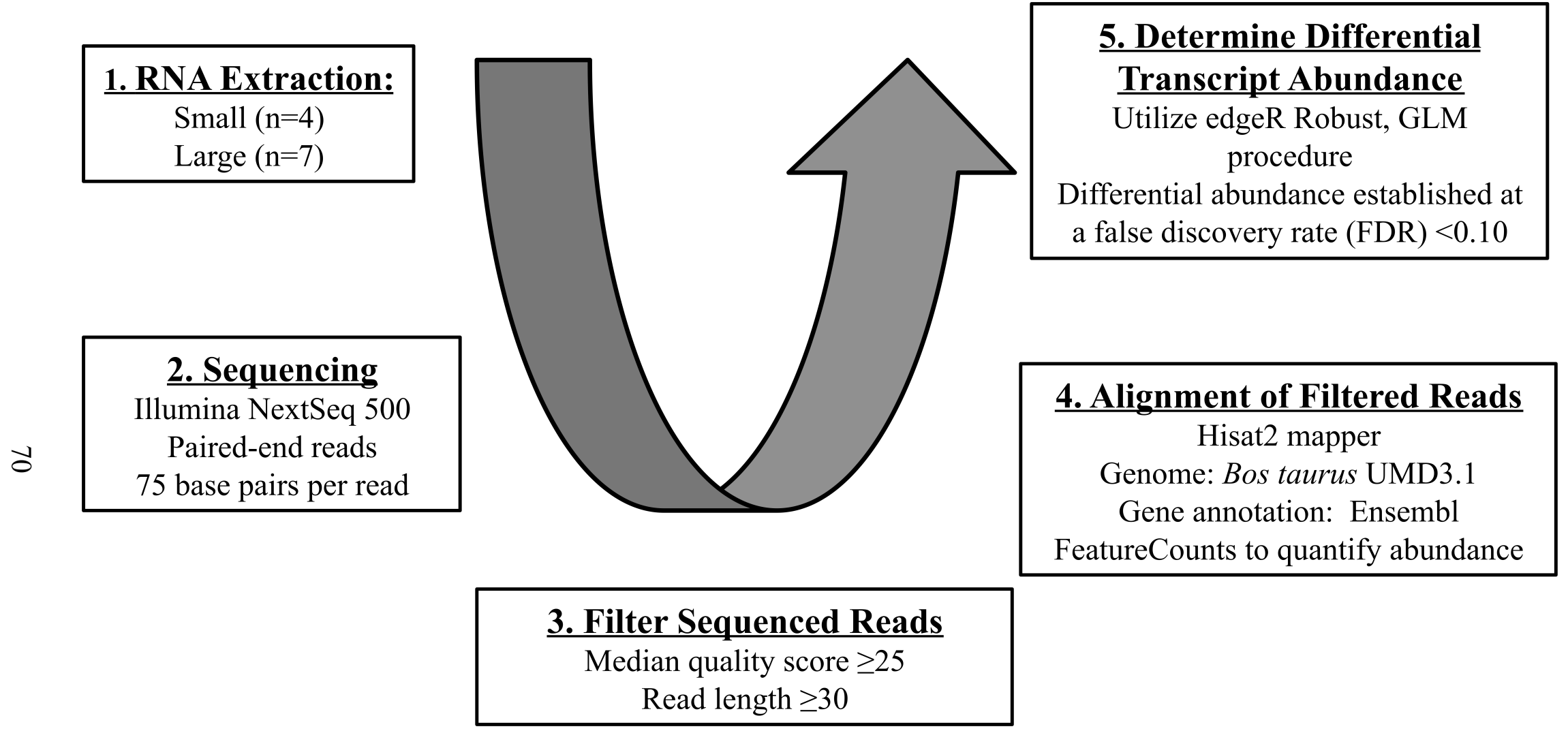

Figure 4.2. The chronological steps employed to generate and analyze the data for this project included the following: 1) Extract total RNA from follicle walls from Small $(10.4 \pm 0.4 \mathrm{~mm})$ and Large $(13.2 \pm 0.2 \mathrm{~mm})$ dominant follicles, 2$)$ Generate nucleotide sequence data, 3) Filter the data based on established criteria, 4) Align the reads to the bovine genome, and 5) Analyze the data for differential transcript abundance by using the edgeR Robust GLM procedure at FDR $<0.10$. 
using Hisat2 mapper (Kim et al., 2015). FeatureCounts (Liao et al., 2014) was used to quantify transcript abundance in each sample using Bos taurus gene notation from Ensembl (http://www.ensembl.org/Bos_taurus/).

\section{Determination of differentially abundant genes}

Experiment 2a: For the purposes of this experiment, samples were divided into two treatment groups based on dominant follicle size on d 0: small $(<11.3 \mathrm{~mm}$; mean $\pm \mathrm{SEM}=10.3 \pm 0.7 \mathrm{~mm})$ and large $(>12.5 \mathrm{~mm} ;$ mean $\pm \mathrm{SEM}=13.3 \pm 0.2 \mathrm{~mm})$. After alignment, a spreadsheet of read counts was generated for each follicle wall. Read counts were submitted to edgeR (Zhou et al., 2014) and an edgeR Robust test was used to determine differentially abundant transcripts. Because the goal of this study was to identify a list of differentially abundant transcripts that can be further examined, a FDR of $<0.10$ was used so as to generate a larger list. Differentially abundant transcripts were submitted to DAVID to analyze for enriched pathways (Huang et al., 2009a; 2009b). No pathways were found to be significant. Transcripts were then submitted to PANTHER to analyze functional gene clusters and GO terms (Mi et al., 2016, Thomas et al., 2006). PANTHER was also used to look for overrepresented GO terms, where the percentage of submitted transcripts that fit a GO term was compared to the percentage of genes in the total genome that fit the same GO term. As no significant or overrepresented GO terms were found, an intensive literature review was performed to determine if the differentially abundant transcripts might be physiologically relevant.

Experiment 2b: The same follicle wall samples were divided into two treatment groups based on serum concentrations of estradiol at $48 \mathrm{hr}$ after PG: low $(<4.0 \mathrm{pg} / \mathrm{ml}$; mean $\pm \mathrm{SEM}=2.3 \pm 0.5 \mathrm{pg} / \mathrm{ml})$ and high $(\geq 4.0 \mathrm{pg} / \mathrm{ml} ;$ mean $\pm \mathrm{SEM}=5.8 \pm 0.6 \mathrm{pg} / \mathrm{ml})$. 
EdgeR Robust was used to determine differentially abundant transcripts, and transcripts were subsequently submitted to DAVID and PANTHER to analyze for pathways and GO terms as described for Experiment 2a (Huang et al., 2009a; Mi et al., 2016; Thomas et al., 2006).

Radioimmunoassays

Serum and follicular fluid concentrations of estradiol (Kirby et al., 1997), progesterone (Zaied et al., 1980), and LH (Atkins et al., 2008) were analyzed by RIA. The intra and inter assay coefficients of variation (CV) as reported by Pohler (2011) were as follows: serum estradiol $=5.02 \%, 15.93 \%$ (inter assay $\mathrm{CV}$ and intra assay $\mathrm{CV}$, respectively); follicular fluid estradiol $=4.09 \%$ (inter assay $\mathrm{CV}$ ); serum and follicular progesterone $=4.23 \%($ inter assay $\mathrm{CV})$; and serum $\mathrm{LH}=3.26 \%($ inter assay $\mathrm{CV})$. Statistical Analysis

Variance was compared using the F-test and the appropriate two-tailed t-test for equal or unequal variance was used to compare mean cow weight, body condition score (BCS), follicular diameter, intrafollicular estradiol, and intrafollicular progesterone. Means were considered to be different at $\mathrm{P}<0.05$. Serum estradiol and LH were analyzed using analysis of variance for repeated measures in SAS (statistical analysis system; SAS Institute Inc., Cary, NC). The model included treatment, time of sample collection, and treatment $\mathrm{x}$ time interaction.

\subsection{Results}

Experiment 2a: Effect of dominant follicle size on the transcriptome of the follicle wall

Mean follicle diameter ( \pm SEM) at $48 \mathrm{hr}$ after PG injection differed between small and large follicle wall classifications $(10.3 \pm 0.4 \mathrm{~mm}$ and $13.2 \pm 0.2 \mathrm{~mm}$, respectively; 
Table 4.1; $\mathrm{P}<0.02$ ). Based on collection of blood samples every eight hours, none of the cows included in the data had a preovulatory surge of luteinizing hormone.

Intrafollicular concentrations of estradiol (mean \pm SEM) were different for the small $(404.9 \pm 72.7 \mathrm{ng} / \mathrm{ml})$ versus large $(768.3 \pm 89.0 \mathrm{ng} / \mathrm{ml})$ follicle groups (Figure 4.3 $\mathrm{P}<0.02)$. However, there was no difference in cow age $(\mathrm{P}>0.54)$, cow weight $(\mathrm{P}>0.61)$, BCS $(\mathrm{P}>0.59)$, or intrafollicular concentrations of progesterone (Figure 4.4; $\mathrm{P}>0.37$; See Table 4.1 for means and ranges of all parameters.) All cows had an estrogen active dominant follicle as determined by an estradiol to progesterone ratio in follicular fluid that was $>1$ (Sunderland et al., 1994). Circulating concentrations of estradiol increased $(\mathrm{P}<0.01)$ from $\mathrm{PG}-$ induced luteolysis to follicle collection, but were not different between groups (Figure 4.5; $\mathrm{P}>0.16$ ).

RNA Extraction, Sequencing, and Analysis

RNA was extracted from fourteen follicle walls classified as either Small or Large based on follicle diameter at harvest $48 \mathrm{hr}$ after PG injection. Two samples were removed from the small classification because of low quality RNA ( RQN < 6.0), and one sample was removed because of incomplete PG-induced luteolysis based on serum concentrations of progesterone, resulting in four follicle walls in the small follicle classification and seven follicle walls in the large follicle classification. Deep sequencing of the preceding samples yielded an average raw read count of 44,286,758 reads per sample. After filtering and trimming an average of $41,869,074$ or $94.5 \%$ of reads aligned to the Bos taurus genome. A summary of read counts that aligned to the Bos taurus genome is depicted in appendix table A.4. 
Table 4.1. Parameters of cows and treatment groups for follicle walls from follicles classified as small or large.

\begin{tabular}{|c|c|c|}
\hline Parameter & Small Follicle $(n=4)$ & Large Follicle(n=7) \\
\hline Cow Age ${ }^{a}$ & $\begin{array}{c}6.0 \pm 1.4 \mathrm{yr} \\
(4-10 \mathrm{yr})\end{array}$ & $\begin{array}{c}4.9 \pm 1.1 \mathrm{yr} \\
(2-10 \mathrm{yr})\end{array}$ \\
\hline Cow Weight ${ }^{b}$ & $\begin{array}{l}616.7 \pm 12 \mathrm{~kg} \\
(590-640 \mathrm{~kg})\end{array}$ & $\begin{array}{c}641 \pm 35 \mathrm{~kg} \\
(501-762 \mathrm{~kg})\end{array}$ \\
\hline Cow $\mathrm{BCS}^{\mathrm{c}}$ & $\begin{array}{l}7.3 \pm 0.3 \\
(7-8)\end{array}$ & $\begin{array}{l}7.0 \pm 0.4 \\
(6-8)\end{array}$ \\
\hline $\begin{array}{l}\text { Follicle Diameter } 48 \mathrm{hr} \text { After } \\
\qquad \mathrm{PG}^{\mathrm{d}}\end{array}$ & $\begin{array}{l}10.3^{\mathrm{x}} \pm 0.4 \mathrm{~mm} \\
(9.5-11.1 \mathrm{~mm})\end{array}$ & $\begin{array}{l}13.2^{\mathrm{y}} \pm 0.2 \mathrm{~mm} \\
(12.7-14.0 \mathrm{~mm})\end{array}$ \\
\hline Intrafollicular Estradiol $^{\mathrm{e}}$ & $\begin{array}{l}404.9^{\mathrm{x}} \pm 72.7 \mathrm{ng} / \mathrm{ml} \\
(244.2-569.2 \mathrm{ng} / \mathrm{ml})\end{array}$ & $\begin{array}{c}768.3^{\mathrm{y}} \pm 89.0 \mathrm{ng} / \mathrm{ml} \\
(562.7-1107.0 \mathrm{ng} / \mathrm{ml})\end{array}$ \\
\hline Intrafollicular Progesterone ${ }^{f}$ & $\begin{array}{c}64.4 \pm 13.5 \mathrm{ng} / \mathrm{ml} \\
(41.12-103.3 \mathrm{ng} / \mathrm{ml}) \\
\end{array}$ & $\begin{array}{c}94.1 \pm 28.9 \mathrm{ng} / \mathrm{ml} \\
(47.3-264.0 \mathrm{ng} / \mathrm{ml})\end{array}$ \\
\hline $\begin{array}{l}\text { Intrafollicular Estradiol to } \\
\text { Progesterone Ratio }\end{array}$ & $\begin{array}{r}6.6 \pm 1.1 \\
(5.9-9.6) \\
\end{array}$ & $\begin{array}{c}11.4 \pm 2.7 \\
(2.4-23.3)\end{array}$ \\
\hline
\end{tabular}

a, Cow age; Mean \pm SEM (range)

${ }^{\mathrm{b}}$ Cow weight; Mean \pm SEM (range)

${ }^{\mathrm{c}}$ Cow body condition score (BCS); (1-9 scale; $1=$ emaciated, $9=$ obese) Mean \pm SEM (range)

${ }^{d}$ Size of the pre-ovulatory follicle at harvest $48 \mathrm{hr}$ after PG injection; Mean \pm SEM (range)

${ }^{\mathrm{e}}$ Concentration of estradiol present in follicular fluid of the dominant follicle at harvest; Mean \pm SEM (range)

${ }^{\mathrm{f}}$ Concentration of progesterone present in the follicular fluid of the dominant follicle at harvest; Mean \pm SEM (range)

${ }^{g}$ Ratio of intrafollicular estradiol to intrafollicular progersterone; Mean \pm SEM (range)

${ }^{\mathrm{x}, \mathrm{y}}$ Numbers within a row with different superscripts are different $(\mathrm{P}<0.02)$. 


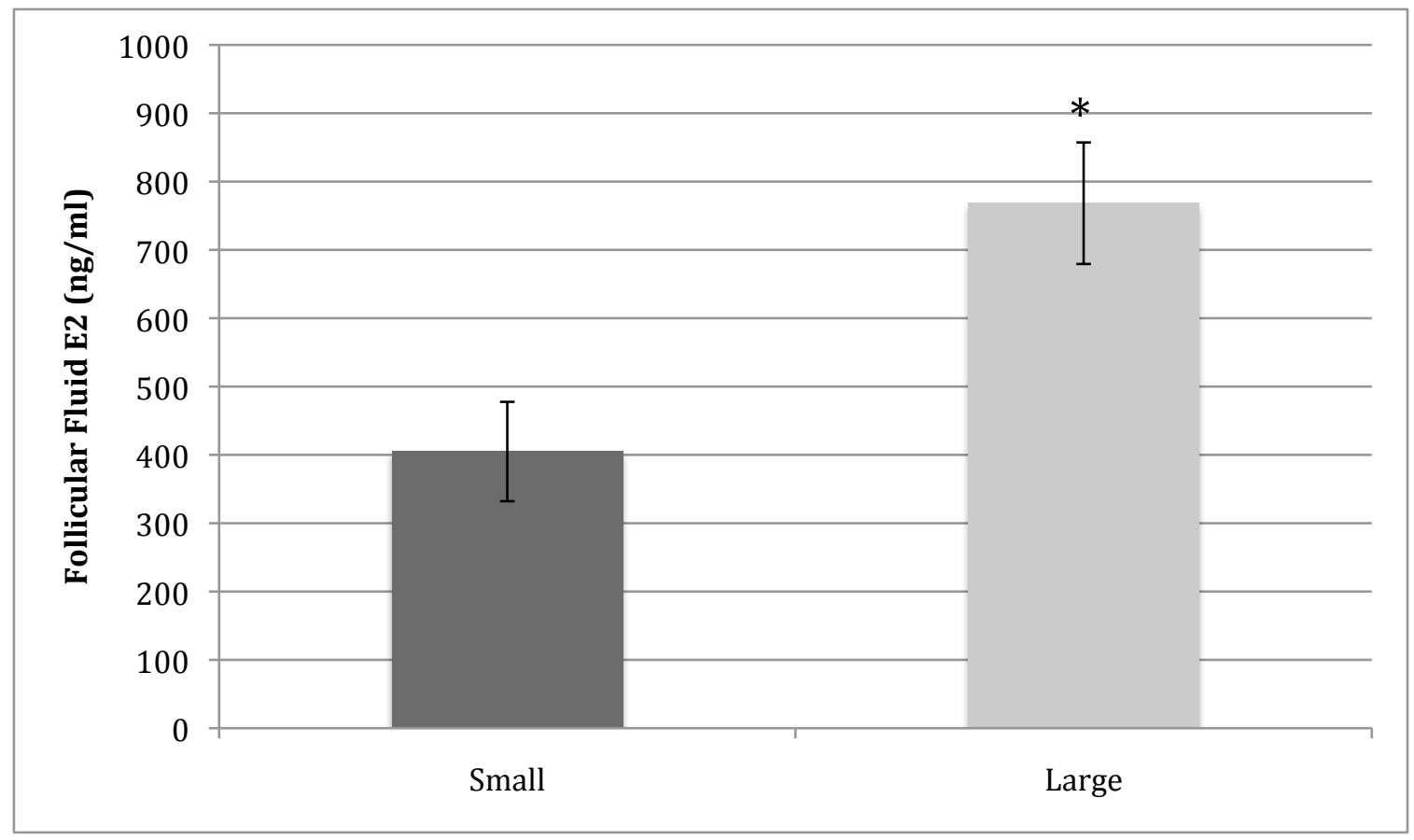

Figure 4.3. Mean $( \pm$ SEM) follicular fluid concentrations of estradiol in small and large dominant follicle classifications collected $48 \mathrm{hr}$ after PG injection. Concentrations of estradiol were different $(* \mathrm{P}<0.02)$. 


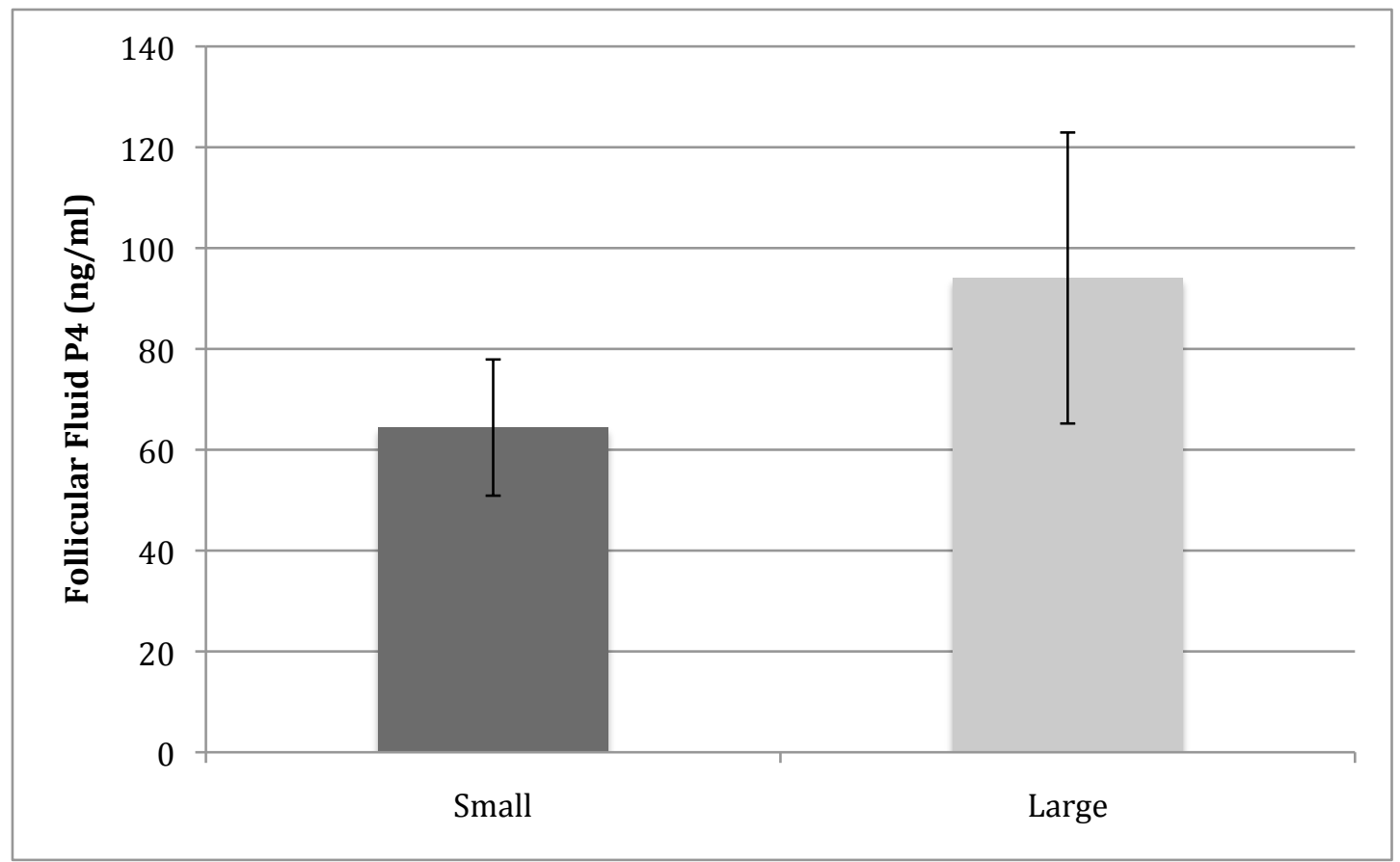

Figure 4.4. Mean ( \pm SEM) follicular fluid concentrations of progesterone in small and large dominant follicle classifications collected $48 \mathrm{hr}$ after PG injection. Concentrations of progesterone were not different $(\mathrm{P}=0.37)$. 


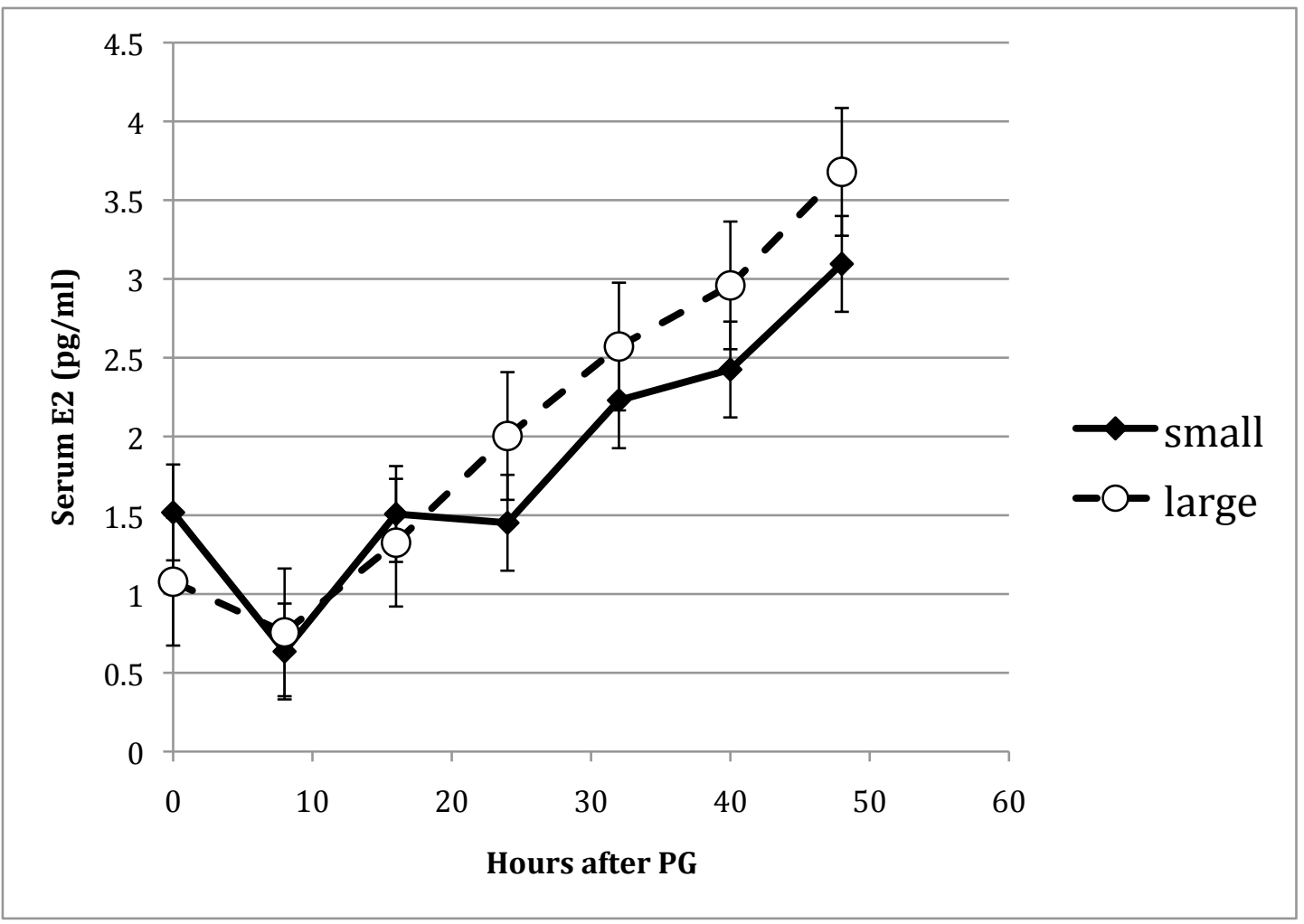

Figure 4.5. Preovulatory serum concentrations of estradiol (mean $\pm \mathrm{SEM}$ ) in cows with small and large dominant follicles at $48 \mathrm{hr}$ after PG injection $(0 \mathrm{hr})$. There was an effect of time $(\mathrm{P}<0.01)$ but not treatment $(\mathrm{P}=0.16)$ or treatment $\mathrm{x}$ time $(\mathrm{P}=0.16)$ on serum concentrations of estradiol. 
Mapped transcripts were analyzed for differential abundance at a $\mathrm{FDR}<0.10$. Two transcripts were more highly abundant in the follicle walls of large follicles and nine were more highly abundant in follicle walls of small follicles. Figure 4.6 is a volcano plot depicting differentially abundant transcripts and shows the fold change differences between follicle size classifications. Of the differentially abundant transcripts, zero transcripts from the large and four transcripts from the small classification (ITGA2, CSMD2, DNER, and TNNI1) were annotated; all other transcripts were unannotated. Table 4.2 lists the differentially abundant transcripts for the small follicle classification. Because a small number of transcripts were differentially abundant, a review of literature was performed to assess the function of differentially abundant transcripts.

Experiment 2b: Transcriptome analysis of follicle walls from cows that had high or low circulating concentrations of estradiol.

The preceding eleven follicle wall samples were divided into two classifications (low $n=6$ and high $n=5$ ) based on serum concentrations of estradiol at $48 \mathrm{hr}$ after PG. Mean serum estradiol ( \pm SEM) at $48 \mathrm{hr}$ after PG differed between the low and high estradiol classifications $(2.3 \pm 0.5 \mathrm{pg} / \mathrm{ml}$ and $5.8 \pm 0.6 \mathrm{pg} / \mathrm{ml}$ respectively; $\mathrm{P}<0.002)$. Circulating concentrations of estradiol increased over time, and differed between groups at 32, 40, and $48 \mathrm{hr}$ after PG (Figure 4.7; $\mathrm{P}>0.05$ ). There was no difference in cow age $(\mathrm{P}=0.64)$, cow weight $(\mathrm{P}=0.29), \mathrm{BCS}(\mathrm{P}=0.059)$, follicle diameter (Figure 4.8; $\mathrm{P}=0.20)$, intrafollicular concentrations of estradiol (Figure 4.9; $\mathrm{P}=0.68$ ) or intrafollicular concentrations of progesterone (Figure 4.10; $\mathrm{P}>0.37$ ). See Table 4.3 for means and ranges of all parameters. 


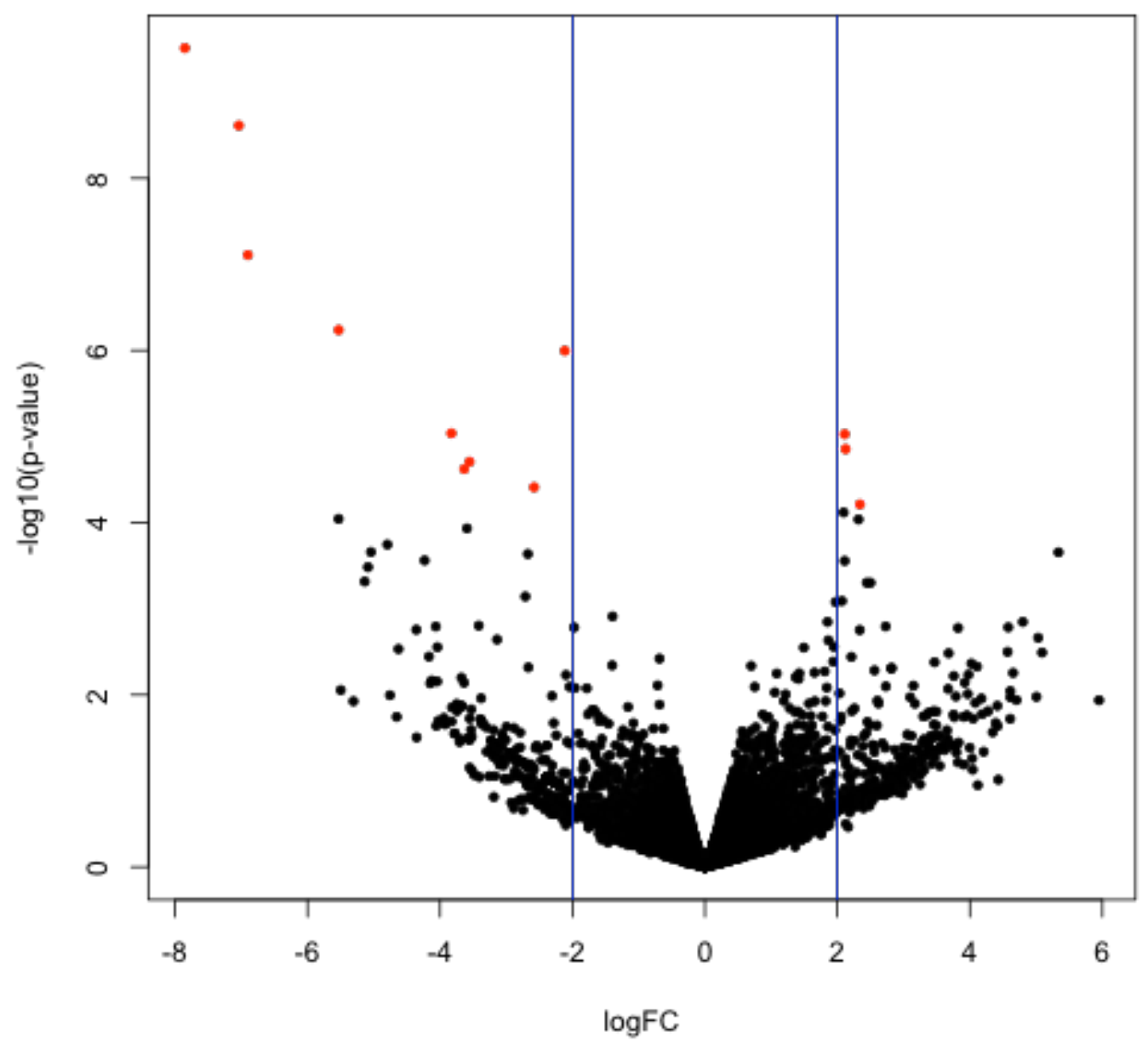

Figure 4.6. Volcano plot depicting differences in transcript abundance between Small and Large classification follicle walls. X-axis denotes the $\log 2$ of the ratio between the normalized edgeR Robust read count values ( $-5=32$ fold higher in small follicle walls; $0=$ equal transcript abundance between follicle classifications; $5=32$ fold lower in small follicle walls). Y-axis denotes - $\log 10$ (FDR P-Value) where 1.3 equals FDR $=0.05$ and 1 equals FDR $=0.10$. Each dot represents one transcript. Red dots denote differentially abundant transcripts between small and large follicle classifications at FDR $<0.10$. 
Table 4.2 Transcripts more abundant in the follicle walls of small compared to large follicles:

\begin{tabular}{|c|c|c|c|c|}
\hline & Gene & & $\log$ & \\
\hline Ensembl ID & ID & Function or Annotated Protein & $\mathrm{FC}^{\mathrm{b}}$ & $\mathrm{FDR}^{\mathrm{c}}$ \\
\hline ENSBTAG00000019289 & ITGA2 & integrin subunit alpha 2 & -2.116 & $3.85 \mathrm{E}-03$ \\
\hline ENSBTAG00000005784 & CSMD2 & CUB and Sushi multiple domains 2 & -3.555 & $3.37 \mathrm{E}-02$ \\
\hline ENSBTAG00000016063 & DNER & delta/notch like EGF repeat containing & -3.634 & 4.19E-02 \\
\hline ENSBTAG00000047231 & TNNI1 & troponin I, slow skeletal muscle & -2.578 & $9.03 \mathrm{E}-02$ \\
\hline
\end{tabular}

${ }^{a}$ Data represent transcripts aligned to a genome and found to be differentially abundant by the edgeR Robust GLM test (FDR $\left.<0.10\right)$.

${ }^{\mathrm{b}} \mathrm{Log} 2$ of the ratio between the normalized edgeR read count values for follicle walls of small or large follicles $(-5=32$ fold higher in small follicle walls; $0=$ equal transcript abundance between follicle classifications; $5=32$ fold higher in large follicle walls.)

${ }^{\mathrm{c}}$ FDR P-Value (adjusted for multiple comparisons) for the difference in transcript abundance between follicle walls derived from small and large follicle classifications. 


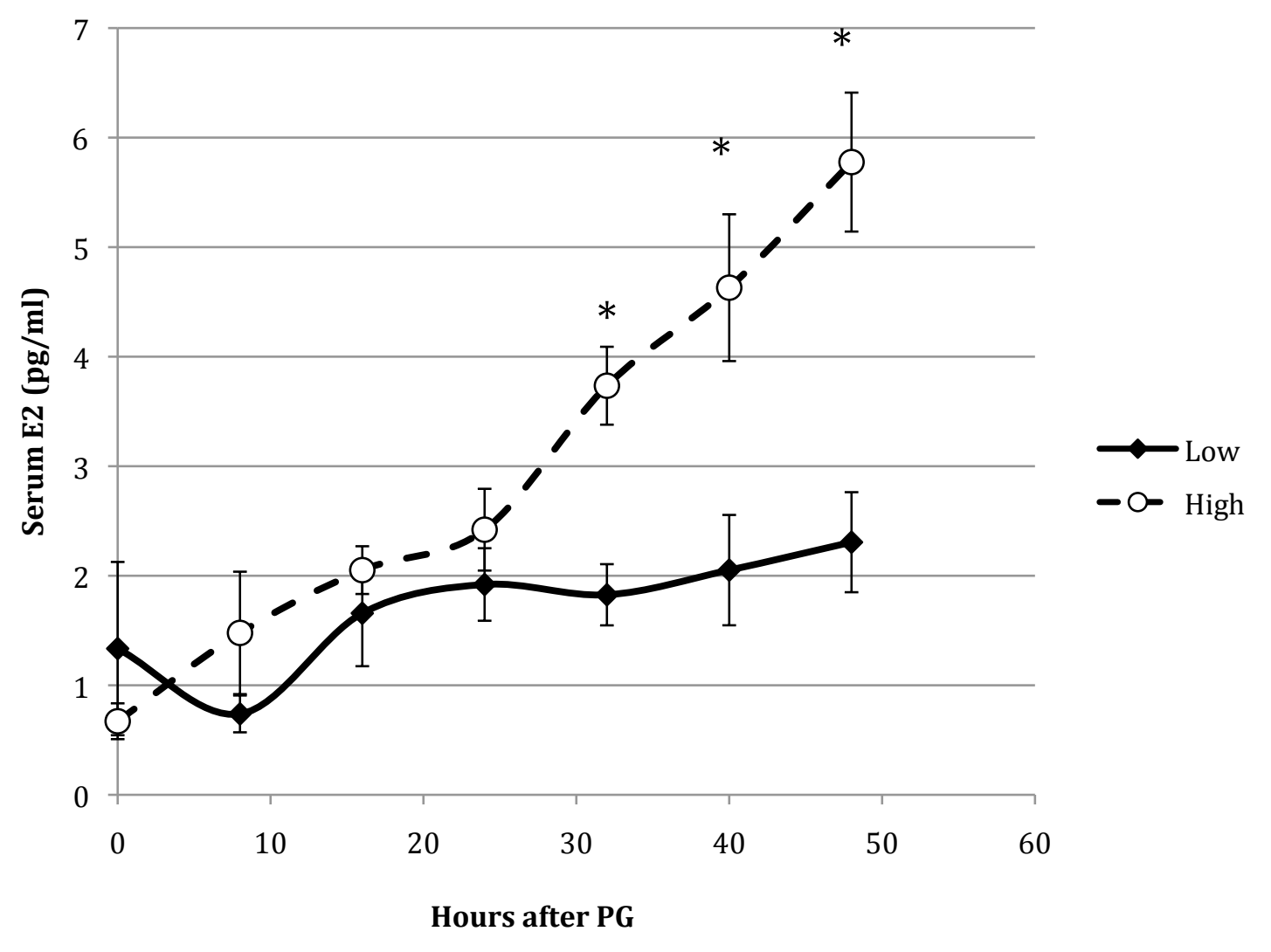

Figure 4.7. Preovulatory serum concentrations of estradiol (mean \pm SEM) after injection of prostaglandin $\mathrm{F}_{2 \alpha}$ in cows classified as having low or high estradiol. Concentrations of estradiol differed at 32,40 , and $48 \mathrm{hr}$ after $\mathrm{PG}$ injection $(* \mathrm{P}<0.02)$ 


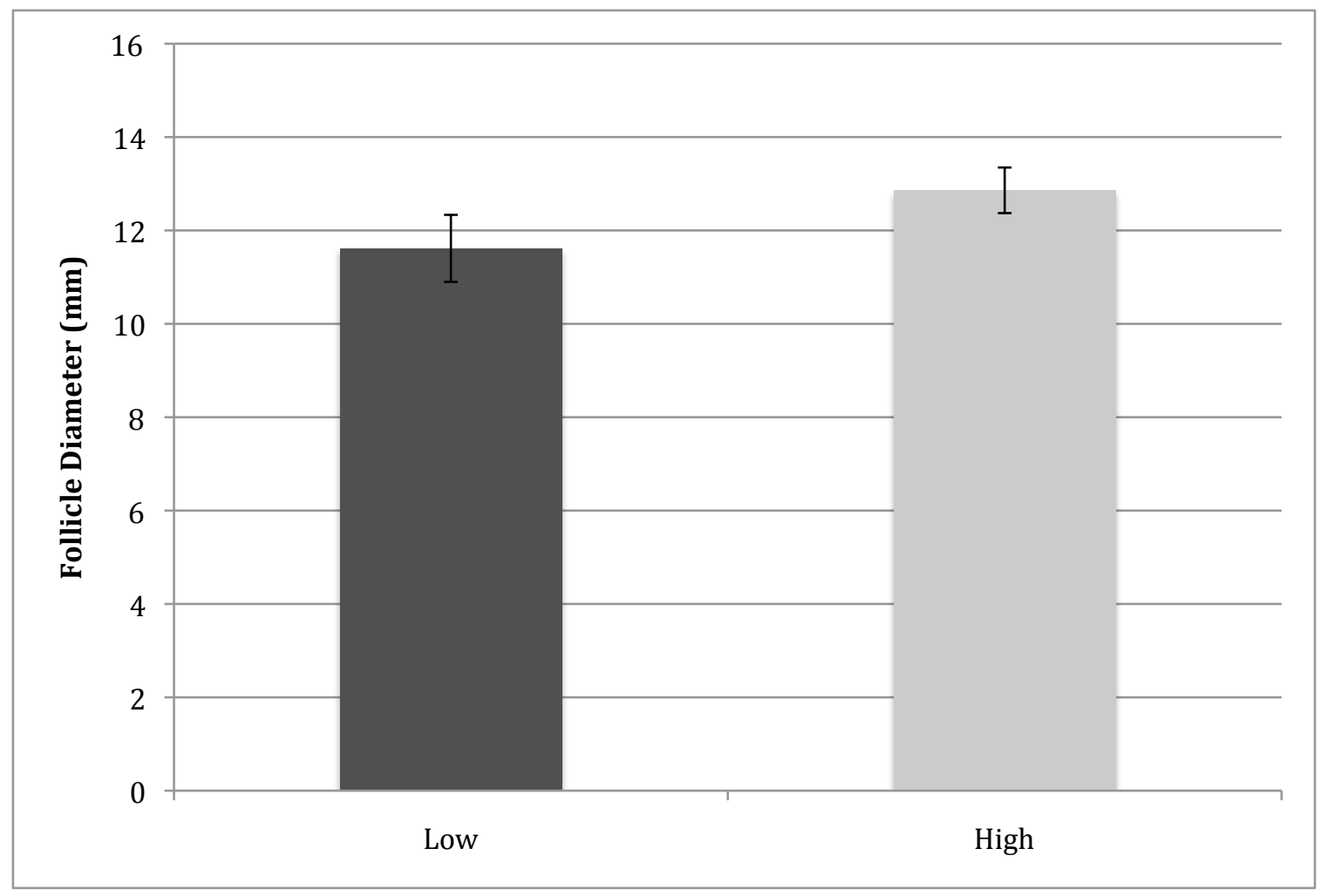

Figure 4.8. Mean ( \pm SEM) follicle diameter of follicles classified as having low or high serum estradiol at $48 \mathrm{hr}$ after $\mathrm{PG}$ injection. Follicle diameters did not differ $(\mathrm{P}=0.19)$. 


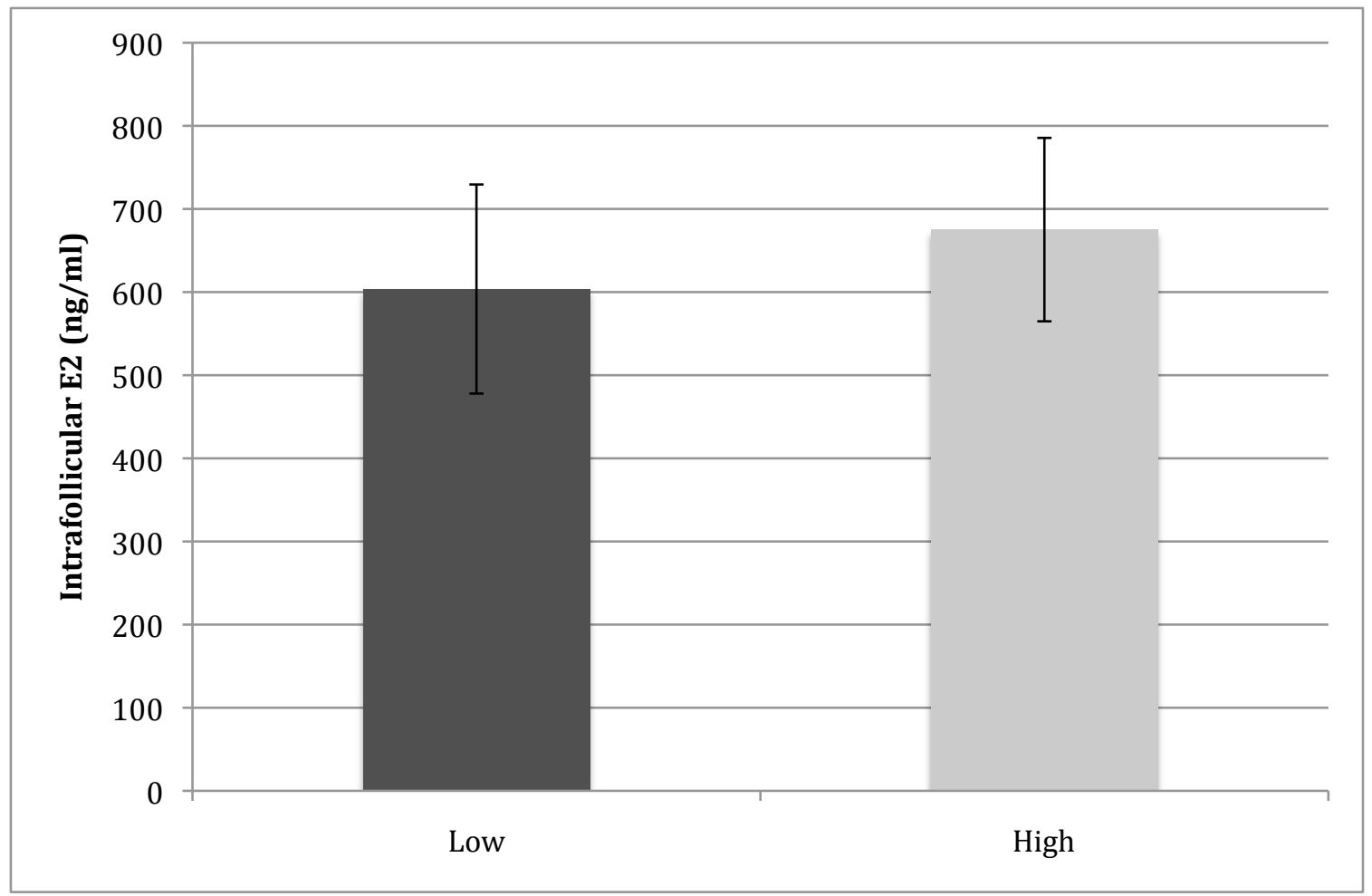

Figure 4.9. Mean $( \pm \mathrm{SEM})$ intrafollicular concentrations of estradiol in dominant follicles classified as having low or high serum estradiol at $48 \mathrm{hr}$ after PG injection. Estradiol concentrations did not differ $(\mathrm{P}=0.68)$. 


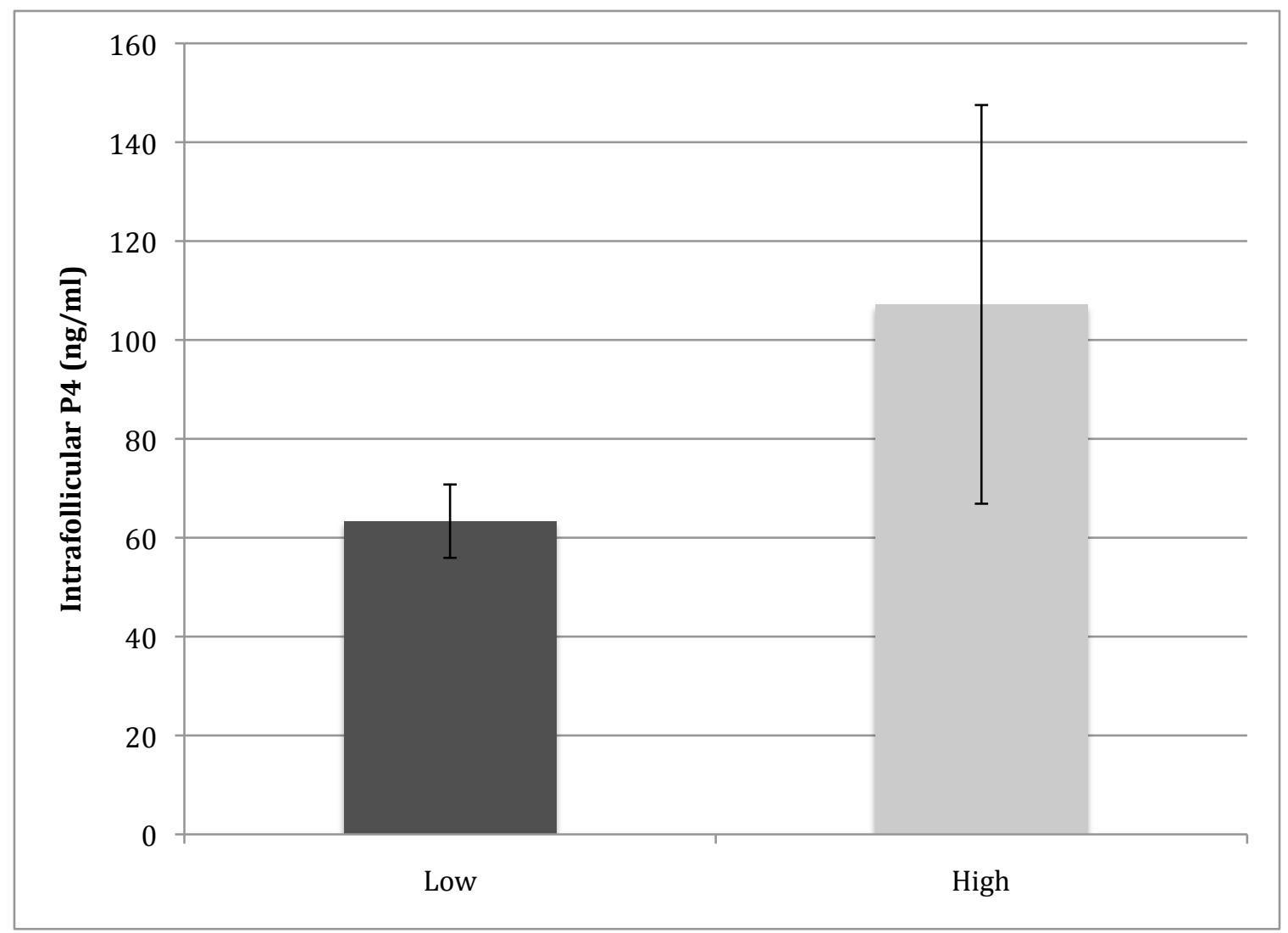

Figure 4.10. Mean $( \pm$ SEM) intrafollicular concentrations of progesterone in dominant follicles classified as having low or high serum estradiol at $48 \mathrm{hr}$ after PG injection. Progesterone concentrations did not differ $(\mathrm{P}=0.34)$ 
Table 4.3. Parameters of cows and treatment groups for follicle walls classified by high or low concentrations of serum estradiol

\begin{tabular}{|c|c|c|}
\hline Parameter & $\begin{array}{c}\text { Low Serum } \\
\text { Estradiol }\end{array}$ & $\begin{array}{c}\text { High Serum } \\
\text { Estradiol }\end{array}$ \\
\hline Cow Age ${ }^{a}$ & $\begin{array}{l}5.3 \pm 1.2 \mathrm{yr} \\
(2-10 \mathrm{yr})\end{array}$ & $\begin{array}{l}4.6 \pm 0.8 \mathrm{yr} \\
(2-7 \mathrm{yr})\end{array}$ \\
\hline Cow Weight ${ }^{b}$ & $\begin{array}{l}609 \pm 28 \mathrm{~kg} \\
(502-709 \mathrm{~kg})\end{array}$ & $\begin{array}{c}658 \pm 35 \mathrm{~kg} \\
(568-763 \mathrm{~kg})\end{array}$ \\
\hline Cow $\mathrm{BCS}^{\mathrm{c}}$ & $\begin{array}{l}6.7 \pm 0.3 \\
(6-8)\end{array}$ & $\begin{array}{l}7.6 \pm 0.2 \\
(7-8)\end{array}$ \\
\hline Serum Estradiol $48 \mathrm{hr}$ After $\mathrm{PG}^{\mathrm{d}}$ & $\begin{array}{l}2.3^{\mathrm{x}} \pm 0.5 \mathrm{pg} / \mathrm{ml} \\
(0.7-3.6 \mathrm{pg} / \mathrm{ml})\end{array}$ & $\begin{array}{l}5.8^{\mathrm{y}} \pm 0.6 \mathrm{pg} / \mathrm{ml} \\
(4.0-7.6 \mathrm{pg} / \mathrm{ml})\end{array}$ \\
\hline Follicle Diameter $48 \mathrm{hr}$ After $\mathrm{PG}^{\mathrm{e}}$ & $\begin{array}{l}11.6 \pm 0.7 \mathrm{~mm} \\
(9.5-13.6 \mathrm{~mm})\end{array}$ & $\begin{array}{c}12.9 \pm 0.5 \mathrm{~mm} \\
(11.1-14.0 \mathrm{~mm})\end{array}$ \\
\hline Intrafollicular Estradiol $^{\mathrm{f}}$ & $\begin{array}{c}603.7 \pm 125.8 \mathrm{ng} / \mathrm{ml} \\
(244.2-1107.0 \mathrm{ng} / \mathrm{ml})\end{array}$ & $\begin{array}{c}675.2 \pm 110.3 \mathrm{ng} / \mathrm{ml} \\
(475.8-1101.9 \mathrm{ng} / \mathrm{ml})\end{array}$ \\
\hline Intrafollicular Progesterone ${ }^{\mathrm{g}}$ & $\begin{array}{c}63.3 \pm 7.4 \mathrm{ng} / \mathrm{ml} \\
(41.1-94.4 \mathrm{ng} / \mathrm{ml}) \\
\end{array}$ & $\begin{array}{c}107.2 \pm 40.3 \mathrm{ng} / \mathrm{ml} \\
(47.3-103.3)\end{array}$ \\
\hline $\begin{array}{c}\text { Intrafollicular Estradiol to Progesterone } \\
\text { Ratio }^{\text {h }}\end{array}$ & $\begin{array}{c}9.4 \pm 1.9 \\
(5.9-18.6)\end{array}$ & $\begin{array}{c}9.9 \pm 3.6 \\
(2.5-23.3)\end{array}$ \\
\hline
\end{tabular}

${ }^{\mathrm{a},}$ Cow age; Mean \pm SEM (range)

${ }^{\mathrm{b}}$ Cow weight; Mean \pm SEM (range)

${ }^{\mathrm{c}}$ Cow body condition score (BCS); (1-9 scale; $1=$ emaciated, $9=$ obese) Mean \pm SEM (range)

${ }^{\mathrm{d}}$ Concentration of estradiol present in serum collected $48 \mathrm{hr}$ after PG injection; Mean \pm SEM (range)

${ }^{\mathrm{e}}$ Size of the pre-ovulatory follicle at harvest $48 \mathrm{hr}$ after PG injection; Mean \pm SEM (range)

${ }^{f}$ Concentration of estradiol present in follicular fluid of the dominant follicle at harvest; Mean \pm SEM (range)

${ }^{\mathrm{g}}$ Concentration of progesterone present in the follicular fluid of the dominant follicle at harvest; Mean \pm SEM (range)

${ }^{\mathrm{h}}$ Intrafollicular estradiol to intrafollicular progesterone ratio; Mean $\pm \mathrm{SEM}$ (range)

${ }^{\mathrm{x}, \mathrm{y}}$ Numbers within a row with different superscripts are different $(\mathrm{P}<0.01)$. 
When sorted by serum concentrations of estradiol, 281 transcripts were more abundant $(\mathrm{FDR}<0.10)$ in the follicle walls of the low estradiol classification and 40 transcripts were more abundant in the follicle walls of the high estradiol group (shown as a volcano plot in Figure 4.11). Of these transcripts, 230 in the low and 33 in the high estradiol classification were annotated. Tables 4.4 and 4.5 list the fifteen most differentially expressed annotated transcripts for each classification based on FDR. The differentially expressed transcripts were analyzed for pathways or functional clusters using PANTHER software (Thomas et al., 2006; Mi et al., 2010); however, no significant pathways were found. However, functional clustering revealed several GO biological process terms associated with each group (Figures 4.12 and 4.13). A statistical overrepresentation test was performed in PANTHER (Thomas et al., 2006) comparing the frequency of each GO term to the frequency of the term in the total Bos taurus genome. Ten GO terms had higher frequency in the low estradiol follicle walls compared to the Bos taurus genome (Figure 4.14), with many of these terms related to metabolic processes and transcription. One GO term (immune response process) was higher in frequency in high estradiol follicle walls compared to the Bos taurus genome (Figure 4.15).

\subsection{Discussion}

In postpartum beef cows that do not express estrus before GnRH-induced ovulation, the preovulatory follicular environment of small dominant follicles may not be adequate for acquisition of oocyte competence and(or) the establishment of a maternal environment (i.e. inadequate preovulatory estradiol secretion) that is conducive to pregnancy. Bidirectional communication between follicular cells and the oocyte is 


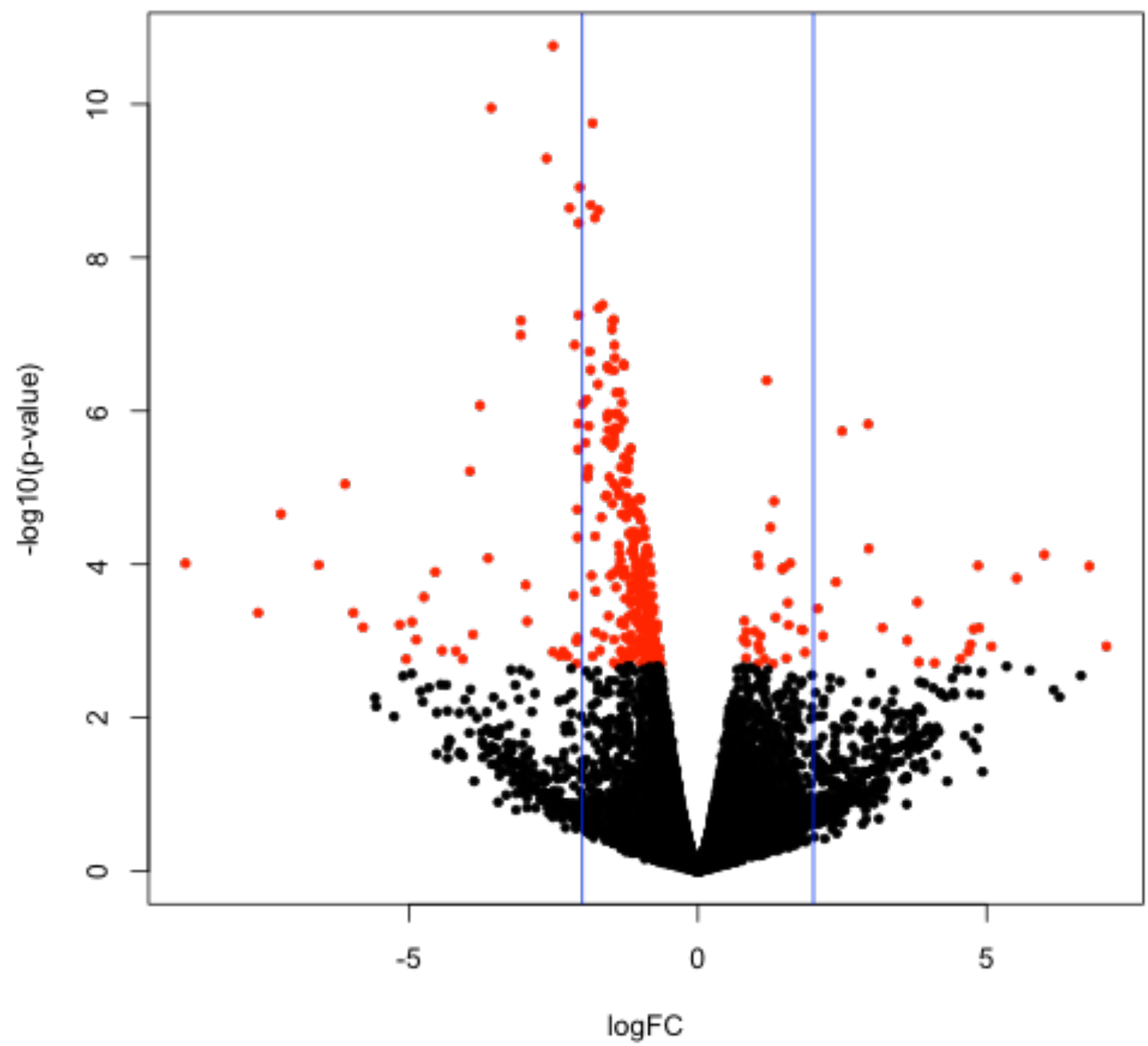

Figure 4.11. Volcano plot depicting differences in transcript abundance in follicle walls of cows classified as having low or high serum concentrations of estradiol at $48 \mathrm{hr}$ after PG injection. X-axis denotes the $\log 2$ of the ratio between the normalized edgeR Robust read count values $(-5=32$ fold higher in follicle walls of the low estradiol group; $0=$ equal transcript abundance between follicle classifications; $5=32$ fold lower in follicle walls of the low estradiol group) $\mathrm{Y}$-axis denotes $-\log 10$ (FDR P-Value) where 1.3 equals $\mathrm{FDR}=0.05$ and 1 equals FDR $=0.10$. Each dot represents one transcript. Red dots denote transcripts differentially expressed between low and high serum estradiol follicle classifications at a FDR of $<0.10$. 
Table 4.4. Top fifteen (by FDR) transcripts more abundant in low serum estradiol follicles compared to high serum estradiol follicles ${ }^{\mathrm{a}}$

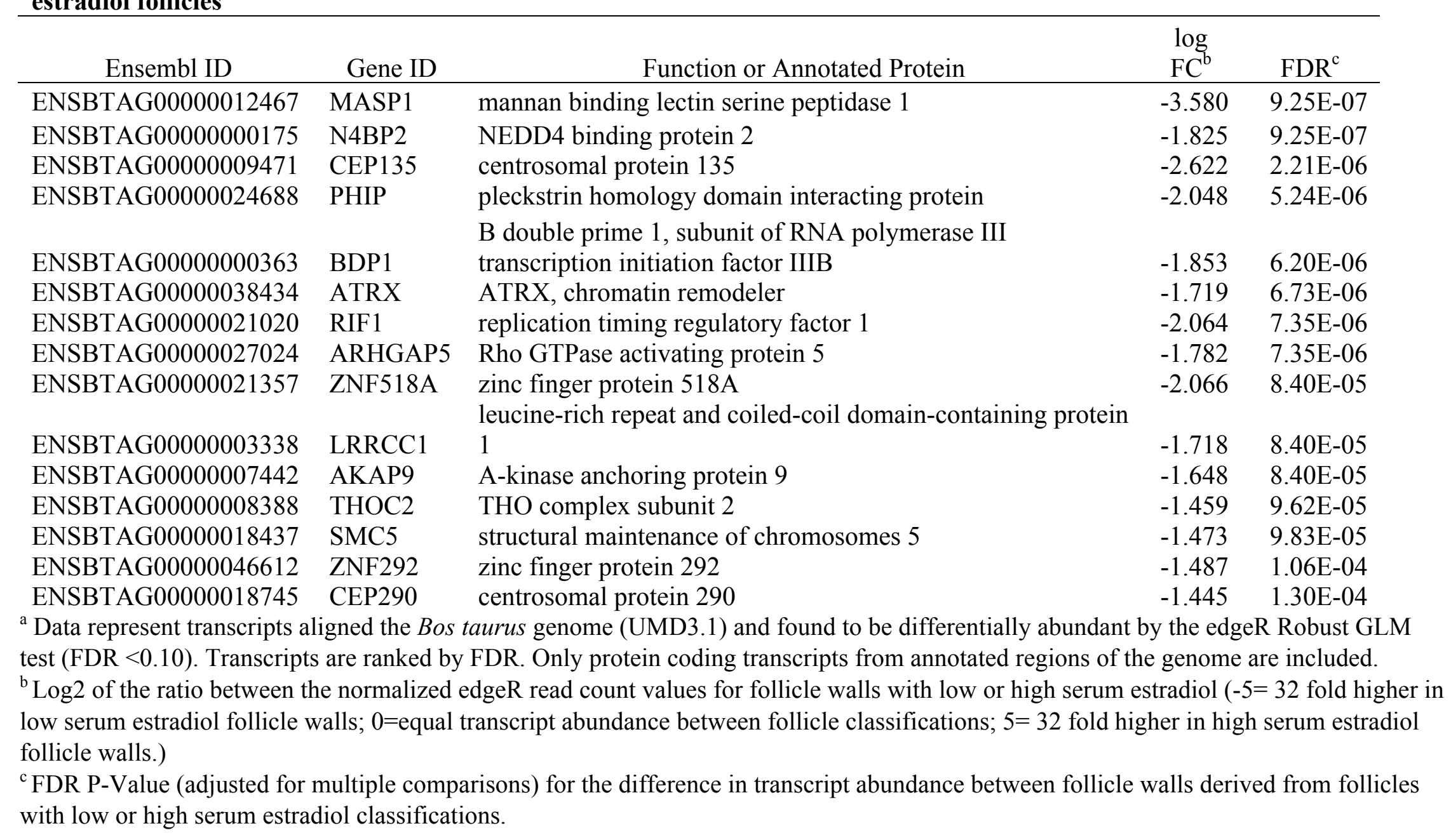


Table 4.5. Top fifteen transcripts (by FDR) more abundant in high serum estradiol follicles compared to low serum estradiol follicles ${ }^{\mathrm{a}}$

\begin{tabular}{|c|c|c|c|c|}
\hline Ensembl ID & Gene ID & Function or Annotated Protein & $\begin{array}{l}\text { Log } \\
\text { FC }^{b}\end{array}$ & $\mathrm{FDR}^{\mathrm{c}}$ \\
\hline ENSBTAG00000002473 & ANGPTL4 & angiopoietin like 4 & 1.191 & $2.78 \mathrm{E}-04$ \\
\hline & & WAP, follistatin/kazal, immunoglobulin, kunitz and netrin & & \\
\hline ENSBTAG00000000731 & WFIKKN2 & domain containing 2 & 1.319 & $3.33 \mathrm{E}-03$ \\
\hline ENSBTAG00000019060 & CLDN11 & claudin 11 & 1.258 & $7.02 \mathrm{E}-03$ \\
\hline ENSBTAG00000013641 & BAG3 & BCL2 associated athanogene 3 & 1.038 & $1.29 \mathrm{E}-02$ \\
\hline ENSBTAG00000026437 & ULBP3 & UL16 binding protein 3 precursor & 6.002 & $1.36 \mathrm{E}-02$ \\
\hline ENSBTAG00000004014 & FBLN2 & fibulin 2 & 1.056 & $1.47 \mathrm{E}-02$ \\
\hline ENSBTAG00000018164 & FNDC4 & fibronectin type III domain containing 4 & 1.599 & $1.47 \mathrm{E}-02$ \\
\hline ENSBTAG00000021360 & RASGEF1C & RasGEF domain family member $1 \mathrm{C}$ & 2.959 & $1.52 \mathrm{E}-02$ \\
\hline ENSBTAG00000003923 & GPBAR1 & $\begin{array}{l}\text { G protein-coupled bile acid receptor } 1 \\
\text { A disintegrin and metalloproteinase with thrombospondin motifs }\end{array}$ & 1.455 & $1.55 \mathrm{E}-02$ \\
\hline ENSBTAG00000013210 & ADAMTS4 & 4 precursor & 1.490 & $1.58 \mathrm{E}-02$ \\
\hline ENSBTAG00000016283 & TMEM63C & calcium permeable stress-gated cation channel 1 & 4.850 & $1.58 \mathrm{E}-02$ \\
\hline ENSBTAG00000010161 & CCL21 & C-C motif chemokine 21 precursor & 2.390 & $2.02 \mathrm{E}-02$ \\
\hline ENSBTAG00000034373 & CDH13 & cadherin-13 precursor & 1.558 & $3.58 \mathrm{E}-02$ \\
\hline ENSBTAG00000039122 & PLA2G5 & phospholipase A2 group V & 3.800 & $3.79 \mathrm{E}-02$ \\
\hline ENSBTAG00000011007 & TTYH2 & protein tweety homolog 2 & 1.346 & 4.47E-02 \\
\hline
\end{tabular}

${ }^{a}$ Data represent transcripts aligned the Bos taurus genome (UMD3.1) and found to be differentially abundant by the edgeR Robust GLM test (FDR <0.10). Transcripts are ranked by FDR. Only protein coding transcripts from annotated regions of the genome are included.

${ }^{\mathrm{b}} \mathrm{Log} 2$ of the ratio between the normalized edgeR read count values for follicle walls with low or high serum estradiol $(-5=32$ fold higher in low serum estradiol follicle walls; $0=$ equal transcript abundance between follicle classifications; $5=32$ fold higher in high serum estradiol follicle walls.)

${ }^{c}$ FDR P-Value (adjusted for multiple comparisons) for the difference in transcript abundance between follicle walls derived from follicles with low or high serum estradiol classifications. 


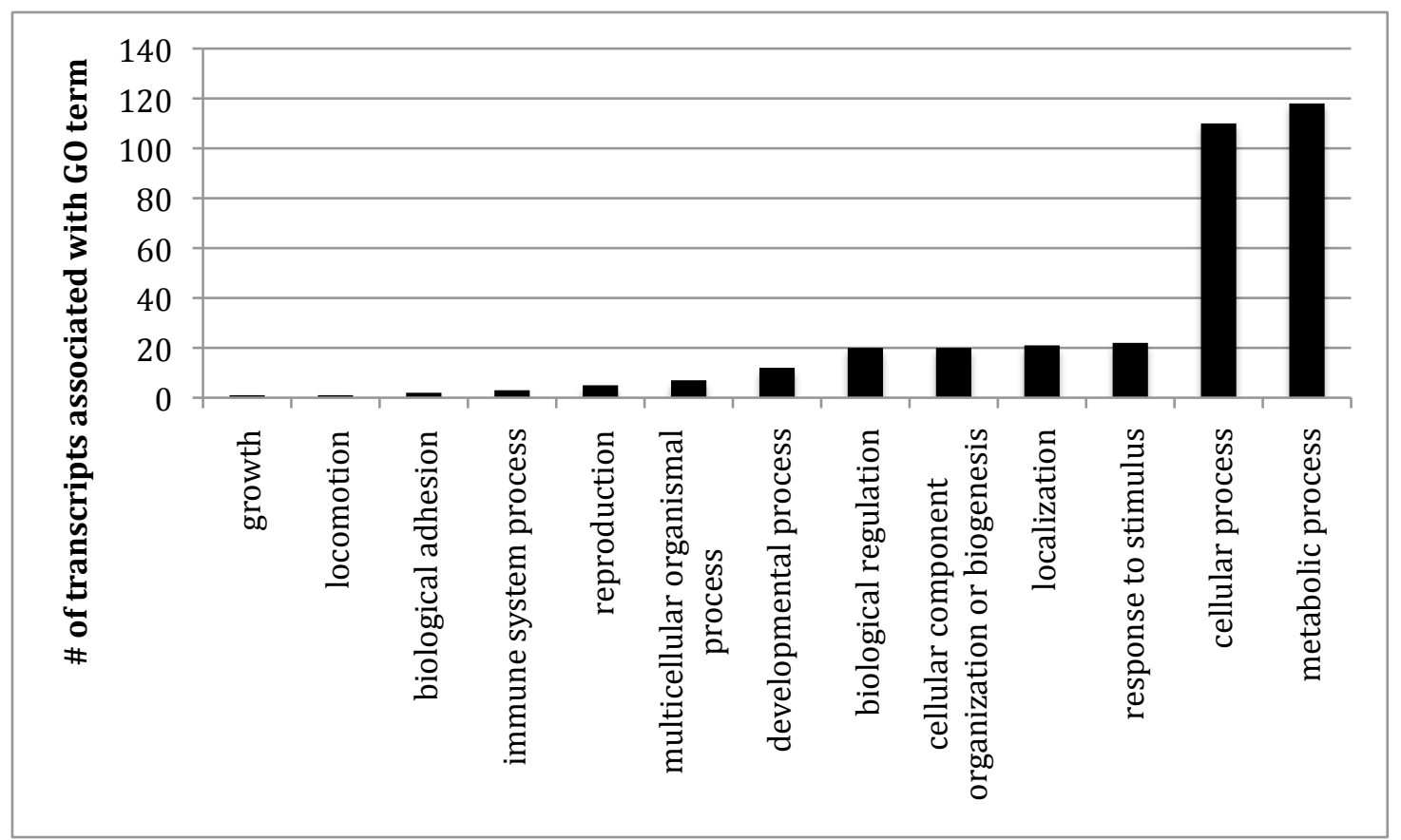

Figure 4.12. Frequency of GO biological process terms associated with genes more highly abundant in follicle walls in the low compared to the high estradiol classification. $\mathrm{Y}$-axis denotes the number of differentially abundant transcripts associated with each term. 


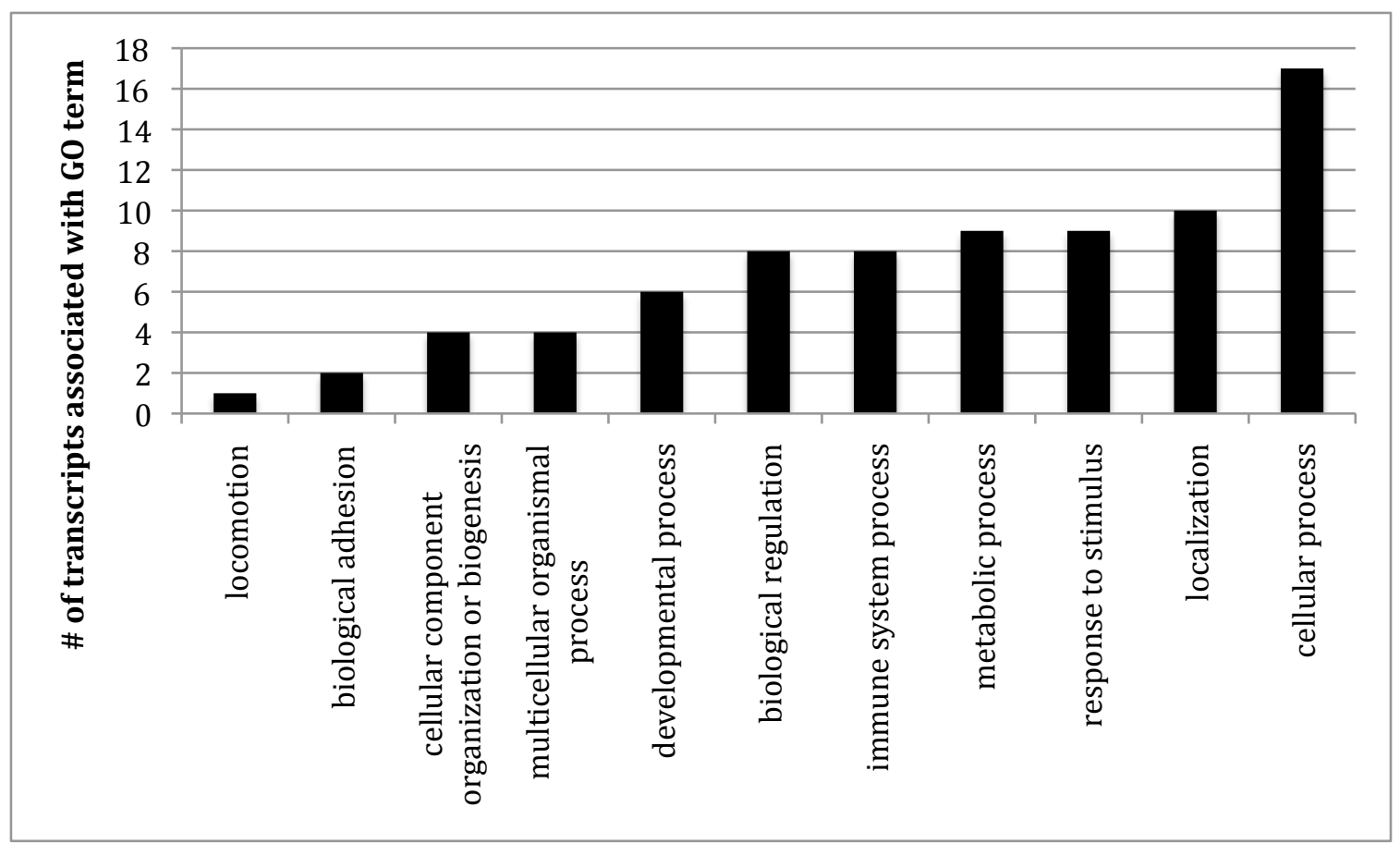

Figure 4.13. Frequency of GO biological process terms associated with genes more highly abundant in follicle walls of the high compared to the low estradiol group. Y-axis denotes the number of differentially abundant transcripts associated with each term. 


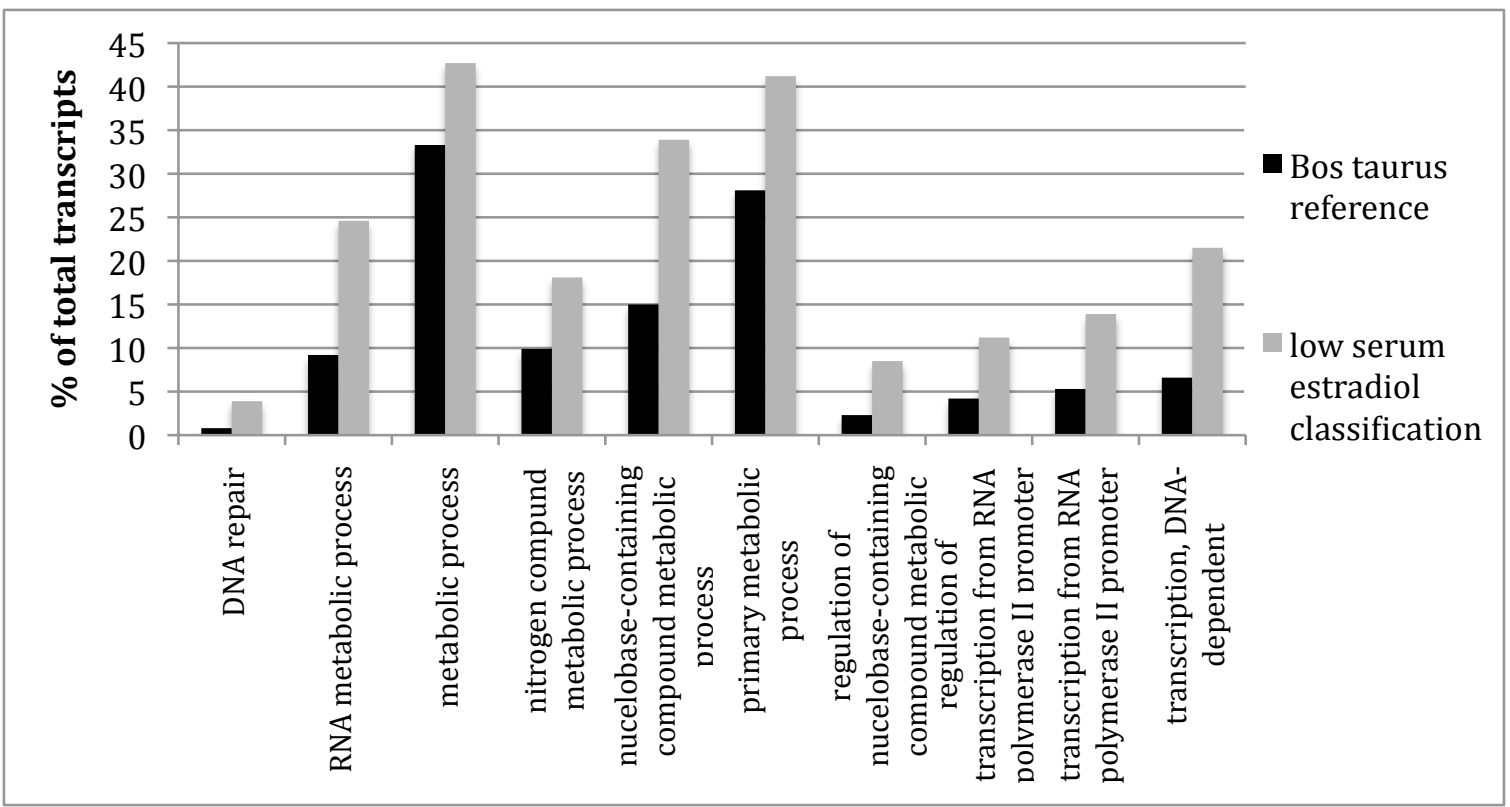

Figure 4.14. Comparison of enriched GO biological process terms between the Bos taurus reference genome and follicle walls from the low serum estradiol classification. Transcript abundance for each GO term is different between groups $(\mathrm{P}<0.05)$. $\mathrm{Y}$-axis indicates the percent of transcripts of the total list associated with the GO term. 


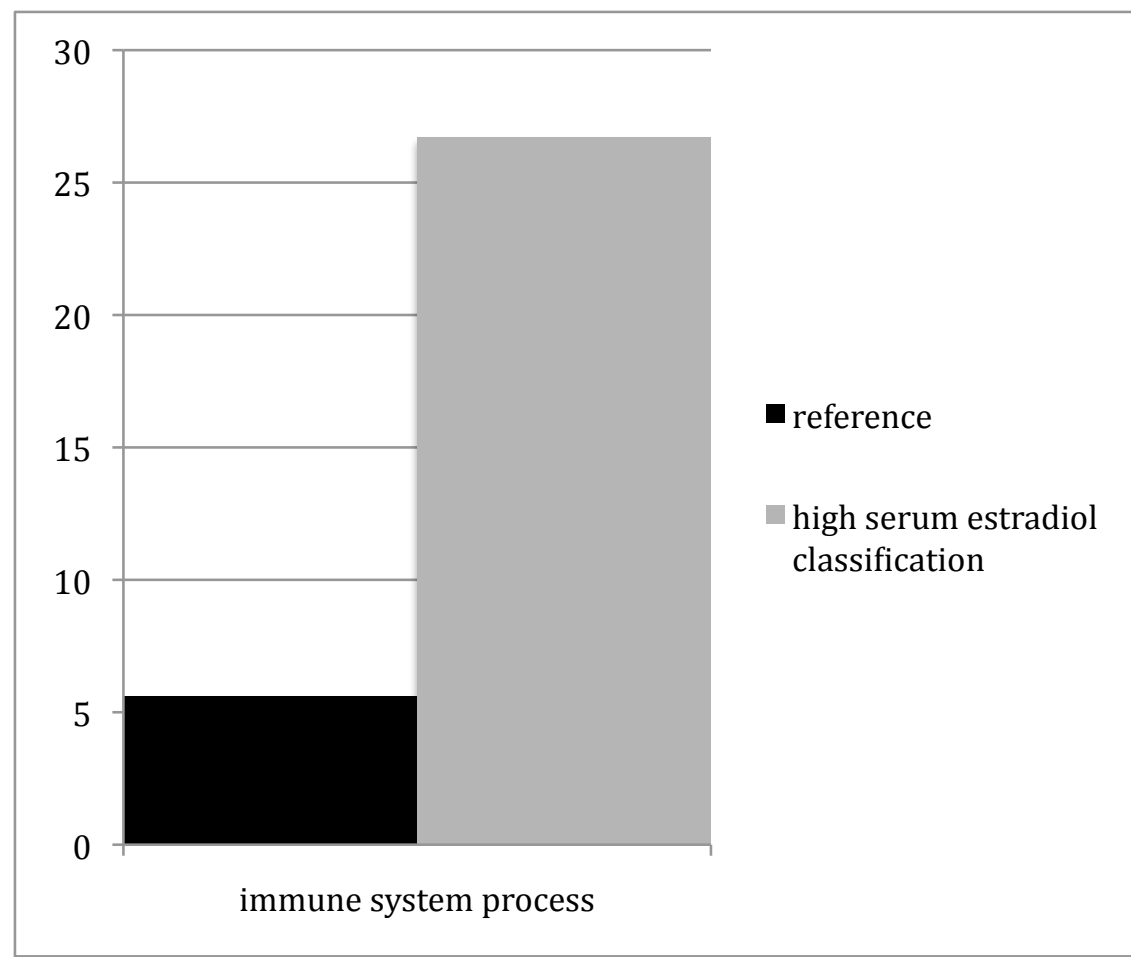

Figure 4.15. Comparison of enriched GO biological process terms between the Bos taurus reference genome and follicle walls from the high serum estradiol classification. Transcript abundance for each GO term is different between groups $(\mathrm{P}<0.05)$. Y -axis indicates the percent of transcripts of the total list associated with the GO term. 
necessary for both oocyte maturation and follicular development and occurs via paracrine, gap junctional, and transzonal communication (Eppig et al.,2001; Gilchrist et al., 2004; Macaulay et al., 2014). In cattle, rapid accumulation and storage of mRNA is initiated in the bovine oocyte during the preantral follicle stage and transcription continues at a low level until germinal vesicle breakdown (GVB; Fair et al., 1997). In addition, cumulus cells contribute to the oocyte transcriptome and the acquisition of oocyte competence through transfer of RNA to the oocyte via transzonal projections. Transfer of RNA continues until the preovulatory gonadotropin surge terminates oocyte transcription and disrupts the TZPs by triggering cumulus expansion (Macaulay et al. 2014; Macaulay et al. 2016). Importantly, mural granulosa cells are connected to cumulus cells via gap junctions (Kidder and Vanderhyden, 2010). Alternatively, mural granulosa affect the COC via paracrine communication (Albertini et al., 2001). The embryo is dependent upon the maternally stored RNA until the maternal zygotic transition (Sirard et al., 2006). Consequently, GnRH-induced ovulation of small dominant follicles may cause ovulation of an oocyte that has not acquired full competence and may therefore compromise embryonic development.

Increased dominant follicle size at GnRH-induced ovulation was positively associated with fertilization rate, probability of recovering a live embryo, and probability of recovering a transferable embryo, but negatively associated with stage of embryonic development on $\mathrm{d} 7$ in postpartum beef cows (Atkins et al., 2013). Furthermore, transcript abundance encoding genes associated with glycolysis were more abundant in cumulus cell pools collected from large compared to small dominant follicles (Chapter 3). Cumulus cell glycolysis is essential for oocyte maturation, as oocytes have a poor 
capacity to metabolize glucose and therefore rely on cumulus cells to supply pyruvate for energy production and other processes necessary for oocyte competence, (SuttonMcDowall et al, 2010). Therefore, the preceding data suggest that oocyte competence may be compromised in small dominant follicles at the time of GnRH-induced ovulation.

In addition to cumulus cells, secretory products of granulosa cells (i.e. kit ligand) may also have a biological role in the oocyte. Previous studies have been performed to identify granulosa cell markers of oocyte competence. Studies in humans and cattle reported that increased expression of $3 \beta$-hydroxysteroid dehydrogenase, ferredoxin 1 , serine proteinase inhibitor clade $\mathrm{E}$ member 2, cytochrome $\mathrm{P} 450$ aromatase, cell division cycle 42, LH receptor, and Sprouty homolog have been positively associated with increased oocyte competence (Robert et al., 2001; Robert et al., 2003; Hamel et al., 2008). However, in the current study, none of these markers were differentially abundant between follicle walls of small and large dominant follicles. Stage of follicular development may be a reason why the preceding granulosa cell markers were not different between follicle size groups, since follicles with a diameter of 3 to $8 \mathrm{~mm}$ were used in the preceding studies compared to dominant follicles in the current study. Alternatively, there may have been no difference in oocyte competence between the two follicle size groups since this was not determined in the present study.

Instead of investigating previously identified granulosa cell markers, we utilized RNA sequencing to provide a more comprehensive approach to identifying potential pathways that may affect acquisition of oocyte competence and(or) an adequate maternal environment. The follicle walls collected from dominant follicles classified as small $(<11.5 \mathrm{~mm})$ or large $(>12.5 \mathrm{~mm})$ were analyzed for differentially abundant transcripts; 
however, relatively few transcripts $(\mathrm{n}=11)$ were differentially abundant between follicle classifications and no significant pathways or functional GO terms were found. Consequently, while dominant follicle diameter may be used as a biomarker to predict pregnancy success in cows that have not expressed estrus, there does not appear to be a significant difference at the transcriptome level.

In Experiment 2a, there was an effect of dominant follicle diameter on concentrations of estradiol in follicular fluid but not circulation. Although there was a positive relationship between dominant follicle diameter at GnRH-induced ovulation and serum concentrations of estradiol in postpartum beef cows, there was also a significant amount of variation in circulating estradiol over a range of dominant follicle diameters (Jinks et al 2013). Heterogeneity of the follicular environment has been reported by others in cattle (Jiang et al., 2003), pigs (Hunter et al., 1989), and mice (Tilly, 2003).

Experiment $2 \mathrm{~b}$ compared the transcriptomes of follicles classified as having either low $(<4.0 \mathrm{pg} / \mathrm{ml})$ or high $(\geq 4.0 \mathrm{pg} / \mathrm{ml})$ serum estradiol $48 \mathrm{hr}$ after PG-induced luteolysis. Although no significant biological pathways were identified; a comparison of the frequency of the GO terms in our list of differentially abundant transcripts against the frequency of the GO term in the Bos taurus genome revealed several GO terms that were more highly represented in our data. GO terms more abundant in low estradiol follicles included terms associated with transcription (i.e. DNA-dependent transcription, transcription from RNA polymerase II promoter) and terms related to metabolic processes (i.e. primary metabolic process, nitrogen compound metabolic process). These data may indicate that follicular cells in small dominant follicles are continuing to 
differentiate; whereas, follicular cells producing higher concentrations of estradiol may be more mature.

Serum estradiol was different at 32, 40 and $48 \mathrm{hr}$ after PG in Experiment 2b, but intrafollicular estradiol concentrations and follicle size were not different. One explanation for the differences in serum and follicular fluid concentrations of estradiol is that follicles in the high estradiol classification may have had increased vascularity in the thecal compartment, which allows for greater access of estradiol to the circulation.

Healthy antral follicles $(3-7 \mathrm{~mm})$ have a greater number of capillaries present in the inner thecal layer with more active angiogenesis compared to smaller $(<3 \mathrm{~mm}$ ) follicles (Jiang et al., 2003). Large dominant follicles with greater intrafollicular estradiol:progesterone ratio also had more well-developed capillaries. Follicles with sparse capillaries are less developed and have an increased number of degenerative structures that likely play a role in atresia (Jiang et al., 2003).

In summary, a small number of transcripts were differentially abundant in the follicle wall of small versus large dominant follicles. However, no specific pathways were identified that might provide insight into how the physiological maturity of a dominant follicle can affect pregnancy rate. However, when comparisons were made between follicle walls from follicles with low or high serum estradiol, a greater number of transcripts were differentially expressed. A larger number of transcripts were more highly abundant in the low estradiol follicles, possibly indicating that a higher level of transcription is taking place in these follicles, implying that they may be less physiologically mature than the larger follicles. In addition, increased circulating 
concentrations of preovulatory estradiol, but not intrafollicular estradiol, may reflect increased vascularity in the high estradiol follicles classification. 


\section{APPENDIX}

\begin{tabular}{|c|c|c|c|c|}
\hline \multicolumn{5}{|c|}{ A.1. Summary of cumulus cell reads generated by deep sequencing ${ }^{a}$} \\
\hline $\begin{array}{c}\text { Sample } \\
\text { ID }^{b}\end{array}$ & Tissue Type & $\begin{array}{l}\text { Number of } \\
\text { raw reads }\end{array}$ & $\begin{array}{l}\text { Number of reads } \\
\text { mapped to the } \\
\text { genome }^{\mathrm{d}}\end{array}$ & $\begin{array}{l}\text { Percentage of } \\
\text { reads mapped to } \\
\text { the genome }\end{array}$ \\
\hline $\mathrm{CC} 1$ & Cumulus Cell Pool & 10639630 & 7885030 & $74.11 \%$ \\
\hline $\mathrm{CC} 1.1$ & Cumulus Cell Pool & 17706928 & 13405915 & $75.71 \%$ \\
\hline $\mathrm{CC} 2$ & Cumulus Cell Pool & 12133859 & 8854077 & $72.97 \%$ \\
\hline $\mathrm{CC} 2.1$ & Cumulus Cell Pool & 20791707 & 15502297 & $74.56 \%$ \\
\hline $\mathrm{CC} 3$ & Cumulus Cell Pool & 8564446 & 6524395 & $76.18 \%$ \\
\hline CC 3.1 & Cumulus Cell Pool & 13909577 & 10842515 & $77.95 \%$ \\
\hline $\mathrm{CC} 4$ & Cumulus Cell Pool & 10294385 & 7664170 & $74.45 \%$ \\
\hline CC4.1 & Cumulus Cell Pool & 17870971 & 13596235 & $76.08 \%$ \\
\hline $\mathrm{CC} 5$ & Cumulus Cell Pool & 12055018 & 9522259 & $78.99 \%$ \\
\hline CC5.1 & Cumulus Cell Pool & 19687527 & 15899647 & $80.76 \%$ \\
\hline $\mathrm{CC} 6$ & Cumulus Cell Pool & 9359596 & 7499844 & $80.13 \%$ \\
\hline CC6.1 & Cumulus Cell Pool & 16231077 & 13260790 & $81.70 \%$ \\
\hline $\mathrm{CC} 7$ & Cumulus Cell Pool & 11503611 & 8547183 & $74.30 \%$ \\
\hline CC7.1 & Cumulus Cell Pool & 20146386 & 15279019 & $75.84 \%$ \\
\hline $\mathrm{CC} 8$ & Cumulus Cell Pool & 12794065 & 8652626 & $67.63 \%$ \\
\hline CC 8.1 & Cumulus Cell Pool & 21313052 & 14735844 & $69.14 \%$ \\
\hline CC9 & Cumulus Cell Pool & 9094675 & 7207530 & $79.25 \%$ \\
\hline CC9.1 & Cumulus Cell Pool & 14639081 & 11838625 & $80.87 \%$ \\
\hline $\mathrm{CC} 10$ & Cumulus Cell Pool & 9961682 & 7961376 & $79.92 \%$ \\
\hline $\mathrm{CC} 10.1$ & Cumulus Cell Pool & 16990058 & 13853693 & $81.54 \%$ \\
\hline $\mathrm{CC} 11$ & Cumulus Cell Pool & 7416685 & 6238174 & $84.11 \%$ \\
\hline CC11.1 & Cumulus Cell Pool & 12601228 & 10824455 & $85.90 \%$ \\
\hline $\mathrm{CC} 12$ & Cumulus Cell Pool & 10587811 & 8157908 & $77.05 \%$ \\
\hline $\mathrm{CC} 12.1$ & Cumulus Cell Pool & 17963185 & 14154990 & $78.80 \%$ \\
\hline $\mathrm{CC} 13$ & Cumulus Cell Pool & 12140029 & 8455530 & $69.65 \%$ \\
\hline $\mathrm{CC} 13.1$ & Cumulus Cell Pool & 24160730 & 17381229 & $71.94 \%$ \\
\hline $\mathrm{CC} 14$ & Cumulus Cell Pool & 11379975 & 8736407 & $76.77 \%$ \\
\hline CC14.1 & Cumulus Cell Pool & 22725375 & 17859872 & $78.59 \%$ \\
\hline $\mathrm{CC} 15$ & Cumulus Cell Pool & 10821474 & 8318467 & $76.87 \%$ \\
\hline CC15.1 & Cumulus Cell Pool & 20878265 & 16439546 & $78.74 \%$ \\
\hline $\mathrm{CC} 16$ & Cumulus Cell Pool & 9790251 & 7633459 & $77.97 \%$ \\
\hline CC16.1 & Cumulus Cell Pool & 19478223 & 15487135 & $79.51 \%$ \\
\hline $\mathrm{CC} 17$ & Cumulus Cell Pool & 9340220 & 7147136 & $76.52 \%$ \\
\hline $\mathrm{CC} 17.1$ & Cumulus Cell Pool & 18718448 & 14589158 & $77.94 \%$ \\
\hline
\end{tabular}

${ }^{\mathrm{a}}$ Sequencing was performed on an Illumina HighSeq 2000. Cumulus cell pools were sequenced in a single lane, 100 base pairs per read, with adaptors removed at trimming.

${ }^{\mathrm{b}}$ Identification (ID) for each sample after first (CC1-17) and second (CC1.1-17.1) sequencing )

${ }^{\mathrm{c}}$ Total number of reads generated for each cumulus cell pool.

${ }^{\mathrm{d}}$ Number of reads that met the minimum criteria for quality and mapped to the Bos taurus (UMD3.1) genome.

${ }^{\mathrm{e}}$ Percentage of total reads (column 3 ) that met the minimum criteria and mapped to the genome. 
Table A.2. Most abundant transcripts in preovulatory cumulus cell pools ${ }^{\mathrm{a}}$

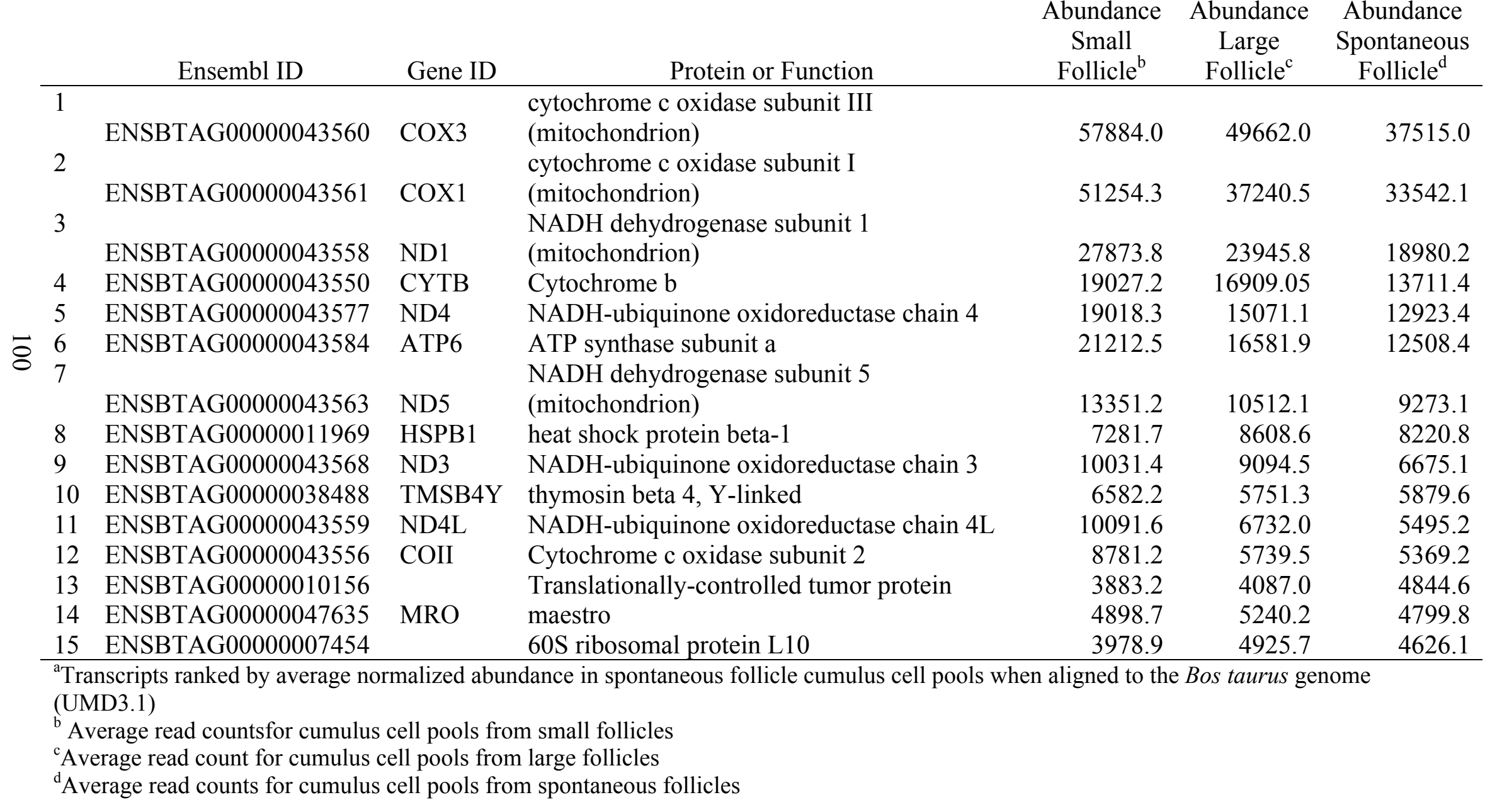




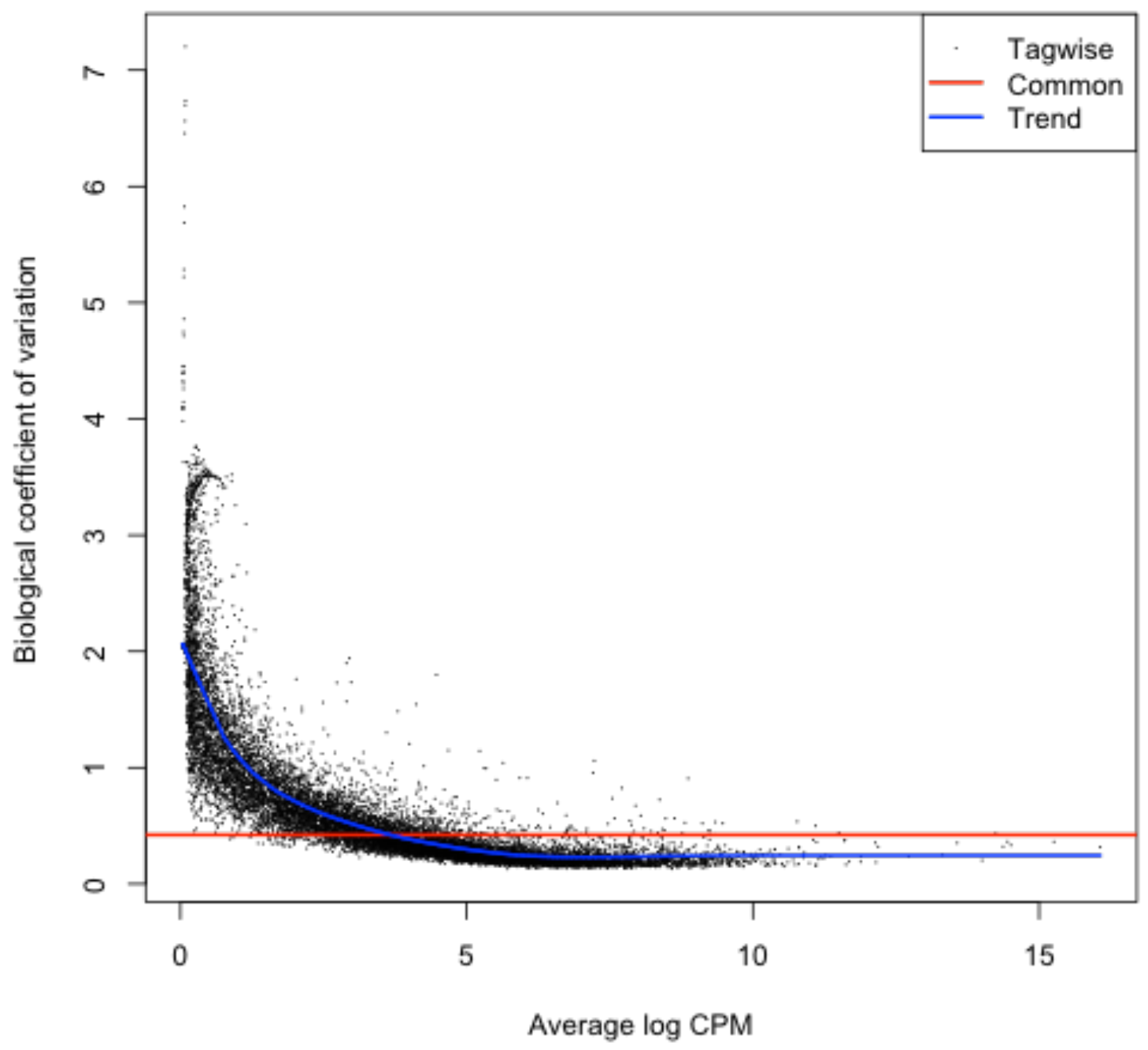

Figure A.1 . Graphical representation of the biological coefficient of variation (BCV) for replicates of small and large follicle cumulus cell pools when alignment was performed to the Bos taurus genome (UMD3.1). The BCV is the coefficient of variation measuring the (unknown) true amount of variation of a gene between replicates if sequencing depth was increased indefinitely. The $\mathrm{X}$-axis denotes average $\log 2$ counts per million for transcript abundance, and the $\mathrm{Y}$-axis denotes the $\mathrm{BCV}$. The red line signifies the overall BCV (0.42), black dots represent the BCV for each transcript, and the blue line is a fitted curve for BCV according to transcript abundance. 


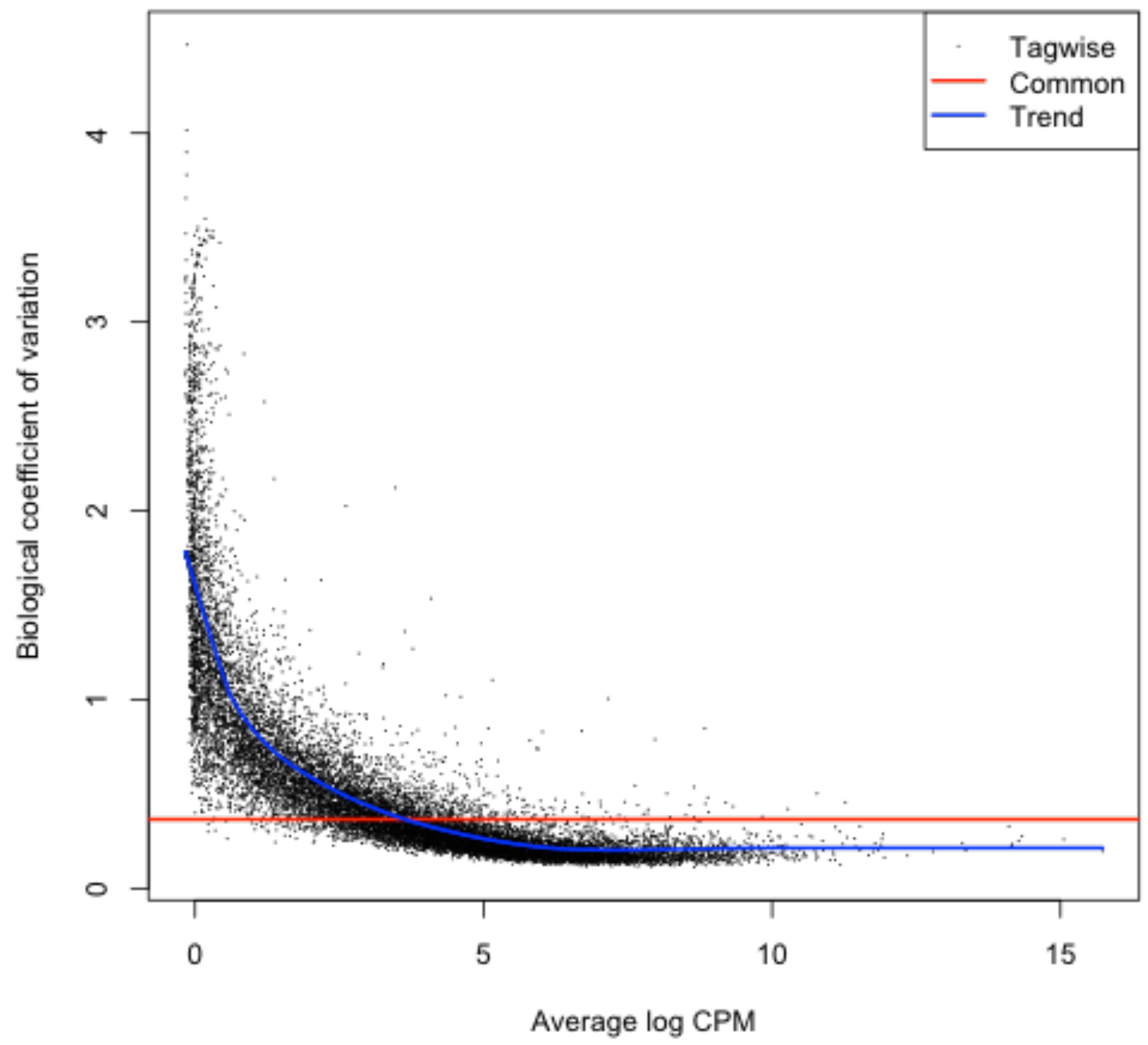

Figure A.2. Graphical representation of the biological coefficient of variation (BCV) for replicates of large and spontaneous follicle cumulus cell pools when alignment was performed to a Bos taurus genome (UMD3.1). The BCV is the coefficient of variation measuring the (unknown) true amount of variation of a gene between replicates if sequencing depth was increased indefinitely. The $\mathrm{X}$-axis denotes average $\log 2$ counts per million for transcript abundance, and the $\mathrm{Y}$-axis denotes the $\mathrm{BCV}$. The red line signifies the overall $\mathrm{BCV}(0.37)$, black dots represent the $\mathrm{BCV}$ for each transcript, and the blue line is a fitted curve for BCV according to transcript abundance. 


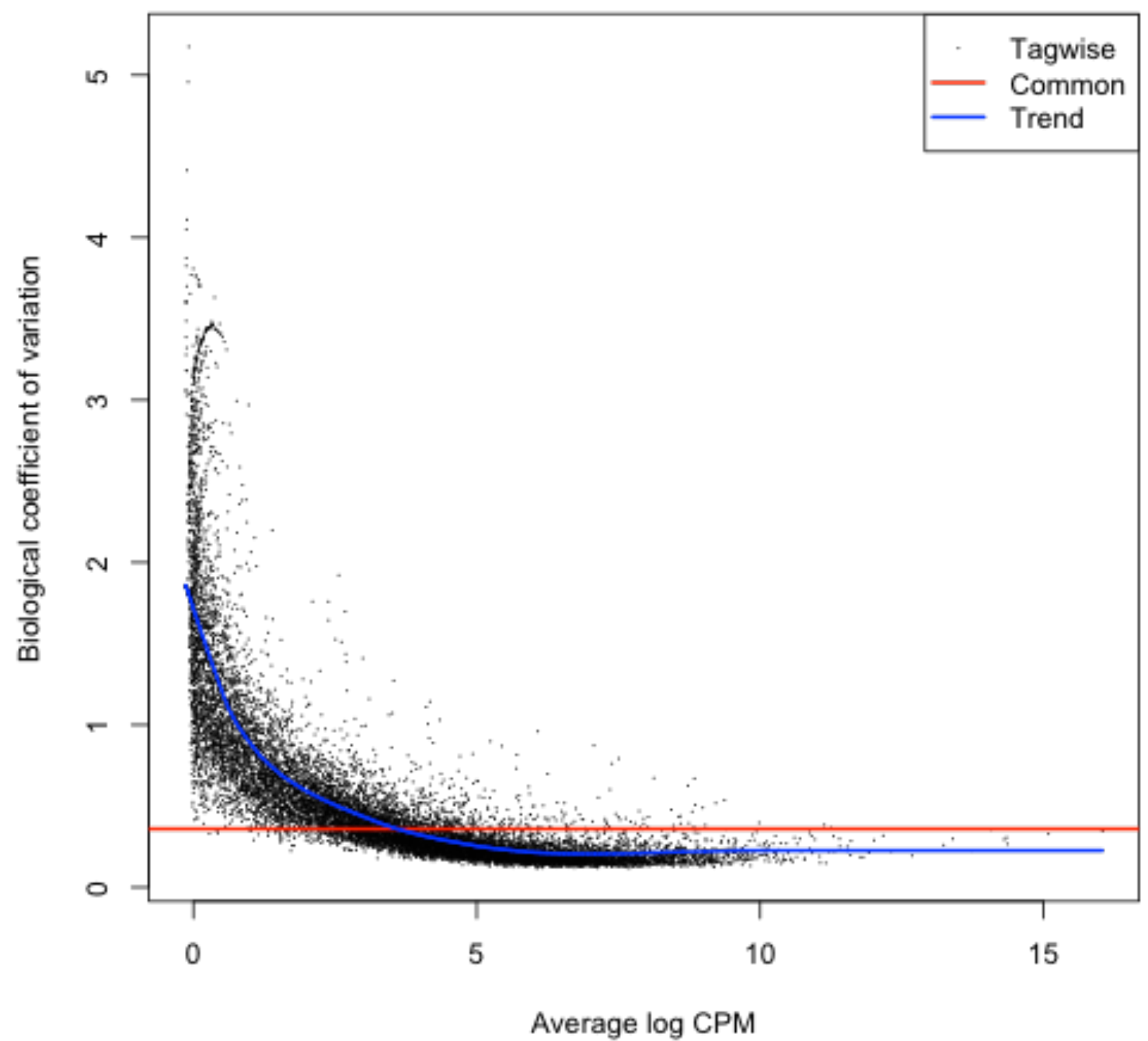

Figure A.3. Graphical representation of the biological coefficient of variation (BCV) for replicates of small and spontaneous follicle cumulus cell pools when alignment was performed to a Bos taurus genome (UMD3.1). The BCV is the coefficient of variation measuring the (unknown) true amount of variation of a gene between replicates if sequencing depth was increased indefinitely. The X-axis denotes average $\log 2$ counts per million for transcript abundance, and the $\mathrm{Y}$-axis denotes the $\mathrm{BCV}$. The red line signifies the overall BCV (0.36), black dots represent the BCV for each transcript, and the blue line is a fitted curve for BCV according to transcript abundance. 


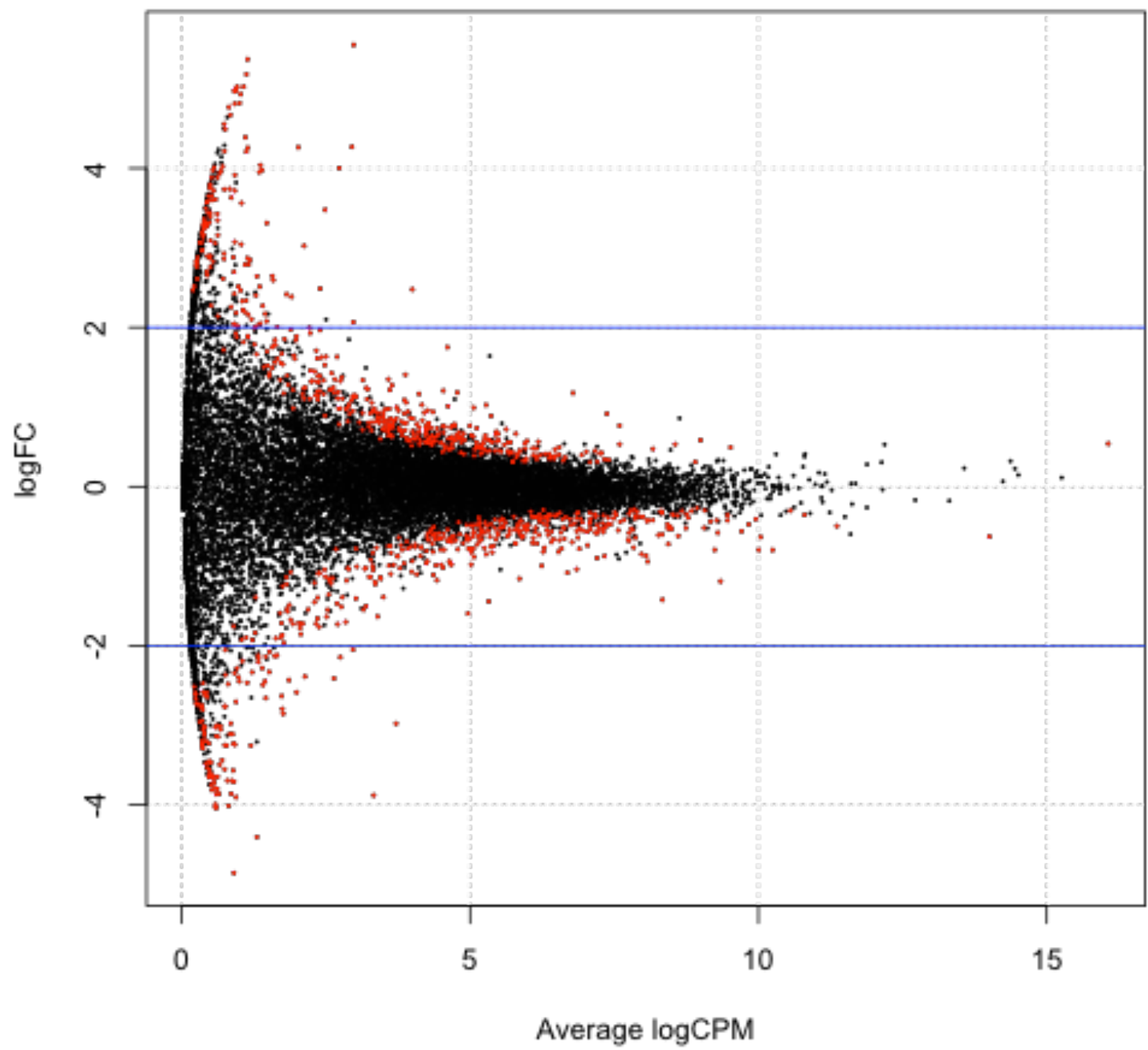

Figure A.4. Smear plot depicting differences in fold change for transcript abundance between small and large follicle cumulus cell pools as average transcript counts per million (CPM) increases. Transcripts were mapped to the Bos taurus genome (UMD3.1). $\mathrm{X}$-axis denotes average $\log 2$ counts per million for transcripts and the $\mathrm{Y}$-axis denotes the $\log 2$ of the ratio between the normalized edgeR robust read count values for small and large follicle cumulus cell pools $(-5=32$ fold higher in small follicle cumulus cell pools; $0=$ equal transcript abundance between follicle classifications; $5=32$ fold lower in small follicle cumulus cell pools). Each dot represents one transcript. Red dots denote transcripts significantly different between small and large follicle cumulus cell pools at FDR $<0.10$. 


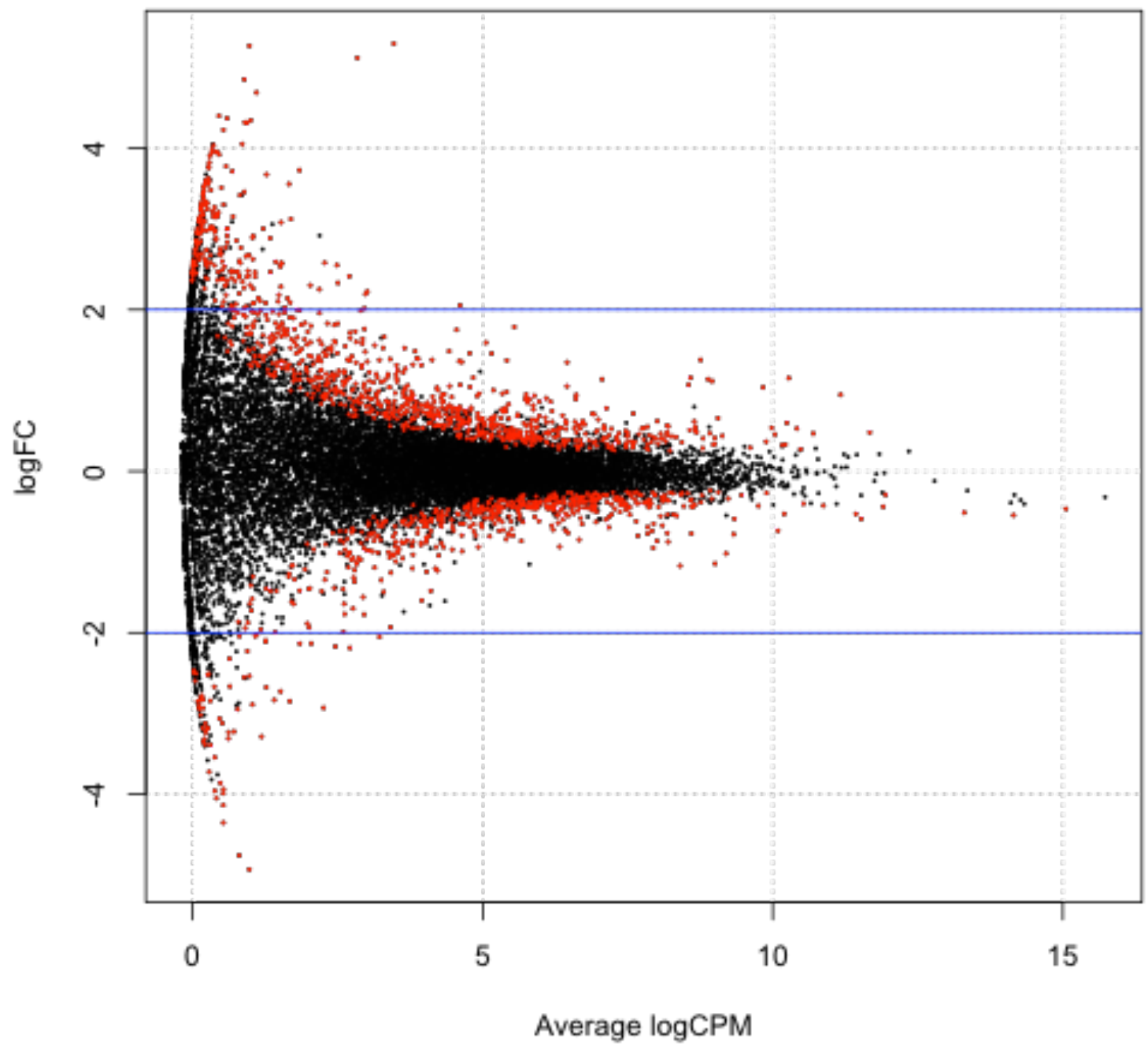

Figure A.5. Smear plot depicting differences in fold change for transcript abundance between large and spontaneous follicle cumulus cell pools as average transcript counts per million (CPM) increases. Transcripts were mapped to the Bos taurus genome (UMD3.1). X-axis denotes average $\log 2$ counts per million for transcripts and the $\mathrm{Y}$-axis denotes the $\log 2$ of the ratio between the normalized edgeR robust read count values for large and spontaneous follicle cumulus cell pools $(-5=32$ fold higher in large follicle cumulus cell pools; $0=$ equal transcript abundance between follicle classifications; $5=32$ fold lower in large follicle cumulus cell pools). Each dot represents one transcript. Red dots denote transcripts significantly different between large and spontaneous follicle cumulus cell pools at FDR $<0.10$. 


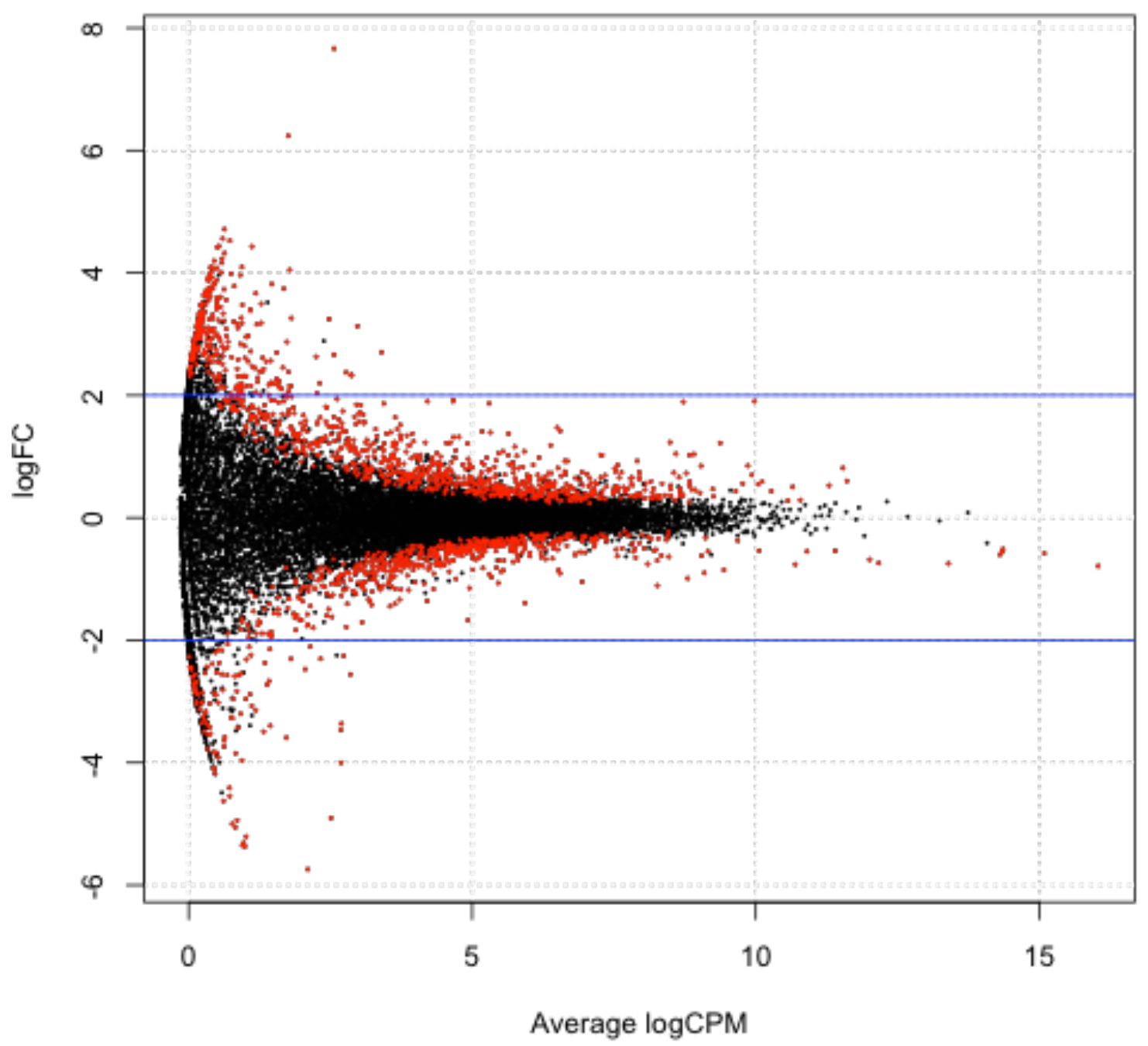

Figure A.6. Smear plot depicting differences in fold change for transcript abundance between small and spontaneous follicle cumulus cell pools as average transcript counts per million (CPM) increases. Transcripts were mapped to the Bos taurus genome (UMD3.1). X-axis denotes average log2 counts per million for transcripts and the $\mathrm{Y}$-axis denotes the $\log 2$ of the ratio between the normalized edgeR robust read count values for small and spontaneous follicle cumulus cell pools $(-5=32$ fold higher in small follicle cumulus cell pools; $0=$ equal transcript abundance between follicle classifications; $5=32$ fold lower in small follicle cumulus cell pools). Each dot represents one transcript. Red dots denote transcripts significantly different between small and spontaneous follicle cumulus cell pools at FDR $<0.10$. 
Table A.3. Summary of pre-gonadotropin surge follicle wall reads generated by deep sequencing ${ }^{\mathrm{a}}$

\begin{tabular}{ccccc}
$\begin{array}{c}\text { Sample } \\
\text { ID }^{\mathrm{b}}\end{array}$ & Tissue Type & $\begin{array}{c}\text { Number of raw } \\
\text { reads }^{\mathrm{c}}\end{array}$ & $\begin{array}{c}\text { Number of reads } \\
\text { mapped to the } \\
\text { genome }^{\mathrm{d}}\end{array}$ & $\begin{array}{c}\text { Percentage of reads } \\
\text { mapped to the } \\
\text { genome }^{\mathrm{e}}\end{array}$ \\
\hline 00386 & Follicle Wall & 42665153 & 40173508 & $94.16 \%$ \\
00750 & Follicle Wall & 47446324 & 45382409 & $95.65 \%$ \\
03708 & Follicle Wall & 41616197 & 39572842 & $95.09 \%$ \\
04638 & Follicle Wall & 46687325 & 44670433 & $95.68 \%$ \\
05644 & Follicle Wall & 48551166 & 46405204 & $95.58 \%$ \\
05676 & Follicle Wall & 43419141 & 41491331 & $95.56 \%$ \\
06612 & Follicle Wall & 43507979 & 41432648 & $95.23 \%$ \\
06799 & Follicle Wall & 41910055 & 39156564 & $93.43 \%$ \\
07860 & Follicle Wall & 44776119 & 42864179 & $95.73 \%$ \\
08851 & Follicle Wall & 41205783 & 39075444 & $94.83 \%$ \\
08998 & Follicle Wall & 48494697 & 46036016 & $94.93 \%$
\end{tabular}

${ }^{a}$ Sequencing was performed on an Illumina NextSeq 500. Follicle walls were

multiplexed, sequenced in a single lane, 75 paired end base pairs per read, with adaptors removed at trimming.

${ }^{\mathrm{b}}$ Cow identification (ID) for each sample

${ }^{\mathrm{c}}$ Total number of reads generated for each follicle wall.

${ }^{\mathrm{d}}$ Number of reads that met the minimum criteria for quality score and read length and mapped to the Bos taurus (UMD3.1) genome.

${ }^{\mathrm{e}}$ Percentage of total reads (column 3 ) that met the minimum criteria for quality score and read length and mapped to the genome. 
Table A.5. Most abundant transcripts in the pre-gonadotropin surge follicle wall ${ }^{\mathrm{a}}$

\begin{tabular}{|c|c|c|c|c|c|}
\hline & Ensembl ID & Gene ID & Protein or Function & $\begin{array}{l}\text { Abundance Small } \\
\text { Follicle Walls }\end{array}$ & $\begin{array}{l}\text { Abundance Large } \\
\text { Follicle Walls }{ }^{\mathrm{c}}\end{array}$ \\
\hline 2 & ENSBTAG00000013103 & COL1A1 & collagen type I alpha 1 chain & 339416.5 & 501335.3 \\
\hline 3 & ENSBTAG00000013472 & COL1A2 & collagen type I alpha 2 chain & 292621.8 & 478204.0 \\
\hline 4 & ENSBTAG00000009972 & INHA & inhibin alpha subunit & 523717.5 & 428384.0 \\
\hline 5 & ENSBTAG00000014835 & SPARC & $\begin{array}{l}\text { secreted protein acidic and cysteine rich } \\
\text { cytochrome P450 family } 19 \text { subfamily A }\end{array}$ & 200586.0 & 318850.4 \\
\hline 6 & ENSBTAG00000014890 & CYP19A1 & member 1 & 237123.5 & 307961.1 \\
\hline 7 & ENSBTAG00000021466 & COL3A1 & collagen alpha-1(III) chain precursor & 198613.5 & 284538.0 \\
\hline 8 & ENSBTAG00000014534 & EEF1A1 & Elongation factor 1 -alpha 1 & 280077.0 & 281134.3 \\
\hline 9 & ENSBTAG00000008717 & SERPINE2 & serpin family $\mathrm{E}$ member 2 & 333362.3 & 239603.3 \\
\hline 10 & ENSBTAG00000004258 & EEF2 & $\begin{array}{l}\text { eukaryotic translation elongation factor } 2 \\
\text { cytochrome c oxidase subunit III }\end{array}$ & 240000.8 & 233921.3 \\
\hline 11 & ENSBTAG00000043560 & $\mathrm{COX} 3$ & (mitochondrion) & 205416.5 & 220930.6 \\
\hline 12 & ENSBTAG00000017389 & RPLP0 & ribosomal protein lateral stalk subunit P0 & 198599.5 & 209508.6 \\
\hline 13 & ENSBTAG00000025775 & INSL3 & insulin like 3 & 224236.8 & 182116.4 \\
\hline 14 & ENSBTAG00000002912 & INHBA & $\begin{array}{l}\text { inhibin beta A subunit } \\
\text { heat shock protein family A (Hsp } 70)\end{array}$ & 269474.0 & 178166.0 \\
\hline 15 & ENSBTAG00000013162 & HSPA8 & member 8 & 161511.8 & 174803.0 \\
\hline
\end{tabular}


Table A.6. Known granulosa cell markers of oocyte competence

\begin{tabular}{|l|l|r|r|}
\hline \multicolumn{1}{|c|}{ Gene } & \multicolumn{1}{c|}{ Reference } & $\begin{array}{c}\text { Small vs } \\
\text { Large }^{\mathrm{a}}\end{array}$ & $\begin{array}{c}\text { Low vs } \\
\text { High }^{\mathrm{b}}\end{array}$ \\
\hline 3 beta-hydroxysteroid dehydrogenase & Hamel et al., 2008 & 0.72 & 1.00 \\
\hline ferredoxin 1 & Hamel et al., 2008 & 1.00 & 1.00 \\
\hline $\begin{array}{l}\text { cytochrome P450 family 19 subfamily } \\
\text { A member 1 }\end{array}$ & Hamel et al, 2008 & 1.00 & 1.00 \\
\hline cell division cycle 42 & Hamel et al., 2008 & 1.00 & 0.96 \\
\hline serpin family E member 2 & Hamel et al, 2008 & 1.00 & 1.00 \\
\hline phosphoglycerate kinase 1 & Hamel et al., 2010 & 1.00 & 1.00 \\
\hline $\begin{array}{l}\text { Bos taurus regulator of G-protein } \\
\text { signaling 2 }\end{array}$ & Hamel et al., 2010 & 1.00 & 0.42 \\
\hline
\end{tabular}

${ }^{\mathrm{a}}$ False discovery rate for known granulosa cell markers when comparing follicle walls from large and small follicles collected before the preovulatory gonadotropin surge.

${ }^{b}$ False discovery rate for known granulosa cell markers when comparing follicle walls from follicles with low or high serum estradiol. 


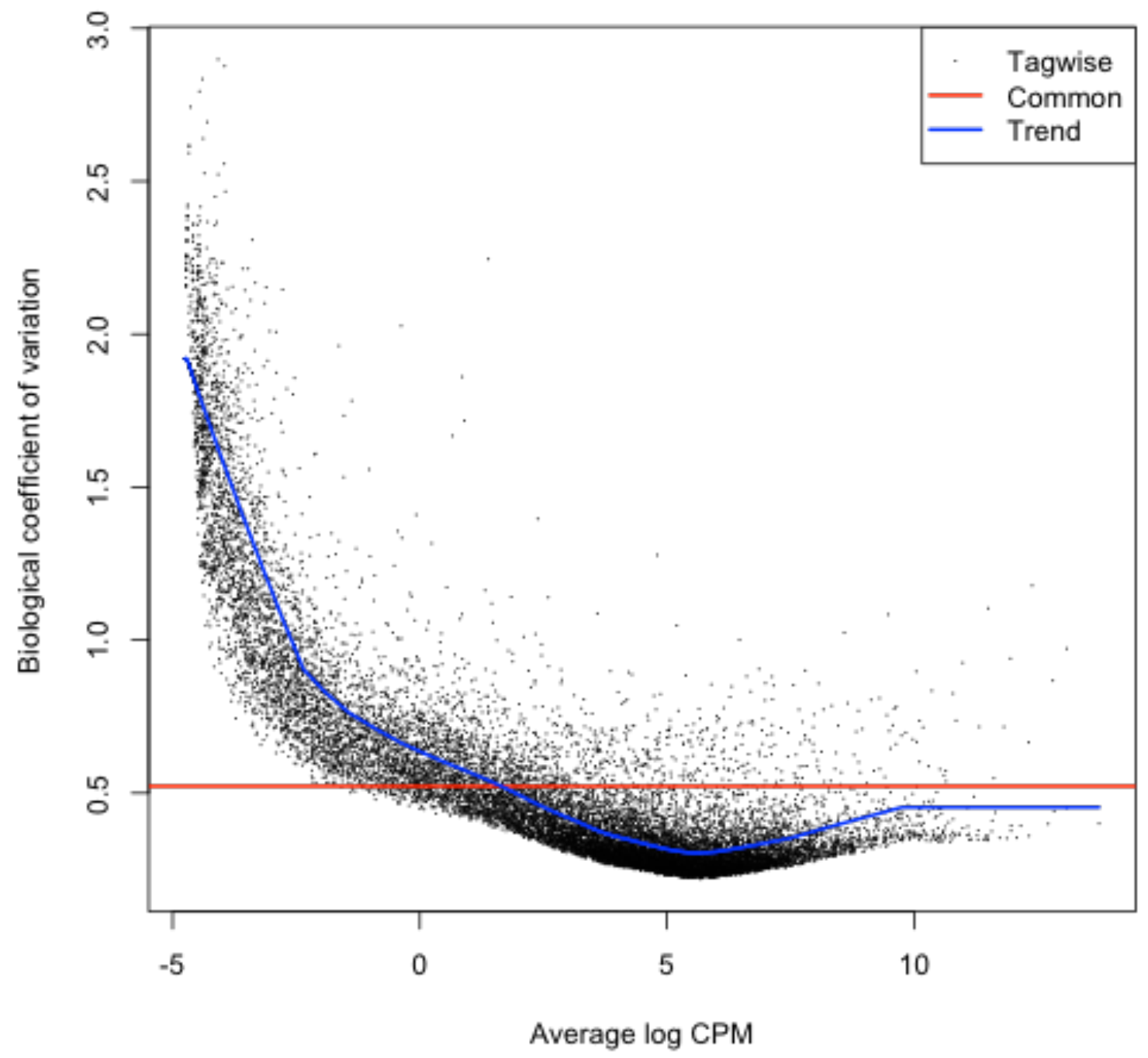

Figure A.7. Graphical representation of the biological coefficient of variation (BCV) for replicates of small and large follicle classification follicle walls when alignment was performed to the Bos taurus genome UMD3.1. The BCV is the coefficient of variation measuring the (unknown) true amount of variation of a gene between replicates if sequencing depth was increased indefinitely. The $\mathrm{X}$-axis denotes average $\log 2$ counts per million for transcript abundance, and the $\mathrm{Y}$-axis denotes the $\mathrm{BCV}$. The red line signifies the overall $\mathrm{BCV}(0.52)$, black dots represent the BCV for each transcript, and the blue line is a fitted curve for BCV according to transcript abundance. 


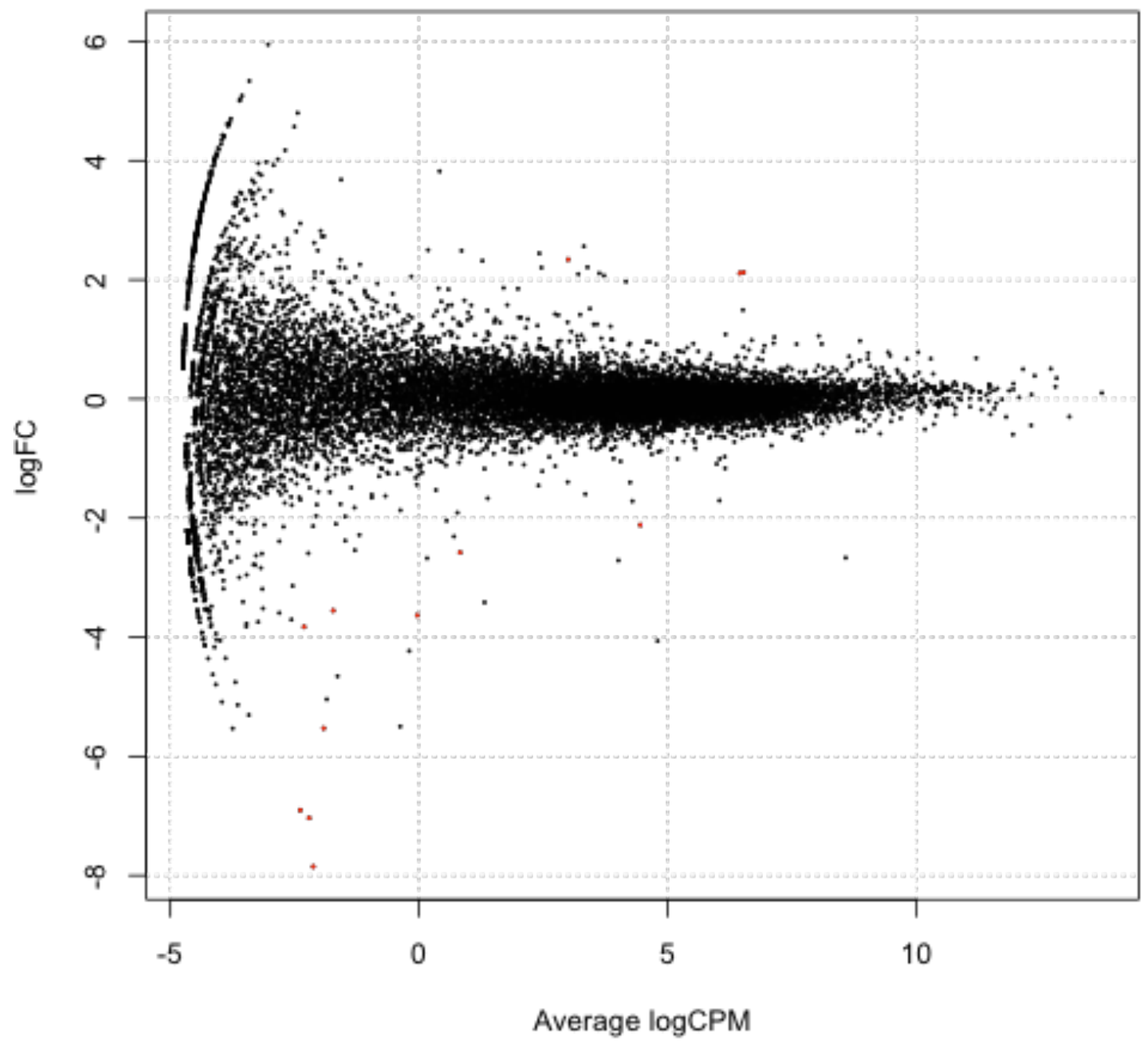

Figure A.8. Smear plot depicting differences in fold change for transcript abundance between small and large follicle classification follicle walls as average transcript counts per million (CPM) increases. Transcripts were mapped to the Bos taurus genome (UMD3.1). X-axis denotes average $\log 2$ counts per million for transcripts and the $\mathrm{Y}$-axis denotes the $\log 2$ of the ratio between the normalized edgeR robust read count values for small and large follicle walls $(-5=32$ fold higher in small follicles ; $0=$ equal transcript abundance between follicle classifications; $5=32$ fold lower in small follicles). Each dot represents one transcript. Red dots denote transcripts significantly different between small and large follicle classification follicle walls at FDR $<0.10$. 


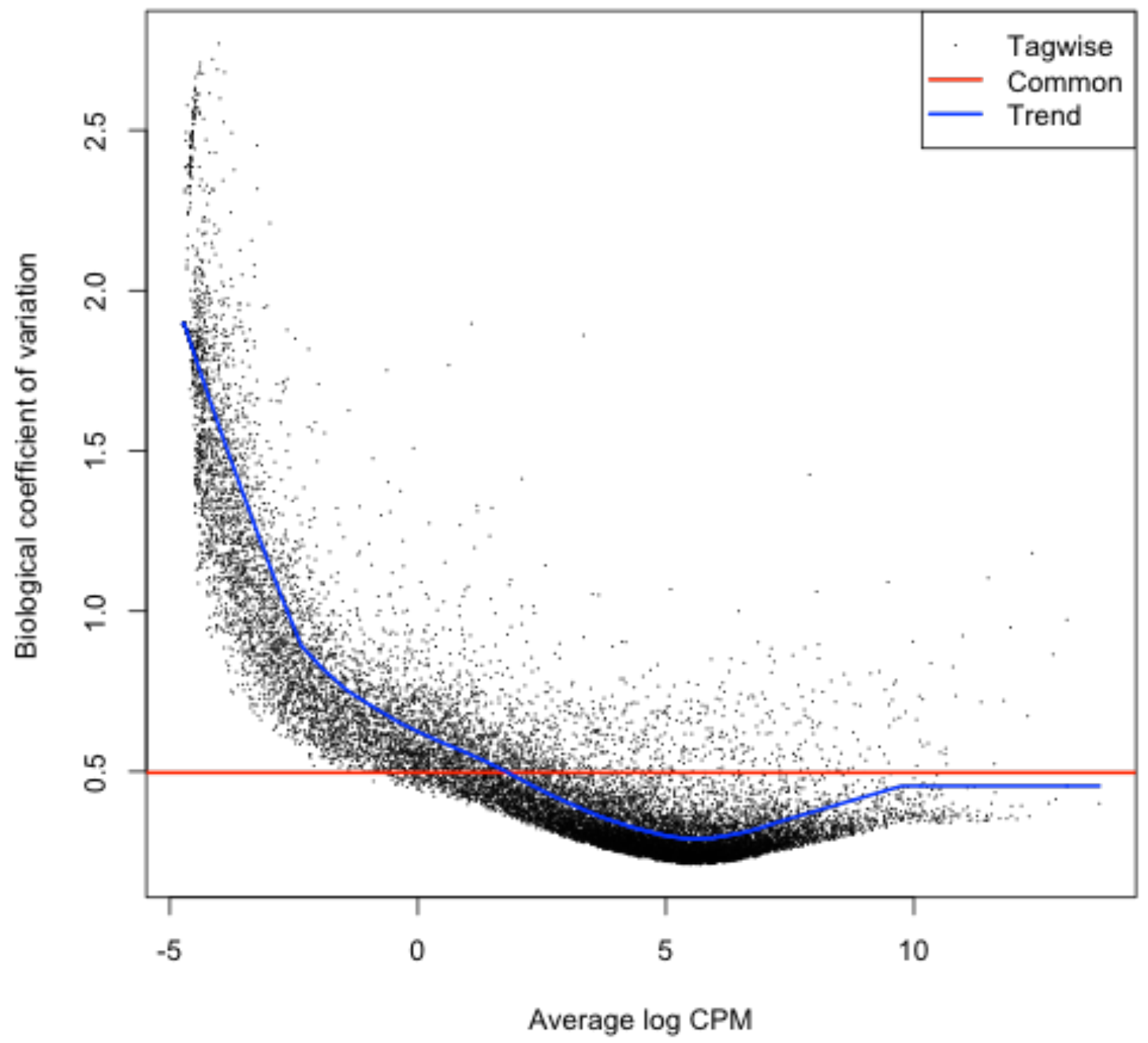

Figure A.9. Graphical representation of the biological coefficient of variation (BCV) for replicates of low and high estradiol classification follicle walls when alignment was performed to the Bos taurus genome UMD3.1. The BCV is the coefficient of variation measuring the (unknown) true amount of variation of a gene between replicates if sequencing depth was increased indefinitely. The $\mathrm{X}$-axis denotes average $\log 2$ counts per million for transcript abundance, and the $\mathrm{Y}$-axis denotes the $\mathrm{BCV}$. The red line signifies the overall $\mathrm{BCV}(0.50)$, black dots represent the $\mathrm{BCV}$ for each transcript, and the blue line is a fitted curve for BCV according to transcript abundance. 


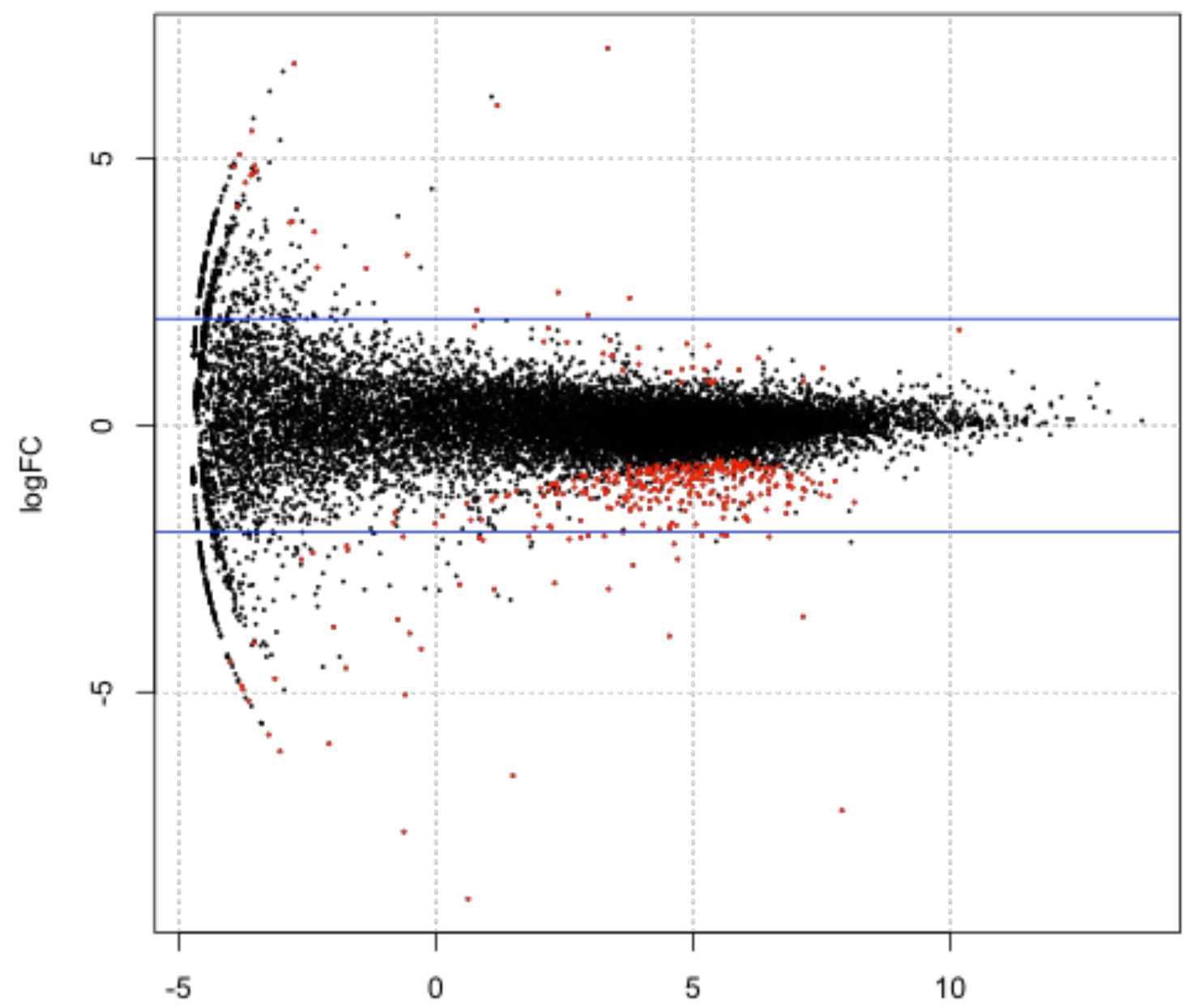

Average logCPM

Figure A.10. Smear plot depicting differences in fold change for transcript abundance between low and high estradiol classification follicle walls as average transcript counts per million (CPM) increases. Transcripts were mapped to the Bos taurus genome (UMD3.1). X-axis denotes average $\log 2$ counts per million for transcripts and the $\mathrm{Y}$-axis denotes the $\log 2$ of the ratio between the normalized edgeR robust read count values for low and high estradiol follicle walls $(-5=32$ fold higher in low estradiol follicles ; $0=$ equal transcript abundance between follicle classifications; $5=32$ fold lower in low estradiol follicles). Each dot represents one transcript. Red dots denote transcripts significantly different between low and high estradiol classification follicle walls at FDR $<0.10$. 


\section{LITERATURE CITED}

Albertini, D.F., C.M. Combelles, E. Benecchi, and M.J. Carabatsos. 2001. Cellular basis for paracrine regulation of ovarian follicle development. Reproduction 121:647653.

Arlotto, T., J.-L. Schwartz, N.L. First, and M.L. Leibfried-Rutledge. 1996. Aspects of follicle and oocyte stage that affect in vitro maturation and development of bovine oocytes. Theriogenology 45: 943-956.

Armstrong, D.T., P. Xia, G. de Gannes, F.R. Tekpetey, and F. Khamsi. 1996. Differential effects of insulin-like growth factor-I and follicle-stimulating hormone on proliferation and differentiation of bovine cumulus cells and granulosa cells. Biol Reprod 54(2): 331-338.

Asdell, J.A., J. de Alba, and J.S. Roberts. 1945. The levels of ovarian hormones required to induce heat and other reactions in the ovariectomized cow. J Anim Sci 4: 277284.

Assidi, M., I. Dufort, A. Ali, M. Hamel, O. Algriany, S. Dielemann, and M.-A. Sirard. 2008. Identification of potential markers of oocyte competence expressed in bovine cumulus cells matured with follicle-stimulatin hormone and/or phorbol myristate acetate in vitro. Biol Reprod 79: 209-222.

Assidi, M., S.J. Dieleman, and M.-A. Sirard. 2010. Cumulus cell gene expression following the LH surge in bovine preovulatory follicles: potential early markers of oocyte competence. Reproduction 140: 835-852.

Atkins, J.A., D.C. Busch, J.F. Bader, D.H. Keisler, D.J. Patterson, M.C. Lucy, and M.F. Smith. 2008. Gonadotropin-releasing hormone-induced ovulation and luteinizing hormone release in beef heifers: effect of day of the cycle. J Anim Sci 86(1): 8393.

Atkins, J.A., M.F. Smith, M.D. MacNeil, E.M. Jinks, F.M. Abreu, L.J. Alexander, and T.W. Geary. 2013. Pregnancy establishment and maintenance in cattle. J Anim Sci 91: 722-733.

Bavister, B. D., and J. M. Squirrell. 2000. Mitochondrial distribution and function in oocytes and early embryos. Human Reproduction 15: 19-198.

Beker-van Woudenberg, A.R., H.T.A. van Tol, B.A.J. Roelen, B. Colenbrander, and M.M. Bevers. 2004. Estradiol and its membrane-impremeable conjugate (estradiol-bovine serum albumin) during in vitro maturation of bovine oocytes: effects on nuclear and cytoplasmic maturation, cytoskeleton, and embryo quality. Biol Reprod 70: 1465-1474. 
Beker-van Woudenberg, A.R., E.C. Zeinstra, B.A. Roelen, B. Colenbrander, and M.M. Bevers. 2006. Developmental competence of bovine oocytes after specific inhibiion of MPF kinase activity: effect of estradiol supplementation and follicle size. Anim Reprod Sci 92(3-4): 231-240.

Bettegowda, A., O.V. Patel, K.B. Lee, K.E. Park, M. Salem, J. Yao, J.J. Ireland, and G.W. Smith. 2008. Identification of novel bovine cumulus cell molecular markers predictive of oocyte competence: functional and diagnostic implications. Biol Reprod 79(2): 301-309.

Binelli M., R. Sartori, J.L.M. Vasconcelos, P.L.J. Monteiro Jr., M.H.C. Pereira, and R.S. Ramos. 2014. Evolution in fixed-time: from synchronization of ovulation to improved fertility. In: 2014 Proceedings 9th International Ruminant Reproduction Symposium. Burton-On-Trent, UK: Context 493-506.

Bridges, G.A., L.A. Hlser, D.E. Grum, M.L. Mussard, C.L. Gasser, and M.L. Day. 2008. Decreasing the interval between GnRH and PGF2 $\alpha$ from 7 to 5 days and lengthening proestrus increases timed-AI pregnancy rates in beef cows. Theriogenology 69: 843-851.

Bridges, G.A., M.L. Mussard, C.R. Burke, and M.L. Day. 2010. Influence of the length of proestrus on fertility and endocrine function in female cattle. Anim Reprod Sci 117: 208-215.

Bridges, G.A., M.L. Mussard, J.L. Pate, T.L. Ott, T.R. Hansen, and M.L. Day. 2012. Impact of preovulatory estradiol concentrations on conceptus development and uterine gene expression. Anim Reprod Sci 133: 16-26.

Brooks, K., G. Burns, and T.E. Spencer. 2014. Conceptus elongation in ruminants: roles of progesterone, prostaglandin, interferon tau, and cortisol. J Anim Sci Biotech 5: 53.

Buschiazzo, J., C. Ialy-Radio, J. Auer, J.-P. Wolf, C. Serres, B. Lefévre, and A. Ziyyat. 2013. Cholesterol depletion disorganizes oocyte membrane rafts altering mouse fertilization. PLOS One 8(4) : e62919.

Cetica, P., L. Pintos, G. Dalvit, and M. Beconi. 2002. Activity of key enzymes involved in glucose and triglyceride catabolism during bovine oocyte maturation in vitro. Reproduction 124: 675-681.

Chomczynski, P. and N. Sacchi. 1987. Single-step method of RNA isolation by acid guanidinium thiocyanate-phenol-chloroform extraction. Anal Biochem 162(1): 156-159. 
Clemente, M., J. de La Fuente, T. Fair, A. Al Naib, A. Gutierrez-Adan, J.F. Roche, D. Rizos, and P. Lonergan. 2009. Progesterone and conceptus elongation in cattle: a direct effect on the embryo or an indirect effect via the endometrium? Reproduction 138: 507-517.

Cushman, R.A., L.K. Kill, R.N. Funston, E.M. Mousel, and G.A. Perry. 2013. Heifer calving date positively influences calf weaning weights through six parturitions. J Anim Sci 91: 4486-4491.

Day, M.L. 2004. Hormonal induction of estrous cycles in anestrous Bos taurus beef cows. Anim Reprod Sci 82-83: 487-494.

Dickinson, S.E. 2016. Effect of pre-ovulatory follicle size on oocyte transcript abundance in beef cows. Master's Thesis. University of Missouri-Columbia.

Dickinson, S.E., T.W. Geary, J.M. Monnig, K.G. Pohler, J.A. Green, and M.F. Smith. 2016. Effect of preovulatory follicle maturithy on pregnancy establishment in cattle: the role of oocyte competence and maternal environment. Anim Reprod 13(3): 209-216.

Downs, S.M., P.G. Humpherson, K.L. Martin, and H.J. Leese. 1996. Glucoseutilization during gonadotropin-induced meiotic maturation in cumulus cell-enclosed mouse oocytes. Mol Reprod 44: 121-131.

Eppig, J.J. 2001. Oocyte control of ovarian follicular development and function in mammals. Reprod 122: 829-838.

Fair, T., P. Hyttel, and T. Greve. 1995. Bovine oocyte diameter in relation to maturational competence and transcriptional activity. Mol Reprod Dev 42(4): 437-442.

Fair, T., P. Hyttel, T. Greve, and M. Boland. 1997. Nucleus ultrastructure and transcriptional activity of bovine oocytes in preantral and early antral follicles. Mol Reprod Dev 46: 208-215.

Fair, T. 2003. Follicular oocyte growth and acquisition of developmental competence. Animal Reproduction Science 78: 203-216.

Ferreira, E.M., A.A. Vireque, P.R. Adona, F.V. Meirelles, R.A. Ferriani, and P.A.A.S. Navarro. 2009. Cytoplasmic maturation of bovine oocytes: structural and biochemical modifications and acquisition of developmental competence. Theriogenology 71: 836-848.

Fortune, J.E., M.Y. Yang, and W. Muruvi. 2010. The earliest stages of follicular development: Follicle formation and activation. Soc Reprod Fertil Suppl 67: 203-216. 
Fortune, J.E., M.Y. Yang, and W. Muruvi. 2011. In vitro and in vivo regulation of follicular formation and activation in cattle. Reprod Fertil Dev 23(1): 15-22.

Fortune, J.E., M.Y. Yang, J.J. Allen, and S.L. Herrick. 2013. The ovarian follicular reserve in cattle: What regulates its formation and size? J Anim Sci 91(7): 30413050 .

Gilchrist, R.B., L.J. Ritter, and D.T. Armstrong. 2004. Oocyte-somatic cell interactions during follicle development in mammals. Anim Reprod Sci 83-83: 431-446.

Goodman, R.L., and F.J. Karsch. 1980. Pulsatile secretion of luteinizing hormone: differential suppression by ovarian steroids. Endocrinology 107(5): 1286-1290.

Hamel M, I. Dufort, C. Robert, C. Gravel, M-C Leveille, A. Leader, M-A Sirard. 2008. Identification of differentially expressed markers in human follicular cells associated with competent oocytes. Hum Reprod 23: 1118-1127.

Hamel, M., I. Dufort, C. Robert, M.C. Léveillé, A. Leader, M-A Sirard. 2010. Genomic assessment of follicular marker genes as pregnancy predictors for human IVF. Mol Hum Reprod 16(2): 87-96.

Hawk, H. W. 1983. Sperm survival and transport in the female reproductive tract. J Dairy Sci 66: 852-858.

Herrick, J.R., A.M. Brad, and R.L. Krisher. 2006. Chemical manipulation of glucose metabolism in porcine oocytes: effects on nuclear and cyoplasmic maturation in vitro. Reproduction 131: 289-298.

Huang, D.W., B.T. Sherman, and R.A. Lempicki. 2009a. Systematic and integrative analysis of large gene lists using DAVID Bioinformatics Resources. Nature Protoc 4(1): 44-57.

Huang, D.W., B.T. Sherman, and R.A. Lempicki. 2009b. Bioinformatics enrichment tools: paths toward the comprehensive functional analysis of large gene lists. Nucleic Acids Res 37(1): 1-13.

Hunter, M.G., S.A. Grant, and G.R. Foxcroft. 1989. Histological evidence for heterogeneity in the development of preovulatory pig follicles. J Reprod Fert 86: 165-170.

Hyttel, P., T. Fair, H. Callesen, and T. Greve. 1997. Oocyte growth, capacitation and final maturation in cattle. Theriogenology 47: 23-32.

Ing, N.H., and M.B. Tornesi. 1997. Estradiol up-regulates estrogen receptor and progesterone receptor gene expression in specific ovine uterine cells. Biol Reprod 56(5): 1205-1215. 
Jiang, J.Y., G. Macchiarelli, B.K. Tsang, and E. Sato. 2003. Capillary angiogenesis and degeneration in bovine ovarian antral follicles. Reproduction 125: 211-223.

Jinks, E. M., M. F. Smith, J. A. Atkins, K. G. Pohler, G. A. Perry, M. D. MacNeil, A. J. Roberts, R. C. Waterman, L. J. Alexander, and T. W. Geary. 2013. Preovulatory estradiol and the establishment and maintenance of pregnancy in suckled beef cows. J Anim Sci 91: 1176-1185.

Juengel, J.L., H.R. Sawyer, P.R. Smith, L.D. Quirke, D.A. Heath, S. Lun, S.J. Wakefield, and K.P. McNatty. 2002a. Origins of follicular cells and ontogeny of steroidogenesis in ovine fetal ovaries. Mol Endocrinol 191: 1-10.

Juengel, J.L., N.L. Hudson, D.A. Heath, P. Smith, K.L. Reader, S.B. Lawrence, A.R. O’Connell, M.P. Laitinen, M. Cranfield, N.P. Groome, O. Ritvos, and K.P. McNatty. 2002b. Growth differentiation factor 9 and bone morphogenic protein q5 are essential for ovarian follicular development in sheep. Biol Reprod 67 (6): 1777-1789.

Juengel, J.L., N.L. Hudson, M. Berg, K. Hamel, P. Smith, S.B. Lawrence, L. Whiting, and K.P. McNatty. 2009. Effects of active immunization against growth differentiation factor 9 and/or bone morphogenetic protein 15 on ovarian function in cattle. Reproduction 138: 107-114.

Kesner, J.S., E.M. Convey, and C.R. Anderson. 1981. Evidence that estradiol induces the preovulatory LH surge in cattle by increasing pituitary sensitivity to LHRH and then increasing LHRH release. Endocrinology 108: 1386-1391.

Kidder, G.M., and B.C. Vanderhyden. 2010. Bidirectional communication between oocytes and follicle cells: ensuring oocyte developmental competence. Can J Physiol Pharmacol 88(4): 399-413.

Kim, D., B. Langmead, and S.L. Salzberg. 2015. HISAT: a fast spliced aligner with low memory requirements. Nat Methods 12(4): 357-360.

Kirby, C.J., M.F. Smith, D.H. Keisler, and M.C. Lucy. 1997. Follicular function in lactating dairy cows treated with sustained-release bovine somatotropin. J Dairy Sci 80(2): 273-285.

Krishner, R.L. and B.D. Bavister. 1999. Enhanced glycolysis after maturation of bovine oocytes in vitro is associated with increased developmental competence. Mol Reprod Devel 53: 1-19.

Kussano, N.R., L.O. Leme, A.L. Guimarães, M.M. Franco, and M.A. Dode. 2016. Molecular markers for oocyte competence in bovine cumulus cells. Theriogenology 85(6): 1167-1176. 
Lamb, G.C., J.S. Stevenson, D.J. Kesler, H.A. Garverick, D.R. Brown, and B.E. Salfen. 2001. Inclusion of an intravaginal progesterone insert plus GnRH and Prostaglandin F2a for ovulation control in postpartum suckled beef cows. J Anim Sci 79: 2253-2259.

Liao Y., G.K. Smyth, and W. Shi. 2014. featureCounts: an efficient general purpose program for assigning sequence reads to genomic features. Bioinformatics 30(7): 923-30.

Lonergan, P., A. Gutierrez-Adan, D. Rizos, B. Pintado, J. De La Fuente, and M.P. Boland. 2003. Relative messenger RNA abundance in bovine oocytes collected in vitro or in vivo before and $20 \mathrm{hr}$ after the preovulatory luteinizing hormone surge. Mol Reprod Dev 66: 297-305.

Lucy, M. C. 2007. The bovine dominant ovarian follicle. J Anim Sci 85: E89-E95.

Macaulay, A.D., I. Gilbert, J. Caballero, R. Barreto, E. Fournier, P. Tossou, M-A. Sirard, H. J. Clarke, E. W. Khandjian, F. J. Richard, P. Hyttel, and C. Robert. 2014. The Gametic Synapse: RNA Transfer to the Bovine Oocyte. Biol Reprod 91(4):90, 112.

Macaulay, A.D., I. Gilbert, S. Scantland, E. Fournier, F. Ashkar, A. Bastien, H.A. Saadi, D. Gagné, M.-A. Sirard, É.W. Khandjian, F.J. Richard, P. Hyttel, and C. Robert. 2016. Cumulus cell transcripts transit to the bovine oocyte in preparation for maturation. Biol Reprod 94(1): 16, 1-11.

Marteil, G., L. Richard-Parpaillon, and J.Z. Kubiak. 2009. Role of oocyte quality in meiotic maturation and embryonic development. Reproductive Biology 9: 20324.

Matoba, S., K. Bender, A.G. Fahey, S. Mamo, L. Brennan, P. Lonergan, and T. Fair. 2013. Predictive value of bovine follicular components as markers of oocyte developmental potential. Reprod Fert Devel 26(2): 337-345.

McNatty, K.P., J.L. Juengel, K.L. Reader, S. Lun, S. Myllymaa, S.B. Lawrence, A. Western, M.F. Meerasahib, D.G. Mottershead, N.P. Groome, O. Ritvos, and M.P. Laitinen. 2005. Bone morphogenetic protein 15 and growth differentiation factor 9 co-operate to regulate granulosa cell function in ruminants. Reproduction 129(4): 481-487.

Mermillod, P., B. Oussaid, and Y. Cognié. 1999. Aspects of follicular and oocyte maturation that affect the developmental potential of embryos. J Reprod Fertil Suppl 54: 449-460. 
Mi, H., Q. Dong, A. Muruganujan, P. Gaudet, S. Lewis, and P.D. Thomas. 2010. PANTHER version 7: improved phylogenetic trees, orthologs, and collaboration with the Gene Ontology Consortium. Nucl. Acids Res 38: D204-D210.

Oren-Benaroya, R., R. Orvieto, A. Gakamsky, M. Pinchasov, and M. Eisenbach. 2008. The sperm chemoattractant secreted from human cumulus cells is progesterone. Hum Reprod 23(10): 23339-2345.

Parrott, J.A. and M.K. Skinner. 1999. Kit-ligand/stem cell factor induces primordial follicle development and initiates folliculogenesis. Endocrinol 140 (9): $4262-$ 4271 .

Perry, G.A., M.F. Smith, M.C. Lucy, J.A. Green, T.E. Parks, M.D. MacNeil, A.J. Roberts, and T.W. Geary. 2005. Relationship between follicle size at insemination and pregnancy success. Proc Natl Acad Sci USA 102: 5268-5273.

Perry, G.A. and B.L. Perry. 2008. Effect of preovulatory concentrations of estradiol and initiation of standing estrus on uterine $\mathrm{pH}$ in beef cows. Domestic Anim Endo 34: $333-338$.

Perry, G.A., O.L. Swanson, E.L. Larimore, B.L. Perry, G.D. Djira, and R.A. Cushman. 2014. Relationship of follicle size and concentrations of estradiol amoung cows exhibing or not exhibing estrus during a fixed-time AI protocol. Domes Anim Endcrinol 48: 15-20.

Pohler, K.G. 2011. Effect of ovulatory follicle size on steroidogenic capacity, molecular markers of oocyte competence and bovine pregnancy associated glycoproteins. Master's Thesis. University of Missouri-Columbia.

Pohler, K.G., T.W. Geary, J.A. Atkins, G.A. Perry, E.M. Jinks, and M.F. Smith. 2012. Follicular determinants of pregnancy establishment and maintenance. Cell Tissue Res 349(3): 649-664.

Prates, E.G., J.T. Nunes, and R.M. Pereira. 2014. A role of lipid metabolism during cumulus -oocyte complex maturation: impact of lipid modulators to improve embryo production. Mediators of Inflamm art. 692067.

Purlsey, J.R., M.O. Mee, and M.C. Wiltbank. 1995. Synchronization of ovulation in dairy cows using $\mathrm{PGF}_{2 \mathrm{a}}$ and $\mathrm{GnRH}$. Theriogenology 44:915-923.

Richardson, B.N., S.L. Hill, J.S. Stevenson, G.D. Djira, and G.A. Perry. 2016. Expression of estrus before fixed-time AI affects conception rates and factors that impact expression of estrus and the repeatability of expression of estrus in sequential breeding seasons. Anim Reprod Sci 166: 133-140. 
Robert, C., D. Gagné, D. Bousquet, F.L. Barnes, and M-A. Sirard. 2001. Differential Display and Suppressive Subtractive Hybridization Used to Identify Granulosa Cell Messenger RNA Associated with Bovine Oocyte Developmental Competence. Biol. Reprod 64.6.1812.

Robert, C., D. Gagné, J.G. Lussier, D. Bousquet, F.L. Barnes, and M.A. Sirard. 2003. Presence of LH receptor mRNA in granulosa cells as a potential marker of oocyte developmental competence and characterization of the bovine splicing isoforms. Reproduction 125(3) 437-446.

Shimada, M. and T. Terada. 2002. FSH and LH induce progesterone production and progesterone receptor synthesis in cumulus cells: a requirement for meiotic resumption in porcine oocytes. Mol Hum Reprod 8(7): 612-618.

Sirard, M-A. 2001. Resumption of meiosis: mechanism involved in meiotic progression and its relation with developmental competence. Theriogenology 1: 1241-1254.

Sirard, M.-A., F. Richard, P. Blondin, and C. Robert. 2006. Contribution of the oocyte to embryo quality. Theriogenology 65: 126-136.

Sirard, M.-A. 2012. Factors affecting oocyte and embryo transcriptomes. Reprod Domest Anim 47(4): 148-155.

Sirotkin, A.V. 1992. Involvement of steroid hormones in bovine oocytes maturation in vitro. J Steroid Biochem Mol Biol 41 (3): 855-858.

Smith, M.F., E.W. McIntush, and G.W. Smith. 1994. Mechanisms associated with corpus luteum development. J Anim Sci 72: 1857-1872.

Steeves, T.E., and D.K. Gardner. 1999. Metabolism of glucose, pyruvate, and glutamine during the maturation of oocytes derived from pre-pubertal and adult cows. Mol Reprod Dev 54: 92-101.

Su, Y.Q., K. Sugiura, K. Wiggleworth, M.J. O’Briend, J.P. Affourtit, S.A. Pangas, M.M. Matzuk, and J.J. Eppig. 2008. Oocyte regulation of metabolic cooperativity between mouse cumulus cells and oocytes: BMP15 and GDF9 control cholesterol biosynthesis in cumulus cells. Development 135(1): 111-121.

Sugiura, K., Y.Q. Su, F.J. Diaz, S.A. Pangas, S. Sharma, K. Wigglesworth, M.J. O'Brien, M.M.Matzuk, S. Shimasaki, and J.J. Eppig. 2007. Oocyte-derived BMP15 and FGFs cooperate to promot glycolysis in cumulus cells. Development 134(14): 2593-2603.

Sunderland, S.J., M.A. Crowe, M.P. Boland, J.F. Roche, and J.J. Ireland. 1994. Selection, dominance and atresia of follicles during the oestrous cycle of heifers. Reproduction 101: 547-555. 
Sutton-McDowell, M.L., R.B. Gilchrist, and J.G. Thompson. 2010. The pivotal role of glucose metabolism in determining oocyte developmental competence. Reproduction 139: 685-695.

Swanson, L. V., and H. D. Hafs. 1971. LH and prolactin in blood serum from estrus to ovulation in holstein heifers. J Anim Sci 33: 1038-1041.

Thomas, P.D., A. Kejariwal, N. Guo, H. Mi, M.J. Campbell, A. Muruganujan, and B. Lazareva-Ulitsky. 2006. Applications for protein sequence-function evolution data: mRNA/protein expression analysis and coding SNP scoring tools. Nucl. Acids Res 34: W645-W650.

Thompson, J.G., M. Lane, and R.B. Gilchrist. 2007. Metabolism of the bovine cumulusoocyte complex and influence of subsequent developmental competence. Soc Reprod Fertil Suppl 64: 179-190.

Tilly, J.L. 2003. Ovarian follicle counts- not as simple as 1, 2, 3. Reprod Biol Endocrinol 1: 11-14.

Uyar, A. S. Torrealday, and E. Seli. 2013. Cumulus and granulosa cell markers of oocyte and embryo quality. Fertil Steril 99(4): 979-997.

van den Hurk, R., and J. Zhao. 2005. Formation of mammalian oocytes and their growth, differentiation and maturation within ovarian follicles. Theriogenology 63: 17171751.

Wrobel, K-H and F. Süß. 1998. Identification and temporospatial distribution of bovine primordial germ cells prior to gonadal sex differentiation. Anat Embryol 197: $451-467$.

Xiao, C.W. and A.K. Goff. 1999. Hormonal regulation of oestrogen and progesterone receptors in cultured bovine endometrial cells. J Reprod Fert 115: 101-109.

Xie, H.-L., Y.-B. Wang, G.-Z. Jiao, D.-L. Kong, Q. Li, L.-L. Zheng, and J.-H. Tan. 2016. Effects of glucose metabolism during in vitro maturation on cytoplasmic maturation of mouse oocytes. Sci Rep 6: 20764.

Yan, C., P. Wang, J. DeMayo, F.J. DeMayo, J.A. Elvin, C. Carino, S.V. Prasad, S.S. Skinner, B.S. Dunbar, J.L. Dube, A.J. Celeste, and M.M. Matzuk. 2001. Synergistic roles of bone morphogenetic protein 15 and growth differentiation factor 9 in ovarian function. Mol Endocrinol 15(6): 854-866.

Yang, M.Y. and J.E. Fortune. 2006. Testosterone stimulates the primary to secondary follicle transition in bovine follicles in vitro. Biol Reprod 75: 924-932. 
Yang, M.Y. and J.E. Fortune. 2008. The capacity of primordial follicles in fetal bovine ovaries to initiate growth in vitro develops during midgestation and is associated with meiotic arrest of oocytes. Biol Reprod 78: 1153-1161.

Zaied, A.A., H.A. Garverick, C.J. Bierschwal, R.G. Elmore, R.S. Youngquist, and A.J. Sharp. 1980. Effect of ovarian activity and endogenous reproductive hormones on GnRH-induced ovarian cycles in postpartum dairy cows. J Anim Sci 50(3): 508-513.

Zhou, X., H. Lindsay, and M.D. Robinson. 2014. Robustly detecting differential expression in RNA sequencing data using observation weights. Nucleic Acids Res 42(11): e91. 


\section{VITA}

Jenna Marie Monnig was born on May 31, 1993 to Kent and Joyce Monnig of Glasgow, MO. She graduated from Truman State University in May 2015 with a Bachelor of Science in Agricultural Science with an Animal Science concentration. After graduation from the University of Missouri with a Master of Science in Animal Science in August 2017, Jenna will head to Princeton, MO where she has accepted a job as the Mercer County Regional Livestock Extension Specialist. 